\title{
A qualitative study investigating the \\ association between social exclusion, stigma and long term problem drug use in a New Zealand town
}

\author{
By \\ Murray David Wilson
}

A thesis submitted to Victoria University of Wellington in fulfilment of the requirements for the degree of Master of Arts in Criminology 


\begin{abstract}
Background: The aim of this study is to investigate the association between problematic drug use (PDU) and social exclusion and stigma in a deindustrialised New Zealand town (DNZT). The purpose of this research is to capture the perceptions; experiences and life course journey of individuals with long term problematic drug use (IPDUs) and contribute new knowledge and understanding of this lived experience.
\end{abstract}

Method: A review of national and international literature related to the phenomena of social exclusion, stigmatisation and problematic drug use was conducted to theoretically inform the study. The small-scale study employed a qualitative approach that involved a nonprobability sample that met the criteria for long-term problematic drug use. This allowed respondents to share their perceptions and experiences of social exclusion, stigma and PDU in their own words and by their own frames of reference. The researcher occupied a position of insider. Following transcription of the interviews a six stage thematic analysis was conducted on the data.

Findings: The downward social and psychological trajectory of this respondent group began before the respondents encountered long-term unemployment and before the onset of problematic drug use, initiated at an early age by common experiences of trauma, exclusion and damaged home environments. For this cohort it appears problematic drug use may have become a coping mechanism or relief from the reverberating impact of stigma, exclusion and marginalisation.

Conclusion: The cohort interviewed show significant experiences of stigma, trauma and a disrupted life journey. These experiences became considerably exacerbated by problematic drug use and it appears most of the respondents have internalised and embraced a permanent status as 'addicts' with limited expectation of change. Respondents spoke of being 'parked' on methadone in respect of their drug problem and excluded from employment. This research suggests there is a need to look beyond the presented problem of addiction and its apparent solution of methadone maintenance treatment (MMT) and explore a more holistic strength-based approach that addresses issues of inequality, social care and discrimination. 


\section{Acknowledgements}

This thesis has emerged due to the large amount of support I have received in my time as a post-graduate student. This support has also been consistently provided throughout my time spent at Victoria University. The people I wish to thank have supported and guided my academic journey to a very high degree. The support I have received has been both considered and wise it has also been given in an unrestricted fashion, particularly the time consuming job of proofing my work and providing feedback. I would also like to thank those in my family and community who have supported this process and those people who participated in the research conducted.

I thank my wife Michelle, our children, my late Mother-in law Margaret and my Mother Fèora who have never wavered in their support and encouragement of my work.

To Dr Kirsten Reid many thanks for being my learning advisor for well over seven years. Thank you for all of your patience when teaching me and your kind words and encouragement throughout this time. I also thank the other members of staff at Student Learning Support Services who have also consistently given me their time, support and encouragement.

Thank you to student disabilities services for your support throughout my tertiary studies. Joanna Clover has been my disabilities support person throughout my time at Victoria University. Having the learning disability dyslexia, it is hard to articulate the importance of the support I have received from Joanna and disabilities. However, without the help of note takers and the reader writers provided for my exams as an undergraduate I doubt this thesis would have emerged.

I thank Prof John McDowall for all the times his door has been open to me, the discussions I have been privileged to have with him and for always providing considered feedback. I also thank John and his wife Jean for their kind support particularly for the proof reading of my work and providing valuable feedback.

I would like to thank my supervisor, Associate Professor Julian Buchanan for inspiring my work. Also for all the occasions his door has been open to me, and the countless academic discussions I have shared with him. It has been a privilege to have Julian as a lecturer, supervisor and friend who has always offered unlimited assistance and wise council.

I would also like to thank all the other members of the school of Criminology in particular, Fiona Hutton, Trevor Bradley and Lizzy Stanley, as they have all encouraged my learning and also for the many occasions they have given me their time while mentoring my academic advancement. I would like to thank my postgraduate colleague Brent Stone for always being there in the good times and bad. Brent's support, calm nature and insight have been a tonic for my stress in many instances.

Finally, I would like to thank all of the people who participated in this research project. Without their co-operation this research could not have proceeded. I am very grateful to the respondents who invited me into their homes and who shared their perceptions and experiences of social exclusion, stigma and PDU in an honest and open manner. I am humbled to have been entrusted with their histories. I thank you for this privilege.

Murray David Wilson

$31^{\text {st }}$ October 2014 


\section{Glossary}

7/7 28 Ops - Seven days cell confinement, seven days loss of remission and twenty-eight days off privileges. A. $\boldsymbol{A}$ - Acetic Anhydride.

Bitch - A prisoner who is assigned duties by another inmate.

Boob gear - Prison issue clothing.

Brace and bit - Modified hypodermic syringe.

Broken arse - Individual who has/is not adjusting to prison life.

Buddha - High quality/strength cannabis imported from Thailand.

C.O.P - Consume on premises.

C.T - Corrective training.

Charger/Parcel - Contraband secreted in the anus.

Cheeked - Contraband secreted between the bum cheeks.

Class - Prison classification board.

Cold Turkey - The process of withdrawing from drug dependency.

Crack/smash/bash - To physically assault someone.

Custodial pathway - A journey from offending to placement in Boy's Home, then CT/borstal and ending in adult prison.

Diversion - The black-market sale of drugs obtained through legal scripts.

Done - Methadone.

E.C.T - Electric Convulsive therapy.

First lag - First time incarcerated.

Greys - 100 milligram MST.

H.C.V - Hepatitis. C. Virus.

Hanging out - The physical and psychological onset of drug withdraw.

Hoisting - Stealing goods to on-sell them, using the profit to buy drugs.

Holding - Being in possession of drugs.

Home bake - Heroin produced using precursors in clandestine laboratories.

Inside - Prison.

$\boldsymbol{K} . \boldsymbol{F}$ - Child molesters/Child sex offenders.

K.P - Prisoner with influence.

Lag - Term of incarceration.

Lag in - Period of time in prison.

Lag out - Period of time outside of prison.

Lucky dips - LSD tablets/trips.

MMT - Methadone maintenance treatment.

Misty/MST - Morphine sulphate tablet (MST).

Narc/Noah's ark - Informant.

Old lag - Individual who has done numerous terms of imprisonment.

On a Charge - Charged with committing an offence within the prison.

Outside - The world.

$\boldsymbol{P D U}$ - Problematic Drug Use

P.T.S.D - Post traumatic stress disorder.

P/Meth - Methamphetamine.

$P 119$ - Prison requisition form.

Piss pot - Chamber pot.

Pound/digger/hole - Solitary confinement block.

Racehorse - Very thin cannabis cigarette.

Rock college - Invercargill borstal.

S.U.D. - Substance use disorder.

Score - To obtain drugs by purchase through the illegal market.

Screw/Mr/Turnkey - Corrections officer.

Shiv/shank - Prison constructed knife.

Slamming/banning - The use of class A drugs through intravenous injection.

Spot - Units of one hundred dollars/year of imprisonment.

Squeezed out - Excluded/expelled from secondary schooling.

Stand over - Taking property by employing intimidation, threats of violence.

Take a ways - Methadone taken home to be consumed at a later time.

Tealeaf - Thief.

Turtle - 200 milligram MST.

W.I.N.Z. - Work and Income New Zealand.

Yard - Exercise yard. 


\section{Contents}

ABSTRACT

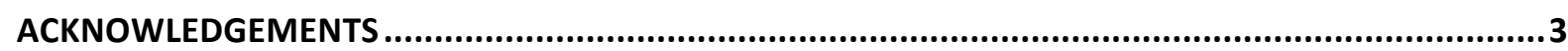

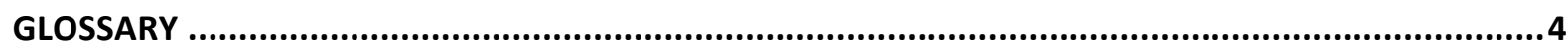

INTRODUCTION ................................................................................................................

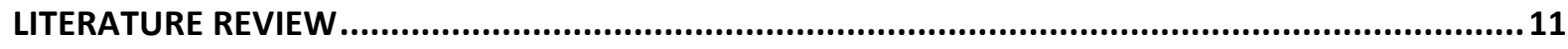

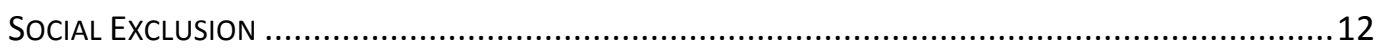

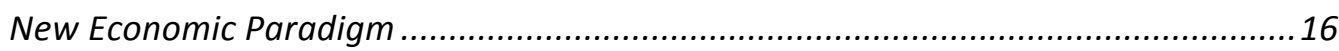

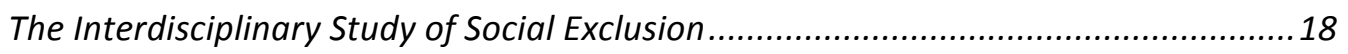

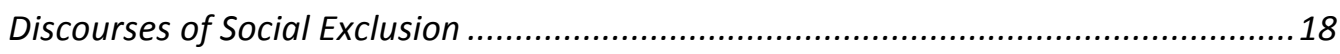

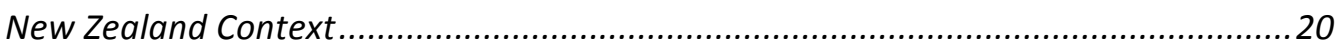

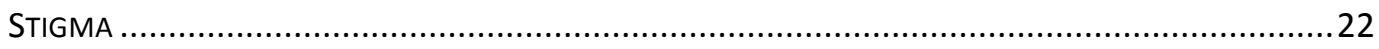

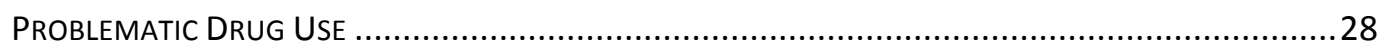

The Place of Drugs in Society and through History .................................................28

Drugs in New Zealand (prevalence of PDU) ............................................................2 29

The War on Drugs (The war between drugs, the war against illegal drug users).........31

The Relationship between PDU and Poverty/Social Exclusion ....................................32

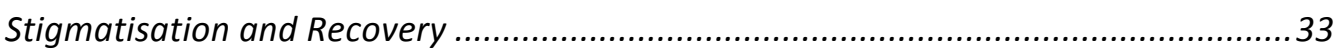

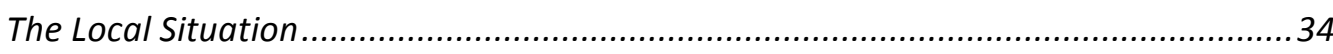

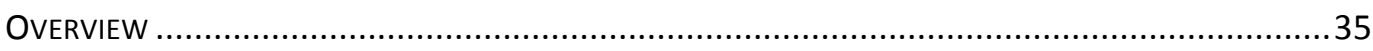

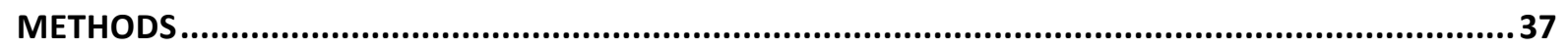

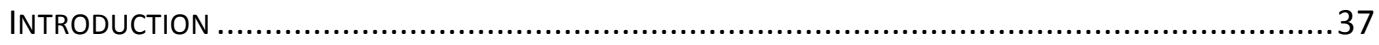

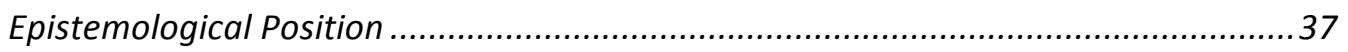

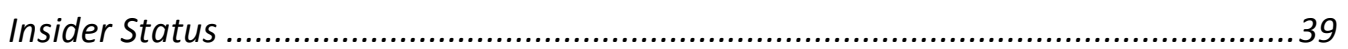

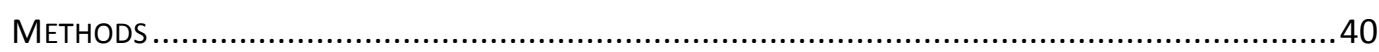

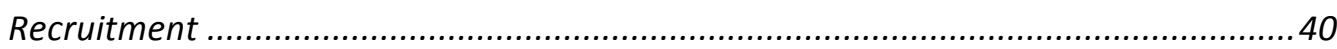

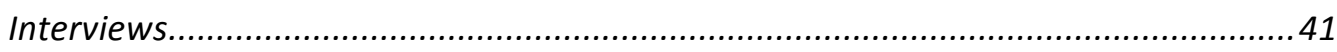

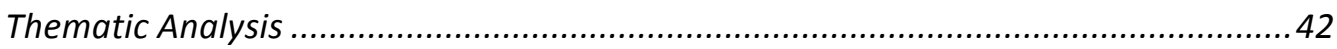

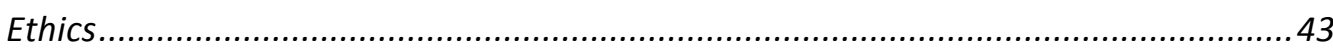

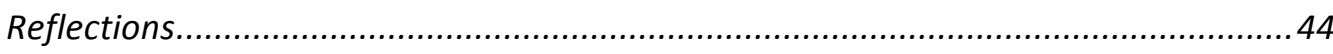

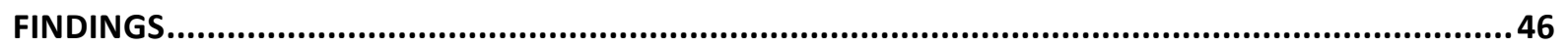

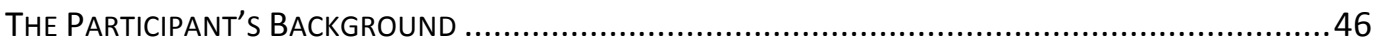

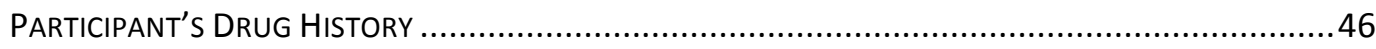

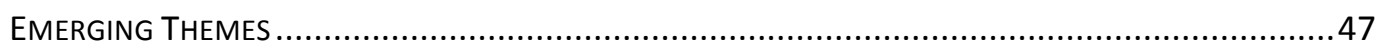

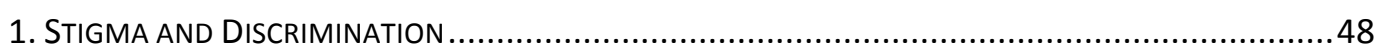

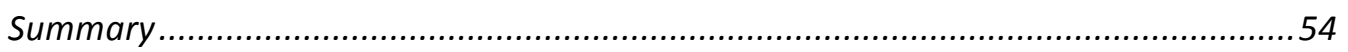

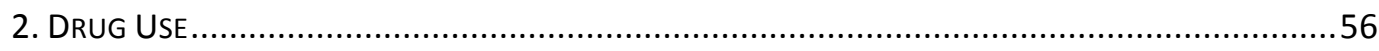

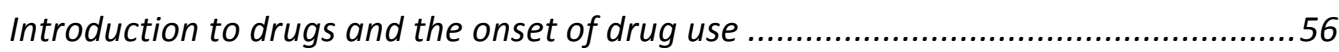

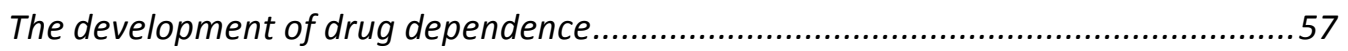

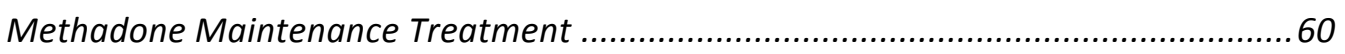

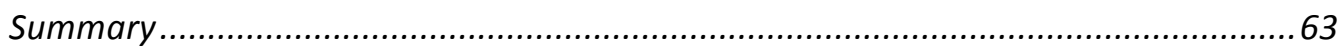

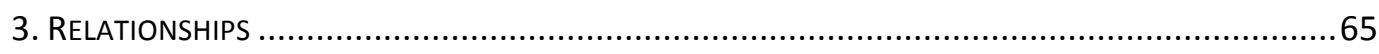

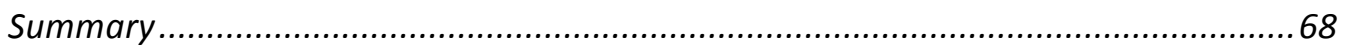




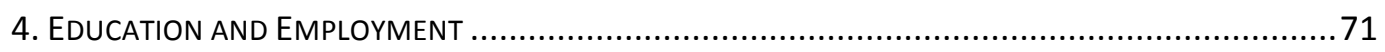

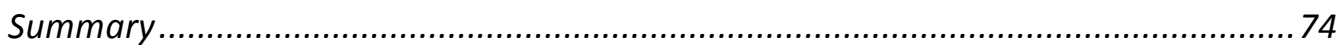

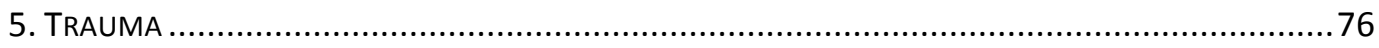

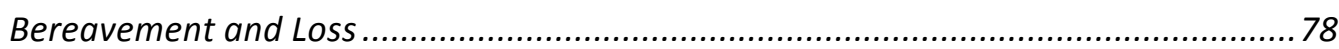

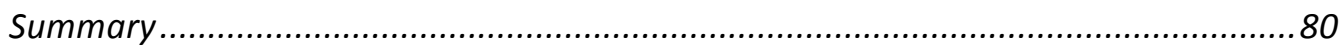

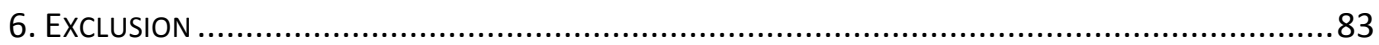

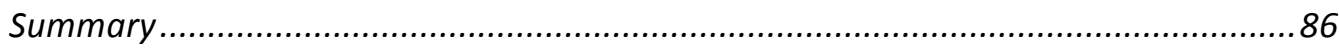

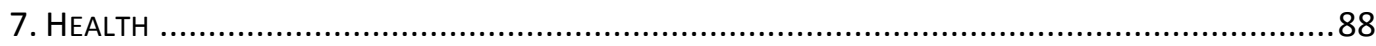

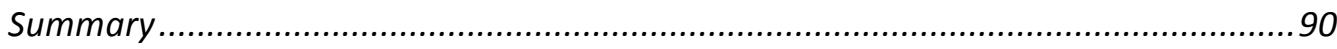

ANALYSIS

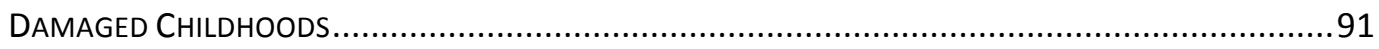

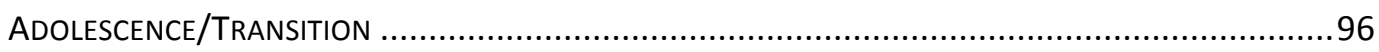

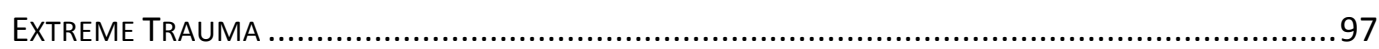

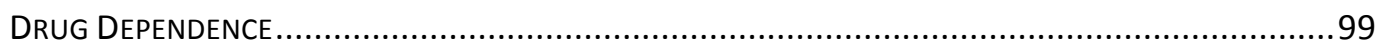

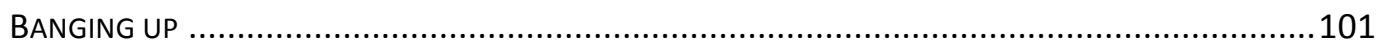

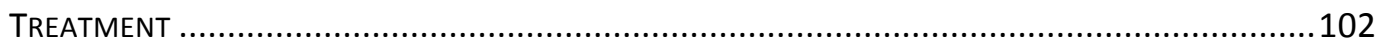

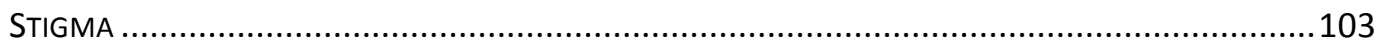

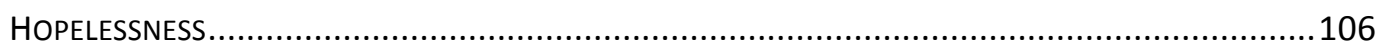

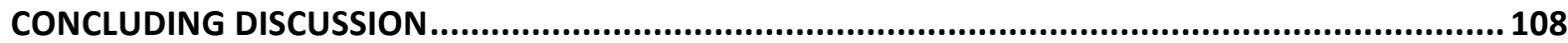

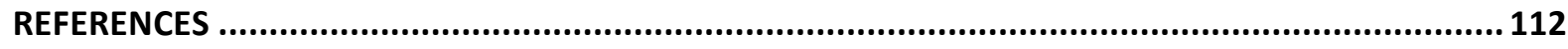

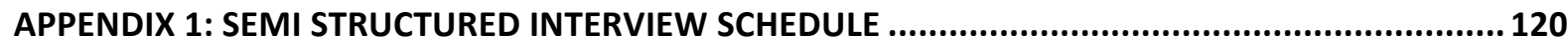

APPENDIX 2: MANUFACTURING DECLINE IN THE DNZT 1986-1996 ........................................... 121 


\section{Introduction}

The aim of this study is to investigate the association between social exclusion and longterm problematic drug use (PDU) within the New Zealand context. The research is focused on a deindustrialised New Zealand town (DNZT) that is working class and geographically ring fenced and isolated from the wider metropolitan area encompassing it. DNZT has a long history of industry, which dates back to the early years of colonisation, and was a part of the original land package secured by the New Zealand Land Company (Alexander, 2000). The population of DNZT expanded exponentially between the 1950s and the 1970s as the town's labour force fed into New Zealand's largest industrial hub (Davidson, 1974). The processes of deindustrialisation have impacted on the town over the past thirty years. DNZT shares much with the Northern UK town in MacGregor and Thickett's (2011) case study. Their study has therefore been utilised to guide and inform this research. DNZT has a diverse population as does the town in MacGregor and Thickett's (2011) study, and both towns have experienced deindustrialisation, social and spatial polarisation and the presence of both deprivation and prosperity. The current study investigates the stigmatisation, marginalisation, and poverty experienced by individuals with PDU (IPDUs) ${ }^{1}$ prior to and following the development of drug dependencies. The focus is to gain an understanding of the experiences and perceptions of long term PDU in relation to upbringing, education, employment, independent living, housing, relationships, drug use and crime. Additionally, the study explores if PDU preceded social exclusion, stigmatisation and crime or if these phenomena were present prior to the development of PDU.

A review of international and national literature was conducted to inform and provide a backdrop for this study. The complexity of the nature of the phenomenon under investigation required the review to be conducted in separate sections. The thesis will introduce the three key phenomena related to the current research in the following literature review. The concepts of social exclusion, stigma and PDU are discussed. The first section covers the multi-layered manifestation of social exclusion. This section covers the "golden age" (Poata-Smith, 2013) to the economic downturn (Rashbrooke, 2013) and a review of the new economic paradigm that emerged as part of neo-liberalism in the 1970s (Grover, 2008). The complex concept of social exclusion is reviewed first. The impacts of neo liberal policies are discussed and arguments that the 'third way' of politics has produced policies that have led to increased inequality and greater levels of social exclusion are

\footnotetext{
${ }^{1}$ The use of the term IPDUs (individuals with problematic drug use) has been employed in this
} 
reviewed. This section includes a right wing perspective in the "underclass thesis" produced by Murray and Alcock (1994). Murray explains social exclusion and poverty as phenomena that emerge when poor life choices are made by "feckless" individuals. The social climate is argued by Murray to be highly influenced by the breakdown of the traditional family unit and an upsurge of illegitimacy that contributes ever increasing numbers to this burgeoning underclass. The New Zealand situation is reviewed by Rashbrooke, Poata-Smith, Humpage and others and the increases in social exclusion and child poverty are discussed. The impacts of child poverty and inequality on the life course of people are reviewed. Secondly, the phenomenon of stigma is unpacked through the work of Goffman, Link \& Phelan and others. In this section the impacts of stigma on mental and general health are explained. Finally, the work of Buchanan, Lloyd, MacGregor and Thickett and others is employed to add to an understanding of the phenomena of problematic drug use (PDU); individuals who are problematic drug users (IPDUs); the process of recovery and reintegration; and the war on drugs. This section brings the war on drugs and its social consequences including the criminalisation of large numbers of society into focus. The management of drug dependency by state agencies is also explored.

A qualitative research method was used for the collection of data. Certain recruitment criteria were employed to capture a small sample of long term IPDUs. They had to have been born prior to 1983, reside in DNZT and have experienced the processes of deindustrialisation during their working lives. Interviews were conducted with ten people who have experienced long term problematic drug use and who reside in DNZT. These were transcribed and a thematic analysis of the data performed. The method of thematic analysis was drawn from Braun and Clarke (2006) who outline the analytical process in six steps. As a result of the thematic analysis, seven themes were identified as being dominant throughout the data corpus. These are education/employment, relationships, drugs, stigma, exclusion, trauma, and health. The research also used secondary sources to build up a clear picture of life in DNZT. Social statistics were employed in mapping and examining indicators of social exclusion and levels of drug use.

The researcher's life history which includes periods of incarceration and PDU has allowed the occupation of a position of insider to this community and this position afforded privileged access to a community traditionally considered 'hard to reach'. The researching of IPDUs is challenging and this is exacerbated by a number of factors including legal status, social stigmatisation, marginalisation and general lack of visibility (Watters \& Biernacki, 1989). There are both advantages and disadvantages when conducting insider research. The disadvantages are outlined by Mercer (2007) and these include informant bias, interview reciprocity and research ethics. A key dilemma is contending with one's 
own preconceptions, and any preconceptions the respondents may have formed about the researcher due to their shared experience (Mercer, 2007). During the interview process the researcher became aware of the need to refrain from commenting on the responses and to bracket his personal opinions. Advantages of the insider position included enjoying freer access, understanding and being able to use the language/jargon of the group, stronger rapport and a shared outlook and deeper knowledge of the group and its culture.

The findings from the research revealed that the interviewed cohort show significant experiences of stigma, trauma and disrupted life journeys before the onset of drug dependency. These experiences became exacerbated with problematic drug use and it appears most of the respondents have internalised and embraced a permanent status as 'addicts' with limited expectation of change. The people interviewed reported how their sense of stigmatisation and discrimination occurred frequently in medical settings both clinical and community. The processes of stigma and social exclusion were also reported to occur during interactions with WINZ and other state agencies. It was during these types of mixed contacts where a power imbalance exists that stigmatisation was commonly reported as having being experienced by the participants. The people interviewed spoke of their being 'parked' on methadone in respect of their drug problem and disregarded in respect of employment. The current study aims to gain an understanding of how society does not allow people with PDU to move their lives forward in a positive pro social fashion. In addition the deindustrialisation of this community and its associated impacts were also explored to gain an appreciation of how inclusion has diminished and exclusion has increased. The occurrence of these social phenomena and their impacts on the lives of the people interviewed are revealed in the findings section where the experiences and perceptions of the current study's participants are reported in their own words.

In the analysis section, the current study's findings are analysed in their totality. This allows the messages from this research to be explored within the wider context of the existing literature and theoretical debates. The employment of thematic analysis (Braun \& Clarke, 2006) was used to analyse and contextualise the participants' narratives. The key phenomena identified as being experienced by the participants were damaged childhoods; blocked transitions; extreme trauma; drug dependence; crime and incarceration; social exclusion, stigma and discrimination; and hopelessness. In their analysis, Darke and Torok (2013) highlight how damaged childhoods, blocked transitions and extreme trauma can have a negative influence across the life course. They found childhood physical abuse (CPA) was highly prevalent among injecting drug users (IDU) with "half or more reporting such abuse" (2013:1). Additionally, the analysis draws on longitudinal studies undertaken by Fergusson and Horwood (1998) and Farrington and West (1990) to demonstrate the 
impact of life events and categorise life events as either being a risk factor or a protective factor in the development of an individual. Risk factors for an individual can result in their developing drug dependence which can be conceptualised across three distinct paradigms: biological, psychological and environmental (Coomber et al., 2013:13). The findings analysed also show that language can influence medical professionals during their interactions with IPDUs (Kelly \& Westerhoff, 2010). The use of blame is central to the stigma process associated with PDU as it places blame on IPDUs for engaging with drug use in the first place; blame also creates the perception that IPDUs have a choice in their current or future use of drugs (Lloyd, 2010). These perceptions allow for the on-going social exclusion and stigmatisation of IPDUs

The central problem to emerge from the current research is what can be done to help uplift the people interviewed from their PDU, exclusion, isolation and poverty. The multilayer complexity of health, financial, and social problems in the lives of the respondents makes any attempt to address the underlying causes of poverty, exclusion, PDU and stigmatisation highly complex. This challenging issue is discussed in the conclusion. 


\section{Literature Review}

The current study explores the associations of social exclusion and illicit drug use in a deindustrialised New Zealand town (DNZT) previously dependent upon factories to provide employment for a predominately unskilled and skilled workforce. The study will rely on the framework of MacGregor and Thickett's (2011) case study of a Northern town in the United Kingdom (UK) to inform and guide this research. The current study explores the impacts of national agendas, governmental policies and deindustrialisation to shed light on the interconnections between historical patterns, socio-economic change, cultural complexity, deprivation, limited opportunities and illicit drugs. Evidence for the links between concentrated multiple deprivations; poor health; acquisitive crime and PDU were drawn from the analysis of local documents and are supplemented through the life experiences reported on by individuals who participated in the semi-structured interviews. The associations between the three key phenomena social exclusion, stigma and PDU are hypothesised to occur in a cumulative fashion. It is further hypothesised that social exclusion and stigmatisation precede and contribute to increased problematic drug use. The links between being disadvantaged and socially excluded from an early age and the development of a drug dependency have been identified by Buchanan (2004) who argues "the key issues drug users face are related to discrimination, isolation, and powerlessness" (2004:135).

The literature has been reviewed in separate sections because of the complexity of the phenomena. The review begins by focusing on social exclusion. A selection of early and later main themes is presented in chronological order. First, the golden age of full employment and economic growth was reviewed. This is followed by a brief discussion of the economic downturn and a review of the new political paradigm. The phenomenon of social exclusion is identified as occurring during the golden age and evidence of increased levels since the emergence of neoliberal policy is noted. The interdisciplinary study of social exclusion and the use of discourse to frame and present the phenomenon are presented. Lastly this section looks at social exclusion in the current local context.

The second section of the literature review explains the phenomenon of stigma. It approaches this in a chronological order. First it looks at the seminal work of Goffman (1963) on stigma and then moves to Link and Phelan (2001) who posit that there is a need for stigma to be described with reference to the relationships between a set of interrelated concepts. Link and Phelan (2001) create their own conceptualisation of stigma and argue 
that stigma occurs when elements of labelling, stereotyping and status loss co-occur in a power situation that allows the components of stigma to unfold. Finally the review discusses the recent work of Lloyd (2010) who argues that stigma impacts on a person's inability to overcome exclusionary processes when attempting reintegration. This leads to a focus on the need for new approaches for professionals who are dealing with the recovery of IPDUs or with those who are socially excluded (Lloyd, 2001).

The third section explores the phenomenon of PDU starting with a brief review of the place of drugs in society in modern history (Reinerman, 1979). Drawing on information from the Law Commission (2011) a discussion of the legal nature of drugs and their use follows. The contested nature of drugs brings a focus to the social construction of drugs in modern society. Furthermore, the legal position of drugs and the personal freedom to use drugs has remained a highly contested area (Reinarman, 1979; Buchanan, 2006; Boland, 2008). The prevalence of PDU in New Zealand is then explored. Prevalence is a key tool for assessing the impacts of policy on the availability and accessibility of illicit drugs. Next the 'war on drugs' and its consequences are reviewed (Global Drug Policy Report, 2011). The section then turns to identifying the association between PDU and social exclusion/poverty and the resulting consequences (Grover, 2008; Rashbrooke, 2013). The impact of stigmatisation on the process of recovery for IPDUs is a major consequence of the 'war on drugs' (Lloyd, 2010; Buchanan, 2006; MacGregor \& Thickett, 2011; Ahern, Stuber \& Galea, 2007) is discussed. Additionally, the stigmatisation and discrimination of IPDUs as it occurs across society is explored by Lloyd (2010). This stigmatisation/marginalisation intensifies social problems rather than relieving them (Anderson \& Ripullo, 1996; Radcliffe \& Stevens, 2008). Finally, the local situation in relation to rates of unemployment, PDU and increased levels of inequality (Poata-Smith, 2013; Wylie, 2013) is outlined. The following review aims to investigate the processes of deindustrialisation and to unpack its links with social exclusion, stigma and PDU bringing a focus to the interrelated nature of these phenomena and their impacts on individuals and communities.

\section{Social Exclusion}

This section examines the impact of deindustrialisation upon communities once dependent upon labour intensive industries and explores the associated phenomena of long-term unemployment (Grover, 2008), social exclusion (Barry, 1998), stigma (Lloyd, 2010), and problematic drug use (Buchanan, 2006). The years following the Second World War and up to the early 1970s have been termed "modernity" (Young, 1999). These years were a period 
of unprecedented economic growth in the USA, Western Europe and the colonised countries of New Zealand, Canada and Australia (Young, 1999). The need for unskilled and semi-skilled labour in factories, heavy industry, coalmines and shipyards over this period ensured full employment (Holman, 1998). Steadily rising affluence in wider society allowed for the gradual incorporation of the working class into the trappings of full citizenship (Hobsbawm, 1994). In New Zealand, Māori also believed their people's service during the Second World War was the price paid for citizenship (Howden-Chapman, Bierre \& Cunningham, 2013).

The post war period 1945 - 1973 has been nostalgically referred to as the golden age (McClure, 2013) where the key spheres of society, family, the site of consumption and work, and the site of production appeared to fit together seamlessly. However, this was not a golden period for all groups in the countries mentioned above. In New Zealand, Māori were occupying the lower levels of segmented labour markets in blue-collar positions. Māori were also experiencing high levels of discrimination and prejudice that restricted opportunities for economic improvement (Poata-Smith, 2013). The urbanisation of Māori during this period was driven by the continued disenfranchisement of the Māori people from their land (Rashbrooke, 2013). The processes of Māori marginalisation was solidified when 3.1 million acres of Māori land was obtained through punitive and coercive practices (Rashbrooke, 2013). Māori were blocked from professional opportunities by a reinforcement of discrimination in the employment practices of this time (Poata-Smith, 2013). Other groups such as women and gay and lesbian people may reflect on modernity differently than it is described in the nostalgic narrative, which explicitly claims it as a prosperous period of history (Rashbrooke, 2013).

The golden age may have been a time of economic growth and an increased standard of living. However, it was also a period when the civil and political rights of women and minority groups were starting to be contested. These resistance movements include the second wave of feminism (Young, 1999) and the organisation of groups that represented ethnic minorities, indigenous peoples and gay rights (Rashbrooke, 2013). Young (1999) describes this as an era which is often viewed as a time of inclusion, affluence and conformity, a consensual and inclusive world with core values built around the family and work and an accent on the assimilation of those outside of society: the working class; women; youth and immigrants. It is a society that did not loathe the 'deviant other' or perceive him or her as an outside adversary but rather as someone who must be cured, socialised, or rehabilitated so they can be absorbed back into the societal fold (Young, 1999). In the New Zealand context, this period saw the creation of the 'modern, inclusivist liberal democracy' (Rashbrooke, 2013). 
The rise of late modernity, during the last third of the twentieth century, was a period of extraordinary change beginning in the 1970s and extending into the present (Young, 1999). Late modernity is marked by shifts in key areas including the economy, technological advancement and cultural practices. The intensification of new individualism triggered a decline of consumer conformity and contributed to a pluralism of lifestyles that were dynamic and diverse (Byrne, 1999). The recession in market demand introduced new levels of poverty through the downsizing and the reduction of the primary labour market, the emergence of the secondary labour market and the creation of an 'underclass' of those who become structurally unemployed (Grover, 2008). Social exclusion of the long-term unemployed, members of the underclass and ethnic minorities was assisted by government legislation that disempowered trade unions and fragmented the working classes and their communities (Byrne, 1999).

These extraordinary changes are underscored by Giddens (as cited in Young, 1999:14) who notes that

"Late modern life is characterised by heightened choice (stemming both from the opportunities of consumption and the flexible demands of work), by a constant questioning of established beliefs and certainties, a raised level of self-reflexivity, a lack of embedded biography and life trajectory and the constant confrontation with a plurality of social worlds and beliefs".

This sense of vulnerability and uncertainty produced increased levels of 'ontological insecurity' threatening stability, consensus, a belief in solidarity and a sense of one's essence and belonging. These increased levels of ontological insecurity resulted in higher perceptions of risk and danger (Young, 1999). This insecurity was enhanced by the shift towards individualism. The increased opportunity for choice and self-creation of the individual add to the pressure felt from the perceived weakening of the protective barrier of certainty and security inherent in the post-modern era (Humpage, 2006). The plural society and the diverse cultural worlds of late modernity undermine the acceptance of previously unquestioned values and absolutist beliefs leading to increased levels of ontological insecurity.

Young (1999) argues economic precariousness and ontological insecurity create an exceptionally inflammable mixture that allows for punitive responses to crime and the scapegoating of individuals and groups within society. Additionally, Young (1999) posits that the emergence of a more pluralistic society can influence the sense of personal security, and undermine the sense of the personal stability of ones being, increasing feelings of insecurity. These conditions lead to increased levels of social exclusion, highlighted by 
unprecedented increases in the ultimate form of social exclusion, incarceration (Pratt, 2008). The rise of prison populations during post modernity is related to the politicisation of crime. The associated political promises of greater penal severity such as 'three strikes' and 'life means life' are employed by politicians in both the UK and New Zealand who, as part of an election platform, wish to be seen as being tough on crime (Grover, 2008; Workman \& McIntosh, 2013).

Boeckmann and Tyler (1997:255) argue such political responses are "more than responses to anxieties about crime, they have become highly symbolic political gestures aimed at restoring a declining state authority". Furthermore, Workman and McIntosh (2013:121) argue the punitive political stance in New Zealand has overseen the formation of a prison population where "most inmates have experienced severe poverty and have higher victimisation rates than the general population and they are also typically young: over 50 per cent of inmates are between the ages of sixteen and thirty-four". The statistics above demonstrate the impact of recent attitudes and policies and how these have contributed to the enlarged incidence of social exclusion experienced by Māori, the working class, minorities and the unemployed (Rashbrooke, 2013). The social exclusion experienced by these groups has been framed by punitive discourses including the moral underclass discourse (MUD) that argues experiencing these negative phenomena are a result of poor life choices and irresponsibility (Levitas, 1998).

Charles Murray, an American neo-conservative academic, focuses on the breakdown of the traditional family unit and increased levels of illegitimacy. He argues that society's problems are in a large part due to the emergence of what he terms as the 'underclass' (Murray \& Alcock, 1994). His underclass thesis has been supported by those who perceived the underclass as immoral or amoral and opposed by those who believed its members had been excluded from mainstream society through the structural consequences of globalisation and free market economics (Barry, 1998).

The issue of declining respect for family and authority have been put forward as an explanation for the increasing level of certain social problems (Murray \& Alcock, 1994). Barry (1998:3) notes that during the 1980s and early 1990s, Murray had particular influence on the politicians of the Reagan, Thatcher and Clinton administrations and the policies they produced. Murray (1994) calls attention to an emerging 'underclass' bringing into focus a scapegoated 'class' within society (Barry, 1998). He posits that the deterioration of poorer neighbourhoods was not due to the structural changes of deindustrialisation but the emergence of a new class that was work-evasive, criminal, violent, promiscuous, and made up predominantly of young people (Murray, 1994). In 
association with a change in social civility, Murray (1994) argues that there was a decrease in family values, work ethic and morality.

If Murray's underclass concept is assessed from an alternative position, such as the argument of Grover (2008) who identifies the influences of structural inequalities and their associations with social exclusion and poverty, it is clear that it was politically expedient. Murray's concept functions to focus on the vulnerable and powerless sectors of society and, in doing so, it diverts attention away from the structural problems which exacerbate poverty and social exclusion in post-modernity. Furthermore, it ignores the elite top five per cent of society, the super class, who have gained the most under the third-way redistributionist tax regime who could otherwise "contribute to the funding of programmes of social care and ecological regeneration based on the proper employment of human labour" (Byrne 1999:136).

\section{New Economic Paradigm}

The introduction of the New Right economic paradigm by the Thatcher government in the United Kingdom (UK) in 1979 was driven by an on-going economic crisis (Jessop as cited in Grover, 2008). The resultant economic shift is described by Grover (2008:10) as a move away from the traditional "Keynesianism model of a planned economy where the state had an obligation to ensure full employment sustained by the use of interventions". The Keynes general theory of Employment, Interest and Money (1936) provided the dominant theory in Western economics and social democratic policies from the 1930s up to the 1970s (Wade, 2013). During the 1970s there was a move towards the new economic paradigm of 'free market' neo-liberalism where jobs are only created if labour is competitive and flexible. This new economic paradigm implemented by the UK New Labour Government 19972007 was "privileging competition and private ownership" (Grover, 2008:10).

The neo-liberal paradigm labelled the 'third way' by UK Prime Minister Blair (as cited in Grover, 2008:10) was "a successful marriage of social justice and global neo-liberalism". The 'third way' involved the privatisation of services previously delivered by government departments. These services include prisons, education and healthcare. The 'third way' also involved the deregulation of industry and the reform of the trade unions (Koller \& Davidson, 2008:309). This shift from an expansive welfarist and interventionist, social democratic political philosophy to a neoliberal anti-interventionist philosophy that emerged in the 1970s delivered circumstances under which a particularly right wing approach to both social policy and crime could be consolidated (Walters \& Bradley, 2005).

The processes of the 'third way' are underpinned by concepts of personal responsibility and free choice (Humpage, 2006). The conditions are in place to explain delinquency as a result 
of a parenting deficit. Thus the problem is placed at the heart of the family and frequently at the feet of the single parent and this parenting deficit narrative obscured the responsibility of the state (Grover 2008). In this model the reproduction of economic inequality becomes central to economic growth but it also increases social problems, including drug dependence, social exclusion and crime (MacGregor \& Thickett, 2011). The shift to the 'third way' of politics in the New Zealand context was implemented by the 1984 Labour government. The finance Minister Roger Douglas rolled out a wide range of 'third way' economic policies described as Roger-nomics. Roger-nomics introduced privatisation and free market neo-liberalism. Following New Zealand governments, including the Helen Clarke led Labour coalition 1999-2008 and the John Key led National coalition from 2008 onwards, have continued to implement and sustain the neo-liberal paradigm. This has resulted in unprecedented child poverty, high unemployment and widening levels of inequality (Rashbrooke, 2013). Inequality stemming from 'third way' policies is evident when considering the continued employment discrimination experienced by Māori and Pacific Islanders in New Zealand this is evidenced by Soldera (1999) who presents results for unemployment rates by ethnicity for the Wellington metropolitan area, 1986, 1991, and 1996. High unemployment areas contain a high concentration of socially excluded people (Soldera, 1999). Living in a highly concentrated unemployment area means less contact with locally employed friends or neighbours, poorer schools and increased levels of illegal market activity and crime (Soldera, 1999).

One of the central social problems of late modernity is the increased level of problematic drug use (PDU) (Buchanan, 2006; MacGregor \& Thickett, 2011). International research broadly shows that economic deprivation and social exclusion are correlated to drug use particularly PDU (Report of The Global Commission on Drug Policy, 2011). Furthermore, Darke and Torok (2013:1) found that childhood physical abuse (CPA) was highly prevalent among injecting drug users (IDU) their study reported that "half of their respondents reported experiencing CPA". The punitive attitude towards PDU leads to increased levels of social exclusion and the associated negative consequences including stigmatisation, marginalisation and poor health outcomes (Lloyd, 2010).

The 'war on drugs' allows for the construction of the undeserving and the deserving poor. This is achieved through the 'third way' concepts of personal-responsibility and free choice (Young, 1999). However, as Buchanan (2004:389) points out, there is a "lack of recognition or appreciation of the social components of dependence, such as structural inequality and discrimination which so often precede problem drug use, and then act as a major barrier to breaking out from a drug centred existence”. The state has played a pivotal role in the social exclusion of many of its citizens as a consequence of the 'war on drugs'. 
This has resulted in highly debilitating stigmatisation and marginalisation of IPDUs (Buchanan, 2004). The impacts experienced as consequences of the economic shift are still both widespread and significant. In post-industrial towns MacGregor and Thickett (2011:478) identify "interconnections between historical change, socio-economic change, cultural complexity, deprivation, limited opportunities and illicit drugs". Thus, through its processes of restructuring in the private sector and new policy development in the state sector, the new economic paradigm has had wide-ranging impacts.

\section{The Interdisciplinary Study of Social Exclusion}

The emergence of neoliberalism and the rise of the exclusive society in the UK which is described by Young (1999) as increasing inequality by sealing off of opportunities that were previously available to the working classes through employment in manufacturing and heavy industry. He argues that once inclusive societies have become exclusive and punitive. This resulted in the proliferation of interdisciplinary research (see for example Young, 1999; Buchanan, 2006; Humpage, 2006; Grover, 2008; Koller \& Davidson, 2008; MacGregor \& Thickett, 2011; Byrne, 1999). This literature seeks to give context and understanding to the resulting social and economic impacts occurring as part of 'third way' governmental processes. Grover (2008:11) argues, "the event of the 'third way' has been about the buttressing of neo-liberalism and securing the position of the 'free market' rather than being concerned with social justice".

The concept of social exclusion has become a continuing theme of British governmental policies (Koller \& Davidson, 2008). Furthermore, Grover, (2008:11) argues that these government policies were implemented in the belief that "neo-liberalism was the means that would allow Britain to secure a position in the global economy". Furthermore, Grover (2008) asserts that the consequences of these actions have been "increasing levels of inequality and stagnantly high levels of poverty". The issue of increased levels of poverty, unemployment and marginalisation in the UK resulted in the Tony Blair Government making a cabinet appointment of a minister of social exclusion (Koller \& Davidson, 2008).

\section{Discourses of Social Exclusion}

The concept of social exclusion was originally articulated within the social policy context in France during the early 1970s (Barry, 1998). In the "French context it was imbued with French Republican notions of the dangers of social fragmentation" (Koller \& Davidson, 2008:307). In the 1980s the concept of social exclusion became an essential element of the European Union's (EU) anti-poverty programmes (Grover, 2008). Social exclusion and inclusion have become key concerns for many governments around the world (Humpage, 2006; Koller \& Davidson, 2008). However, there is cynicism towards the use of the 
concept. For example Oyen (1997 as cited in Grover 2008) is critical of what she defines as a "political rather than an analytical concept" and Koller and Davidson (2008:308) claim that "on one level social exclusion has being conventionalised as a new multidimensional form of disadvantage, incorporating a dynamic diachronic analysis and a relational view of disadvantage between an included majority and an excluded minority". However this framework of social exclusion/inclusion is established on the false division between two supposedly standardised groups the excluded/included. This fails to recognise that people may be included on one level while still experiencing absolute rejection on another level. Additionally, the movement back and forth between the boundaries of exclusion/inclusion by individuals or groups is a phenomenon that has drawn inadequate acknowledgement (Humpage, 2006).

The phenomenon of social exclusion as a concept has drawn interest from policy makers and academics and has become deeply embedded at an institutional level with the development of several discourses (Koller \& Davidson, 2008). Space does not permit a full discussion of these but the discourses identified by Levitas (1998) and Miliband (2006) are both relevant for the current research.

Levitas (1998) identifies three social exclusion discourses. Firstly, the redistributionist discourse (RED), which constructs social exclusion as an issue of social justice or rights and, in policy terms, focuses on tackling structural inequalities. Secondly, there is the moral underclass discourse (MUD) that argues social exclusion emerges from individual pathology, and character traits, attitudes and lifestyles are seen as key causal factors. Policies structured through MUD take an individual approach aimed at changing individual attitudes and behaviours and making people more responsible. Thirdly, the social integrationist discourse (SID) is a narrow focused discourse concerned with unemployment and economic inactivity, that suggests social cohesion, can be achieved through the inclusion of workless people in paid employment. The dominant discourse is that the rights and responsibilities of citizenship stem from paid employment. Thus, (SID) argues that paid employment offers the most direct and effective appropriate route out of social exclusion. The RED discourse was dominant during the 1930s when the NZ welfare state was first established by the Michael J Savage. The SID discourse dominated in NZ during the 'golden age'. The most prevalent discourse reported on by interviewees in the current study is MUD Levitas (1998). In MUD the phenomena of social exclusion and poverty are framed by individual pathology, personal responsibility and the deserving/undeserving poor. Policies related to MUD emerged in NZ following the 1999 election of the Helen Clark led Labour-coalition (Humpage, 2006). These introduced Job seeker agreements based on the concept of 'mutual responsibilities' giving WINZ the ability to invoke benefit 
suspension for non-compliance (New Zealand Government, 2001). Miliband (2006) also identifies three social exclusion discourses. The first is the wide social exclusion discourse. Wide social exclusion covers all who suffer from a range of disadvantage, one of a large group. Second, there is the deeply socially excluded discourse where social exclusion is to suffer from multiple forms of disadvantage. Third, Concentrated social exclusion refers to the geographical concentration of disadvantage.

\section{New Zealand Context}

In the New Zealand context, the period of a golden age is identified as occurring from 1945-1973 (McClure, 2013). The introduction of the Social Security Act (1938) and the increased standard of living following the Second World War increased perceptions of ontological security. Perceptions of ontological security had previously being undermined by the 1928 Wall Street crash. During the subsequent depression years the precarious nature of life had been accentuated through mass-unemployment and its associated consequences. McClure (2013) explains how this brief period of economic security would be halted in New Zealand by the 1973 and 1978 oil shocks and by the United Kingdom's entry into the European Economic Community (EEC). Furthermore, McClure describes how the associated inflation and increased unemployment of these events would result in the rediscovery of poverty for large sections of New Zealand society (McClure, 2013).

Porter and Craig (as cited in Humpage 2006:226) state "New Zealand has long borrowed, experimented with and tweaked international policy and public sector reform models". So it was in keeping with this tradition the concept of social exclusion/inclusion emerged in New Zealand political policy during the last third of the twentieth century. The labour led coalition government of the period (1999-2008) was anxious to kick-start a renewed interest in social policy. Furthermore, the understandings of social exclusion/inclusion that propelled New Zealand's social policy agenda reproduced a distinctive, Anglo-Saxon form of Third Way politics (Humpage, 2006). The New Zealand Labour-coalition social policy agenda was highly influenced by the policies and ideologies of Tony Blair's New Labour government in Britain as these built on the ideologies of Roger-nomics introduced by the Lange Labour government 1984-1990 (Humpage, 2006). Thus NZ policy was devised with ideals of normalisation, which would bring back the excluded to some idealised homogenised centre where social order and cohesion are paramount. While simultaneously trying to protect this centre and its benefits from the genuine contestation of the excluded by stigmatising them as deviant and marginalising them so they are designated 'other' and remain socially excluded (Humpage, 2006). 
Humpage (2006) posits that the ways in which these policies and ideologies have played out in New Zealand highlights the explicit relationships that exist in states containing an internally colonised indigenous population. New Zealand's government has obligations to Māori under the auspices of the Treaty of Waitangi 1840 (Walters \& Bradley, 2005). There are countless complications that result in an exceedingly high level of risk when endeavouring to apply a policy discourse that has been developed out of continental Europe and the UK in massively differing contexts than those within New Zealand. These risks include historic agreements such as the treaty obligations above. There may also be unresolved issues relating to sovereignty and land ownership that make implementation of imported policy highly problematic. Māori poverty must be considered against the historical event of colonisation. The New Zealand Expert Advisory Group (EAG) on Child Poverty state research and analysis of material deprivation and financial difficulty affecting whanau (extended family) is incomplete without considering the impact of colonisation, land confiscation and war. These key historical events have caused pain and grief to Māori and have left lasting impacts that have been exacerbated by institutional and social reinforcement of discrimination (Poata-Smith, 2013).

The statistical evidence provided by the New Zealand Expert Advisory Group on Solutions to Child Poverty (EAG, 2012:4) states that when "calculations where child poverty rates in New Zealand based on both 50 per cent and 60 per cent of median disposable income which is set at $\$ 1,000$ for a family of two adults and two children (after housing costs). Note that the rates in 2011 were around 16 per cent and 25 per cent respectively. This equates to about 170,000 children using the lower threshold (indicating deeper levels of poverty), and 270,000 children with the higher threshold" (EAG, 2012:1).

The above evidence paints a bleak picture for a large slice of New Zealand society. The EAG (2012) argue that being trapped in a life of child poverty involves material deprivation and hardship. It means, for instance, less chance of a balanced diet that includes the required amounts of nutritious food, going to school hungry, wearing worn out shoes or going barefoot, a lack of adequate clothing, and living in a cold, damp house. It involves missing out on activities that most New Zealanders take for granted, such as birthday parties or playing sport. These impacts also include lower educational achievement, worse health outcomes and social exclusion. Additionally, these differential outcomes as well as the neurological responses to growing up in poverty mean that childhood poverty can have lifelong consequences, including reduced employment opportunities, reduced income, poor health, PDU and higher rates of criminal offending in adulthood (EAG, 2012). 
The rise of the punitive attitudes in New Zealand society have been fertilised through the increasingly influential and insistent voice of the mass media, moral entrepreneurs and lobby groups such as the Sensible Sentencing Trust (Pratt, 2008). Penal populism has influenced the largest historic increase in New Zealand prison numbers. 4,736 prisoners were incarcerated in 1996 and by 2006 the number had swollen to 8,000. The rate of imprisonment in New Zealand had increased from 130 per 100,000 of population to 188 per 100,000 (Pratt, 2008). Furthermore, there is a disproportionately high rate of Māori imprisonment as revealed by Walters and Bradley (2005:30) who cite the Department of Statistics: "Māori who represent 14.5 per cent of the New Zealand population comprise 51 per cent of all male inmates. Over the period 1950-1989 Māori incarceration has increased seven fold, this is four times the rate of increase of the non-Māori prison rate over the same period".

The recent history of economic and social policy in New Zealand as briefly outlined above has had far reaching impacts. The social exclusion from sections of society continues for both individuals and groups. These include social exclusion from schooling, employment, housing, health and social activities (EAG, 2012). United Kingdom and international research shows the consequences of social exclusion include increased criminal offending (Young, 1999) increased stigma (Lloyd, 2010) and increased PDU (Buchanan, 2004). The current research aims to investigate the occurrence and impacts of social exclusion as part of the processes of deindustrialisation in the New Zealand context.

\section{Stigma}

The term stigma describes an identified failing or differentness associated with an individual and can be traced back to ancient Greek society as "a tattoo or puncture mark made with a sharp object" (Lloyd, 2010:16). The act of stigma was used to brand and identify slaves; this process allowed for "the universal recognition of their status and to act as a deterrent to absconding" (Lloyd, 2010:16). Today, stigma is "a mark of disgrace or infamy; a sign of severe censure or condemnation, regarded as impressed on a person or thing; a brand" (Oxford English Dictionary, 2013). Stigma manifests as self-stigma, socialstigma and structural-stigma (Livingston et al., 2011). Self-stigma involves the internalisation of negative perceptions about one's social group by an individual (Ahern, Stuber and Galea, 2007). Social stigma relates to "the phenomenon of large social groups endorsing stereotypes about and acting against a stigmatised group" (Livingston et al, 2011:39), while structural stigma relates to the political and intuitional procedures and 
policies that obstruct the rights and opportunities of a stigmatised group (Livingston et al, 2011). The manifestation of self, social and structural stigma impact on the lives of those labelled as problematic drug users (IPDUs) at both the diagnostic and community level as they operate together simultaneously (Luoma et al., 2007).

At the diagnostic level, stigma is a significant barrier to the uptake and continued participation in mental health and general health care for many marginalised communities (Ahern, Stuber and Sandro, 2007). Self-stigma associated with the label of PDU is identified as a key reason for both the avoidance of and the early exit from drug treatment programmes (Luoma et al, 2007). The impact of stigma at the community level includes discrimination and marginalisation which manifest as structural stigma resulting in exclusion from schooling, mortgages, employment, insurance and other social opportunities (Hatzenbuehler, Phelan \& Link, 2013). Furthermore, the framing of stigmatised individuals as dangerous and untrustworthy can result in their being perceived as undeserving nuisance drug seekers in the hospital setting and as trouble makers by the police and their misrepresentation in the media (SANE, 2013). Misrepresentation of groups and the distortion of facts in the media are described by Cohen (1972) as a moral panic. Murji (1998:69) sums up media influence as having been "implicated in the triggering of drug scares and moral panics that lead to 'knee jerk' drug crackdowns and punitive responses". The incidence of a moral panic and the framing of the group involved as 'folk devils' is accomplished through "the generation of diffuse normative concerns" including deviance, fear of crime, gangs and threats to the established value system (Cohen, 1972:61). The language produced as part of the 'war on drugs' discourse is stigmatising and allows those who use or have used drugs to be framed as dirty, dishonest and evil (Buchanan, 2004). This separation of us/them increases in the incidence of social stigma at the community level and leads to a hardening of negative attitudes that perpetuate stigma and marginalisation of PDU (Murji, 1998).

The consequences of stigma were illuminated by the seminal work of Erving Goffman Stigma, Notes on the Management of Spoiled Identity (1963). Goffman creates a typology of stigma and identifies three types of stigma: First, the abominations of the body which encompasses a wide range of physical deformities. Secondly, the blemishes of individual character perceived as weak will, domineering or unnatural passions, treacherous and rigid beliefs, and dishonesty emerge from the knowledge that the person has a history of addiction, mental health diagnoses, incarceration or sexual deviance. Thirdly, there are the tribal stigma of race, nation and religion (Goffman, 1963:14). These descriptions are important as they identify that it is possible for an individual to suffer from multiple 
stigmas. An individual may be a person with problematic drug use who is Māori and longterm unemployed - three aspects of identity that carry stigma.

Furthermore, Goffman explains that when the stigmatised person's difference is obvious and visible they can easily become subject to stigma perceived merely by observation. In short, they are visibly identified as a 'discredited' person. Examples of the discredited stigma include noticeable birth defects or the tattooed face of a gang member. A person whose difference is not immediately apparent is described as 'discreditable' (1963:16). Examples of discreditable stigma include being an IPDU or a paedophile where the management of the stigma means it can be covered allowing the holder to pass as a nonstigmatised person (Goffman, 1963). Mixed contacts are the interactions that occur between a stigmatised individual and non-stigmatised people. Goffman (1963:12) argues these encounters are influenced by the mutual awareness of the attribute that stigmatises its possessor. This may result in 'the awareness of inferiority' and 'increased anxiety'. Examples in the local context include IPDU appointments with government agencies for social welfare or probation, reporting to a caseworker who is aware of their client's personal history. Visiting Drug and Alcohol clinics for appointments with caseworkers is another situation where the phenomena of stigma can play out during a mixed contact. Hatzenbuehler et al (2013:815) argue that mixed contacts may cause social isolation, fears of rejection and negative evaluation that lead individuals with concealable stigmas to avoid social relationships. Furthermore, they posit: "stigma is linked to poor health, stigma is associated with greater social isolation, and social isolation increases risk for poor health outcomes the stigma-health relationship is significantly attenuated after adjustment for social isolation". Goffman claims when interpersonal engagement occurs between stigmatised and the non-stigmatised individuals and the mixed contact is a conversational encounter, then the need arises for the effects of the stigma to be confronted by both sides. This allows for the occurrence of a primal sense of sociology "the uncertainty of not knowing, on meeting a new acquaintance what their attitude will be; rejecting or accepting, deserving or undeserving, can lead to increased stress" (1963:14). The stress associated with stigma, impacts on levels of individual physical health and mental health (Ahern, Stuber and Galea, 2007). This underlines the importance of how the holder of an attribute that identifies differentness deals with the management of their stigma. Strategies practised by the respondents when managing their stigma in mixed contacts and the on-going impacts experienced from these actions are an area of investigation for the current research.

Goffman provides a detailed description of the processes and consequences of being stigmatised. He investigates the subjects of group alignment and ego identity and describes both social identity (SI) and personal identity (PI). PI is the unique combinations of life 
history items that come to be attached to the individual. PI is the assumption that the individual can be differentiated from all others (1963:56). SI is the embodied signs including prestige and stigma symbols and a biographical history (1963:60). Furthermore, he also examines the techniques of information control including the concepts of 'passing' where someone can pass as a non-stigmatised individual and 'covering' which is an individual's effort to restrict the display of those failings most centrally identified with the stigma concept (1963:102). The key concept of the 'daily round' links the individual to social situations, a frame of reference that describes the navigation of social encounters in the daily life of the stigmatised individual, including the routine cycle of restrictions faced regarding social acceptance (1963:91). Buchanan (2006) draws on the concept of the daily round to argue that the $24 / 7$ demands of a drug centred lifestyle provides purpose and structure to the lives of IPDUs and in doing so provides an alternative to the boredom and monotony caused by marginalisation and unemployment. Goffman (1963), then, laid a solid foundation for the understanding of stigma and acted as a catalyst for further research into the phenomenon. Link \& Phelan (2001) and Lloyd (2010) build on Goffman (1963) and increase the theoretical understanding of stigma. The following section will now turn to this work.

Link and Phelan (2001) highlight the variations in the definitions of stigma. The original definition of the stigma concept put forward by Goffman describes stigma as an "attribute that is deeply discrediting" that reduces the bearer "from a whole and usual person to a tainted and discounted one" (Goffman, 1963:3). Since Goffman's original work, definitions have varied significantly. For example Stafford and Scott (1986 as cited by Link and Phelan) claim that stigma "is a characteristic of persons that is contrary to a norm of a social unit" (2001:364). Additionally, Crocker, Major and Steel (1998:365 as cited by Link and Phelan) propose that "stigmatised individuals possess (or are believed to possess) some attribute, or characteristic, that conveys a social identity that is devalued in a particular social context". Finally, Goffman's observation that stigma can be seen as a relationship between an "attribute and a stereotype" is used by Jones et al., (1984 as cited in Link and Phelan) in the construction of Jones et al.'s definition of stigma "a mark (attribute) that links a person to undesirable characteristics (stereotypes)" (2001:365).

Link and Phelan (2001) argue that there are two prominent reasons for these differences in definitions of stigma. First, the stigma concept is applied to a wide range of circumstances. Each circumstance is unique and due to their differences it is likely the investigators will be influenced to conceptualise stigma in relatively different ways. Secondly, research on stigma is evidently multidisciplinary, with a wide range of contributors including political scientists, sociologists, anthropologists, psychologists and social geographers. Furthermore, 
those individuals within disciplines may approach the concept of stigma from different theoretical orientations. This could create rather different visions of what should be included in the concept, allowing for different frames of reference that can lead to different conceptualisations. Link and Phelan (2001) posit that there is a need for stigma to be described with reference to the relationships between a set of interrelated concepts. To achieve this they have created their own conceptualisation of stigma.

For Link and Phelan (2001) stigma exists when the following interrelated components converge. In the first component, people distinguish and label human differences. In the second, dominant cultural beliefs label persons to undesirable characteristics that attract negative stereotypes. In the third, labelled persons are placed in distinct categories so to accomplish some degree of separation of "us" from "them". In the fourth, labelled persons experience status loss and discrimination that lead to unequal outcomes. Finally, stigmatisation is entirely contingent on access to social, economic, and political power that allows the identification of differentness, the construction of stereotypes, the separation of labelled persons into distinct categories, and the full execution of disapproval, rejection, exclusion, and discrimination. Thus the term stigma occurs when elements of labelling, stereotyping and status loss co-occur in a power situation that allows the components of stigma to unfold (Link and Phelan, 2001).

Link and Phelan underscore that when viewed from a holistic position, stigma processes are likely to play a significant role in life chances. Thus they deserve scrutiny from the wider body of social scientists that have an interest in the distribution of life chances. A point which is important for this study is that Link and Phelan (2001) identify the central elements of labelling, stereotyping and discrimination used by those in power to reinforce stigma upon the powerless - a particular issue for IPDUs.

Lloyd (2010) identifies the Individual Problem Drug User (IPDU) as being a highly stigmatised group in the UK. In surveys of public attitudes towards drug users conducted in 1998 and 2003 respondents were asked how far each of eight statements applied to a person with a drug addiction. In the report 60 to 78 per cent of respondents believed drug addicts to be 'unpredictable,' 'dangerous to others,' 'hard to talk with' and have 'only themselves to blame' (2010:26). On the other hand, fewer than 50 per cent thought that drug addicts 'feel different to the way we feel at times,' 'could pull themselves together if they wanted,' 'would not improve if given treatment,' or 'will never fully recover' (2010:26). Survey results surprisingly showed IPDU to be considerably more stigmatised than those suffering from mental illnesses (2010:26). Lloyd's (2010) findings highlight the problems faced by IPDUs including being perceived as dangerous and responsible for their 
own PDU. Furthermore, they are framed as 'other' and undeserving of inclusion in mainstream society.

Lloyd draws from Goffman (1963) and sees the identity of IPDU as a master status which obscures all others. As a master status Lloyd claims that PDU can regularly provoke disgust, anger, judgment and censure in others. Lloyd argues the master status influence on mixed contacts and the stigmatisation of IPDUs must have an effect on a person's sense of self-worth and ultimately may impact on their ability to escape addiction. In the conclusions of his report, Lloyd identifies how the issue of blame lies at the heart of the stigmatisation of PDU. The key issue then to counter the stigmatisation of IPDUs therefore involves challenging the widely held belief that IPDUs "only have themselves to blame" for their condition (Lloyd, 2010:66). Risk factors associated with PDU are described by Kreek et al., (2005:66) who note that "the vulnerability to addiction stems from a combination of genetic and environmental factors that predispose users to addictive use once exposed to a substance or activity" and the psychological, social and physiological impacts of addiction conspire to create individuals who have limited social capital, few life choices and who are frequently socially excluded (Lloyd, 2010). Lloyd suggests there is a need for serious consideration of the role stigmatisation plays in preventing the social reintegration of IPDUs. Additionally, there is an opportunity for compassion as opposed to stigmatisation particularly when it relates to the issue of recovery. Lloyd argues the negative effects of stigmatisation on social reintegration should make countering stigmatisation of IPDUs a political policy. The processes and impacts of stigmatisation and marginalisation in preventing the recovery and integration of IPDUs in the local context will be an area of focus for the current research.

In summary, the literature reviewed demonstrated stigma to be an interrelated concept (Link \& Phelan, 2001). Stigma carries wide reaching consequences for those it impacts upon. These impacts include poor physical and mental health outcomes (Ahern, Stuber and Galea, 2007). Individual devaluation through stereotype and blame can result in exclusion from mainstream society and stigma impacts on the inability to overcome exclusionary processes when attempting reintegration (Lloyd, 2010). There is a need for new approaches when dealing with the recovery of IPDUs or the socially excluded (Lloyd, 2010). It is important that these approaches avoid the use of negative stereotypes that lead to stigmatisation, which can result in the 'othering' of, marginalised communities (Link \& Phelan, 2001). 


\section{Problematic Drug Use}

The previous sections examined the phenomenon of social exclusion and stigma and their related consequences for those who have experienced poor mental health outcomes or problematic drug use. This section will examine deindustrialisation and its relationship with problematic drug use (PDU) exploring how deindustrialisation increases social exclusion (Grover, 2008) reduces resources, limits opportunities and pushes individuals with problem drug use (IPDUs) towards a drug centred lifestyle (Lloyd, 2010; MacGregor \& Thickett, 2011).

\section{The Place of Drugs in Society and through History}

The use of drugs spans prehistoric times to the present (Shiner, 2009). The knowledge of drugs, their effects and their use is shaped through social norms, beliefs and expectations (Durrant \& Thakker, 2003). In recent history the use of drugs include recreational and social opium consumption during the 1800s and 1900s and the use of opium based patent medicines during the 1800s which was wide spread in the United States of America (USA) and the British colonies (Reinarman, 1979; Boland, 2008). The problematic use of opiates has increased throughout the developed world during the second half of the twentieth century (Pearson, 1987). The modern emergence of the international drug trade and the resulting problematic drug use is argued to have occurred in the years immediately following the Second World War in the large American cities of New York and Chicago and in the last third of the twentieth century in the UK (Pearson, 1987).

A key piece of international law introduced to combat the proliferation of local drug use and the increasing international drug trade was the United Nations (UN) The Single Convention on Narcotic Drugs (1961). New Zealand is obligated as a member state of the UN to uphold the Convention. The Convention would set the scene for the emergence of a drugs problem and ultimately a 'war on drugs' (Caulkins, et al., 2005). In the New Zealand context the New Zealand Misuse of Drugs Act (1975) fulfilled New Zealand's Treaty obligations. The Act (1975) employs a three-tier (a) (b) (c) classification system (Law Commission, 2011) to broadly indicate the potential risk of harm and the degrees of control deemed necessary. Other legal drugs (alcohol, tobacco and caffeine) have remained outside of the Single Convention and are generally not seen as drugs (Nutt et al., 2007). This social construction of illegal and legal drugs has been achieved through the enshrinement of international treaties, national policies, mainstream political debate and case law (Boland, 2008). 
The everyday use of patent medicines allowed for the construction of drugs as beneficial and acceptable. The journey from the common use of patent medicine containing opium or cocaine to the modern 'war on drugs' where drugs are framed as illegal and dangerous demonstrates how the social construction of drugs and the 'drugs problem' has evolved over the past one hundred years (Boland, 2008). Currently the dominant discourse maintains illegal drugs are extremely addictive, which is a contested point (Nutt et al., 2007). Furthermore, addiction is said to turn otherwise law-abiding citizens into criminals who then contribute to the growing levels of crime (Boland, 2008). However, the relationship between drug taking and crime is more complex and contested (Stevens, 2007). The social construction of drugs in modern society has remained a highly contested area (Reinarman, 1979; Buchanan, 2006; Boland, 2008). The arbitrary exclusion of alcohol and tobacco from the classification and schedules of harm is highly hypocritical to the extent that Nutt et al (2007) argue "the current drug classification systems have little relation to the evidence of harm" (Nutt et al., 2007:1564).

\section{Drugs in New Zealand (prevalence of PDU)}

Prevalence rates of problematic drug use are constructed by the information given in the self-reporting format by individuals who disclose the use of opiates every day or nearly every day (Adamson, et al., 2012). There is no clear definition for PDU and the above definition used by Adamson et al., (2012) focuses on disclosure and in doing so contrasts with the criteria set out in the DSM IV American Psychiatric Association, (2000) where a systematic approach that considers tolerance, withdraw, and maladaptive patterns of behaviour co-occurring over a twelve month period are employed to diagnose substance dependence. There is a lack of shared understanding about what constitutes PDU and there are differing conclusions about the New Zealand prevalence rates of PDU being reported in the research data. These differences arise because different methodologies have been employed, and these differences are significant.

The national household surveys $(1998,2001,2003, \&$ 2006) employ a Computer Assisted Telephone Interview (CATI) methodology (Wilkins \& Sweetsur, 2008). The age ranges of the random digit dial (RDD) samples from each survey were 15-45 years old. The sample sizes of the surveys were 5475 in 1998; 5504 in 2001, 3042 in 2003 and 1902 in 2006. The survey shows an increase in the use of crystal methamphetamine in 2006 compared to 2003 ( 2.5 vs. $1.7, \mathrm{p}=0.0214$ ). The survey reported the use of thirteen substances, but surprisingly it did not report on prevalence rates for opiate use. Limitations of this research include that it only reached people that occupied a dwelling and who had access to a landline telephone. The ever-decreasing sample size impacts on the uniformity of these studies. 
Wilkins, Sweetsur and Griffiths (2011) draw on findings from the (2006, 2007, 2008, \& 2009) Illicit Drug Monitoring System (IDMS). The IDMS interviews three groups of 100 frequent drug users from the three main cities in New Zealand using a purposive sampling and 'snowballing' recruitment. The 300 frequent illegal drug users consisted of 100 frequent methamphetamine users, 100 frequent ecstasy users and 100 frequent injecting drug users, Wilkins et al (2011) report that, in 2009, 63\% of the frequent injecting drug users were male with an average age of 38 years, $77 \%$ were European, and $79 \%$ were unemployed. Wilkins, Sweetsur and Griffiths (2011) found pharmaceutical morphine rather than heroin was the principal drug used by IPDUs. They argue New Zealand's geographical isolation, small population and effective border control have limited the international supply of heroin, resulting in opiates being sourced from the diversion of pharmaceutical morphine, 'homebake' heroin manufactured in makeshift laboratories from codeine based over the counter medicines. The injection of methadone was common among IPDUs. Wilkins, Sweetsur and Griffiths (2011) posit that the evidence suggests there is a small population of IPDUs in New Zealand. A limitation to this study was the broad definition employed for frequent use (injected in the past six months). Further limitations are the restriction of the research to three locations and the use of a small sample.

Adamson et al (2008) calculate the New Zealand prevalence rates of PDU using the Multiplier method. The method used a two arm face-to-face survey of 97 regular opioid drug users (daily or almost daily) from those in methadone maintenance treatment and needle exchange programmes in Auckland, Tauranga and Christchurch. The multiplier of 2.16 estimated an opium dependent population of 9,953 (95\% CI 8,940 - 10,967). A limitation to this study was the relatively small sample size and the narrow sample selection.

The 2007/2008 New Zealand Alcohol and Drug Use Survey (NZADUS) measured alcohol and drug use among over 6,500 New Zealanders aged between 16-64 years (NZADUS) (Ministry of Health, 2010). Interviews were conducted in the participant's home using a computer to carry out assisted personal interviews (CAPI). The participant would enter their response into a laptop computer, sensitive questions were answered in private using audio computer assisted self-interview (A- CASI). Overall 3.6\% (95\% CI: $3.0-4.1)$ of adults aged between 16-64 had used an opiate at some point in their lifetime. This equated to around 94,000 people in NZ who had ever used opiates. The overall prevalence of use in the past twelve months was $1.1 \%$ (95\% CI: $0.8-1.4$ ) of 16-64 year olds had used an opiate (including heroin and prescription painkillers such as morphine) for recreational purposes in the last twelve months. This equates to about 28,800 people in New Zealand. A limitation to this research is the possible incidence of interviewer bias. Additionally the 
participants needed to reside in a dwelling, have access to a computer and be willing to speak aloud about illicit drug use.

The research above identifies the vastly different Prevalence rates reported for PDU. The differences in methodology may go some way in explaining the variances. These different prevalence rates also highlight the contested nature of illicit/legal drugs and their use in New Zealand. However, they all suggest that there are a significant number of IPDUs in New Zealand. The variance in the suggested numbers of IPDUs in NZ identifies the need for the construction of a reliable prevalence methodology. Additionally it also underscores the need for a good understanding of the current NZ drug policy which is overarched by the international 'war on drugs'.

\section{The War on Drugs (The war between drugs, the war against illegal drug users)}

In 1971 President Nixon declared a total 'War on Drugs'. This policy has been central to the USA gaining an exceptional influence over international drug policy (Shiner, 2009). While international conventions and national legislation have criminalised illegal drug use their employment in medical (health care) or industrial sectors (hemp fibre products) is still permissible (Durrant \& Thakker, 2003). The Rand Report (Caulkins, et al., 2005) brings into focus the problems that emerge as collateral damage from this war, including erosion of civil liberties, erosion of police integrity, exacerbation of drug-related harms and the generation of consequences beyond the criminal justice system. These consequences are also identified in the Report of The Global Commission on Drug Policy (2011) and include extensive policy displacement and the perception and treatment of drug users, who experience stigmatisation, marginalisation and exclusion. Lifelong negative consequences experienced by many young people as a result of the war on drugs is argued to cause significant individual and social harm (Buchanan, 2004)

The punitive prohibition of illicit drugs has not resulted in any long term reduction in drug use, which is a key goal of the war on drugs (Global Commission Drug Policy, 2011). The current American national drug control strategy has education, treatment and market disruption as priorities and appears to be driven by a desire to reduce the adverse consequences of drug use. The war on drugs has aimed for the securing of a drug free world. However, there is no specific plan to reduce the negative consequences related to drug use including overdoses, lost productivity, and HIV infection (Global Commission on Drug Policy, 2011). The American 'war on drugs' budget requires a change to its dominant focus on enforcement 53\%, treatment 29\% and prevention 18\% (Caulkins et al., 2005). More equal distribution of funds between treatment, educational, and enforcement 
strategies is needed if any improved long-term outcomes in the reduction of PDU are to be achieved.

Buchanan (2004:394) explains that the discourse regarding drugs use in contemporary society is "dominated by notions of fear and war, which leads to strategies that focus on punishment, control and exclusion of drug users, instead of concentrating on care, rehabilitation and inclusion". A drug policy based on prohibition and centred on enforcement has resulted in the widespread discrimination and stigmatisation of IPDUs and has contributed to the war on drugs becoming a war on drug takers who are framed as criminals deserving of punishment (Global Drug Policy Report, 2011). Government policies, treatment agencies and families can sometimes place unrealistic expectations upon IPDUs that increase stigma, criminalisation and 'othering' eventually resulting in poor physical and mental health outcomes (Ahern, Stuber \& Galea, 2007).

\section{The Relationship between PDU and Poverty/Social Exclusion}

The consequences of deindustrialisation, inequality, the widening gap in income distribution, child poverty, and reduction of life chances and poor health outcomes are both widespread and significant in New Zealand and the UK (Grover, 2008; Rashbrooke, 2013). In post-industrial towns of the UK MacGregor and Thickett (2011:478) identify "interconnections between historical change, socio-economic change, cultural complexity, deprivation, limited opportunities and illicit drugs". Areas of high unemployment endure many negative consequences including social isolation from employed peers, poorer schools and increased levels of black market activity and crime (Soldera, 1999).

Young (1999:81) uses the term 'bulimia' as a description for the processes of modern society which "both devours people and then steadfastly rejects them". Society is shaped by the messages taught through education and repeated by media (Irving, 2009). Both prepare children for work by instilling notions of career, of meritocracy and success. Key to this discourse is the market; a place of reward which is realised through participation and involvement. The dispossessed are encouraged to follow their dreams and to make the best of their lives by accessing the opportunities on offer (Irving, 2009). The processes of deindustrialisation, restructuring and out-sourcing has contributed to the dislocation of people, cut adrift from economic opportunity, and spatially segregated by both class and race (Young, 1999). For the unemployed the result is increased cultural inclusion through the images of consumer participation that is contrasted by the reality of economic and social exclusion enforced by the increased partitioning of society.

In this context, Buchanan (2004:391) asserts that "PDU is largely a socially constructed phenomenon that has less to do with individual choice or physical dependence, and much 
more to do with the structural disadvantages, limited opportunities, alternatives and resources". MacGregor and Thickett (2011:480) state that a "wealth of information from sociological and official sources confirms the relationship between PDU, unemployment, economic inactivity and living in a deprived area". Thus there is a need to eject policies that explain PDU through pathological behaviour and the choice of a drug centred lifestyle (Buchanan, 2006). These could be replaced by policies that confront the problem of deep rooted structural inequality and racism that have underwritten poverty and the social exclusion of a significant portion of society (Grover, 2008). This issue has been raised by Buchanan (2004:132) who asserts that IPDUs who are in the process of recovery encounter a 'wall of exclusion' when attempting re-integration into society. The bricks that make up the 'wall of exclusion' include but are not limited to, racism, inequality, stigmatisation, structural inequality, poor education, and poverty. Furthermore, Buchanan argues that the social context and structural realities faced by IPDUs need to be acknowledged and incorporated as a part of a recovery and reintegration strategy.

\section{Stigmatisation and Recovery}

A major consequence of the 'war on drugs' reported in international literature (Lloyd, 2010; Buchanan, 2006; MacGregor \& Thickett, 2011; Ahern, Stuber \& Galea, 2007) is the stigmatisation and discrimination of IPDUs which occurs across society. It is argued that this stigmatisation/marginalisation intensifies social problems rather than relieving them (Anderson \& Ripullo, 1996; Radcliffe \& Stevens, 2008). Earnshaw et al. (2012) demonstrated that individuals receiving methadone maintenance therapy (MMT) experience prejudice, stereotypes, and discrimination from healthcare workers and pharmacy workers. The impacts of stigmatisation and discrimination include poor mental health which may exacerbate PDU rather than reducing it through social deterrence (Caulkins, et al., 2005). The perceived stigmatisation of IPDUs by health professionals can act as a barrier to drug treatment (Ahern et al, 2007). Harris and McElrath (2012) report retention of IPDUs in MMT programmes in the UK is the exception and not the rule. Furthermore, in some studies upwards of $40 \%-60 \%$ of MMT clients were shown to have left treatment within 12 to 14 months of their initiation (Harris \& McElrath, 2012). However, reasons for leaving treatment should be viewed on a case-by-case basis rather than by a success or failure dichotomy.

Ahern, Stuber and Galea (2006:188) state "stigmatisation has been directly a detrimental influence on physical and mental health stemming from exposure to chronic stress including experiences of discrimination... [the] rejection by others and expectations of rejection may cause chronic stress and may lead to coping approaches that involve withdrawal and isolation, leading to social exclusion, further harming the mental wellbeing 
of IPDUs". Hatzenbuehler, Phelan and Link (2013) argue stigma is a central driver of morbidity and mortality and encompassing multiple statuses and characteristics, such as illicit drug use, HIV status and beneficiary/employment status. Discrimination at both the individual and structural level is a key feature of stigma. Stigmatisation impacts negatively on both physical and mental health outcomes (Hatzenbuehler, Phelan \& Link, 2013). The public consumption of methadone in the pharmacy setting is highly problematic as it exposes the recovering IPDU to the critical 'public gaze' (Lloyd, 2010). Radcliffe and Stevens (2008) argue that as part of a treatment regimen the supervised consumption of methadone can be highly stigmatising. In a small community this behaviour could lead to an individual's private information becoming known and the 'junkie' master status becoming fixed (Radcliffe \& Stevens, 2008)

The process of daily consumption of methadone frames individuals in MMT as undeserving and creates a situation where their lives have to be organised around the pharmacy dispensing hours and the weekly appointments for testing, monitoring and counselling (Richardson et al., 2012). The pattern of life on MMT may impact on the individuals previous daily routine with the commitments above taking the place of 24/7 drug-lifestyle. However these commitments are often perceived negatively and are commonly referred to as being 'liquid handcuffs' and can be a real barrier to an individual's ability to find or hold down a job. There is a need for more flexibility in the time clinic appointments are made and to the hours for pharmacy consumption (Richardson, et al., 2012). The investigation into the perception of stigma experienced by IPDUs in the current research is a key strand in gaining an understanding of the consequences of the 'war on drugs' on IPDUs in the New Zealand context.

\section{The Local Situation}

The DNZT being investigated in the current research has many of the phenomena that are reported in the international literature. These phenomena include a high number of unemployed young people (MacGregor \& Thickett, 2011), enduring unemployment (Soldera, 1999), schools that struggle to provide an adequate education for children thus limiting life opportunities (Wylie, 2013), and increased levels of inequality (Grover, 2008). Poata-Smith (2013:154) argues that "the New Zealand government's commitment to neoliberal policy and fiscal austerity have substantially increased inequality". Poata-Smith (2013:154) reports unemployment rates have risen significantly for Māori to 13.3\% in 2012 from 7.95\% five years earlier. Furthermore, on a different measure in 2012 17.6\% of Māori males and $27.5 \%$ of Māori females were classified as not being in employment, education or training, compared with $11.5 \%$ of all males and $14.6 \%$ of all females in the age group. The major ethnic groups making up DNZT reported by the Census (2006) are European 
63\%, Māori 17\%, Pacific Peoples 12\%, Asian 5\%, Middle Eastern/Latin/African 1\% and other ethnic groups $9 \%$. The number of residents in receipt of the unemployment benefit in DNZT has a significant variance in the affluent area unit the rate is $2.1 \%$ while in the other area units the rate ranges between $4.3 \%$ and $5.8 \%{ }^{2}$ These statistics demonstrate that there is a significant variance in the amount of income people receive in NZDT. The census data reveals an increase in inequality that is in keeping with that reported by EAG (2012). The Expert Advisory Group on Solutions to Child Poverty (2012: VI) report that as many as 270,000 children in New Zealand live in poverty. The town's high school has the lowest published achievement rates $50.30 \%$ for the attainment of NCEA qualifications regionally in 2012. The 2012 achievement rate, while very low is a substantial improvement on the 2004 rates. During this time the national achievement mean was 58\% the DNZT achievement rate was $18 \%$. The statistics above highlight the impacts of deindustrialisation and government policy and demonstrate growing inequality. Additionally the dramatic and swift nature of the deindustrialisation process in DNZT is shown by the deindustrialisation map that appears in the appendix section of this thesis. the Growing inequality, poverty and limited opportunity alongside severe disadvantage, stigma and social exclusion are internationally recognised components that tend to precede PDU (Social Exclusion Unit, 2002; Home Office, 2004a; Buchanan, 2006; Ahern, Stuber and Galea, 2006; Anderson \& Ripullo, 1996; Radcliffe \& Stevens, 2008; Wilkins, Sweetsur \& Griffiths, 2011; Boland, 2008).

\section{Overview}

Over the past thirty-five years the gap between the high, middle, and low income of New Zealanders has continued to increase. This gap has widened to the stage where, across all adults, the super-elite who make up the top $1 \%$ of the population now have ownership of three times more wealth than the collective bottom 50\% who make up the poorest section of society (Rashbrooke, 2013). The processes of neoliberalism have helped to create this gap and have led to increased levels of unemployment, low levels of remuneration and a reduction of career opportunities in New Zealand society (EAG, 2012). Deindustrialisation and its associated phenomena include social exclusion, stigma and problematic drug use (PDU) (Grover, 2008; Young, 1999; McGregor \& Thickett, 2011; Buchanan, 2004). The impacts of these phenomena on the lives of people have driven this research. The consequences of deindustrialisation and its associated phenomena; social exclusion, stigma

\footnotetext{
${ }^{2}$ Reference omitted to protect anonymity
} 
and PDU in a deindustrialised New Zealand town (DNZT) were investigated. The aim of this research is to gain an understanding into a discarded community by capturing the perceptions and experiences of long term IPDUs and contribute to the filling of a gap at the national level. 


\section{Methods}

\section{Introduction}

The research employed a qualitative research design phenomenology (Husser 1859-1938) as the respondents shared their experiences and perceptions of social exclusion, stigma and PDU in their own words and by their own frames of reference (Bryman, 2008). From a personal position the research is seen through the lens of critical realism and in the wider context the researcher occupies a position of insider. The epistemological position of interpretivist is held alongside an ontological position of constructionism. The methods used during this research process included: self-selective sampling; semi-structured interviews; national and international literature review; and a thematic analysis of the qualitative data gathered. The thematic analysis (TA) undertaken in this research is guided by Braun and Clarke's (2006) a six-stage method for identifying, analysing and the reporting of patterns (themes) from within qualitative data corpus.

\section{Epistemological Position}

Epistemology influences form, voice, and representation in method and defines how the investigator interrelates with their audience and the conceptualisation of the role of the audience, the analyst and the respondents in the work (Mantzoukas, 2004). "Epistemology contains values and thus is normative. It is the foundation for explaining rightness or wrongness, admissibility or inadmissibility, of types of knowledge and sources of justification of that knowledge" (Carter \& Little, 2007:1322). In the current research the researcher occupies an interpretative epistemological position. This is in keeping with a phenomenological approach where an interpretative process is undertaken when the researcher "mediates" between different meanings; of the meaning of the lived experiences (Creswell et al., 2007:253). Interpretivism is influenced by the work of Max Weber (18641920) who described sociology as "a 'science' which attempts the interpretive understanding of social action in order to arrive at a causal explanation of its cause and effects" (as cited by Bryman, 2008:15). Additionally Bryman points out "that the crucial point to the task of 'causal explanation' is that it is undertaken with reference to the 'interpretive understanding of social action' rather than to external forces that have no meaning for those involved in that social action" (Bryman, 2008:15).

Miller and Brewer (2003:41) state that the social constructionist perspective within the social sciences is part of a much wider historical tradition that is referred to as 
constructionist or constructivist. They refer to constructionists as believing that people make their own reality and that there are no universal laws external to human interaction waiting to be uncovered, while constructionism argues that scientific knowledge and everyday knowledge both emerge from the interactions and social processes that make up everyday life (Miller \& Brewer, 2003). Immediate foundations of constructionism can be traced to the work of the Chicago School in the first part of the twentieth century and to the phenomenology of Alfred Schultz (Miller \& Brewer, 2003).

The seminal work on stigma by Goffman (1963) Notes on the Management of Spoilt Identity took a constructionism approach as its focus was on how meaning, identity and culture are created in the process of interaction. Goffman's (1963) emphasis was also on asserting the context-bound, fluid and open-ended nature of social relationships. The work of Berger and Luckmann (1966) put forward the claim that reality is constructed through three 'moments': Externalisation (the way societies, cultures and social groups of different kinds make sense of- and therefore 'make'- their social worlds, which include a wide range of social institutions and constructs); Objectification (how those constructs and social institutions are then perceived as being 'out there', just as 'nature' is 'out there' thus a set of coincidental events and occurrences get turned into a 'thing' and by associating them together as a 'thing', it has become objectified); Internalisation (where the objectified social world becomes known through processes of socialisation and enculturation. For example gender; children learn that 'male' and 'female' are distinct and important categories, and they internalise this knowledge to the point where it becomes self-evident and taken for granted. However, this knowledge acquired during childhood is not fixed- internalisation is an on-going process) (Stainton Rogers \& Stainton Rogers, 2001). The author's research approach employs both interpretative and critical methodologies.

Miller and Brewer (2003) discuss critical realism in their work and trace its emergence back to the early work of Immanuel Kant (1724-1804). Kant argued that, "rather than taking our reason and knowledge for granted, we can only gain understanding through critical engagement with the conditions that make such reason and knowledge possible" (as cited in Miller \& Brewer, 2003:57). Miller and Brewer (2003:57) draw three early theorists together to explain critical theory. Firstly the aim of critical theory is to dig down and look beneath the surface of knowledge and reason (Kant 1724-1804). This is done to expose the distortion of knowledge and reason that occurs in an exploitative society (Marx 18181883). This allows for the possibility and emergence of less distorted forms of knowledge and reason (Hegel 1770-1831). I engaged with a reality during my fieldwork. However, I acknowledge that this reality was, to a large part, constructed and negotiated through social 
interaction. I remain therefore, somewhat, critical and although I have the utmost commitment to methodological rigour, I regard my data as contestable knowledge.

\section{Insider Status}

The researcher's position as an insider in the communities being explored must be acknowledged. As a younger man I was incarcerated at different times between the ages of seventeen and twenty-seven. An on-going cycle of PDU, criminal offending and prison were the pattern of my life until the long process of recovery through methadone maintenance was initiated some twenty-three years ago. The researcher's background has afforded opportunities for contact with the community being researched. IPDUs can be difficult to access as they belong to a hidden population that need to keep their activity out of view (Watters \& Biernacki, 1989). Researching the health consequences and social harms amongst IPDUs is challenging, exacerbated by a number of factors including legal status, social stigmatisation, marginalisation and general lack of visibility (Watters \& Biernacki, 1989). Discussing the insider (emic) and outsider (etic) distinction, Merton (1972:11) posits: "particular groups have 'monolithic' or at least 'privileged' access to particular kinds of knowledge". Merton (1972:21) conceptualised that "insiders are the members of specified groups and collectives, or occupants of specified social statuses. Outsiders are the non-members". The insider outsider dichotomy has been challenged by a number of academic authors including Mercer (2007) and Hellawell (2006) who both draw from Merton (1972) when explaining their claim that insider and outsider positions are best framed as being part of a continuum in ethnographic fieldwork. Hellawell (2006:488) argues, "the researcher can occupy a place between the two poles; from 'complete observer' at one extreme to 'complete participant' at the other end". Mercer (2007:4) states that "we are all 'multiple' insiders and outsiders" and that there is a movement between the continuum poles as researchers "move back and forth across different boundaries" to accommodate situations where diverse values emerge causing different positions to be activated and the margins of separation to move.

Being an insider and a known member of the community where the research was conducted afforded me the privileged position of easier access to this otherwise hard to reach group. The common knowledge of my drug using history and incarceration amongst the long-term drug using population in the town arguably provided acceptance and accommodation that helped to establish trust between me as the interviewer and the respondents. There could have been a significant hindrance if my credibility in the community was challenged or lacking, in isolation insider status is not sufficient. 
There are a number of advantages and disadvantages when undertaking insider research. Disadvantages include contending with one's own preconceptions, and any preconceptions the respondents may have formed about the researcher due to their shared experience. The key dilemmas faced when conducting insider research are informant bias, interview reciprocity and research ethics. Interviewees will inevitably form preconceptions about any researcher they have a previous knowledge of or a shared culture with and for this reason the insider researchers should refrain from publicising their own opinions about their research topic and should not contribute their own experiences or perceptions during the research process (Mercer 2007). Furthermore, to guard against making assumptions about what is said and not seek the clarification from the interviewee as an outsider researcher would. The ethics of only using what is covered by the informed consent must be strictly upheld. Using information drawn from overheard conversations due to proximity would damage the ability to maintain any trust formerly established. Advantages of insider research include enjoying freer access, understanding and being able to use the language/jargon of the group, stronger rapport and a shared outlook and deeper knowledge of the group and its culture. The shared outlook and deeper knowledge that comes from the researcher investigating their community or subcultural-group is operationalised from a position of advantage (Mercer, 2007). Davies (2005) states, that this position of advantage is termed 'positionality' and that the insider's interpretation of the results and the presentation of the study's findings can be influenced by the positionality of the researcher. Davies (2005:2) stresses the importance of the researcher engaging in the process of selfreflexivity and that this "self-reflexivity is continually heeded to ensure the validity of both data collection and reporting". The need to maintain reflexivity throughout the research process is highlighted by Davis (2005), who identifies the importance of ensuring that notions of insider and outsider are well defined for the researcher, as there are occasions when the two positions are likely to overlap as they are regularly in a constant state of flux.

\section{Methods}

\section{Recruitment}

The current study employed a qualitative approach that involved a non-probability sample drawn from people who met the sample requirements (Cozby, 2007). Participation in the research was dependent on the respondents meeting with the predetermined criteria for inclusion: the respondents currently lived in DNZT, were thirty years of age or over (had a birthdate earlier than 1983) so they would have had experience of the processes of 
deindustrialisation through their working lives, and that they had been an individual with problematic drug use (IPDU) for more than ten years. Initially, recruitment posters with a simple outline of the current research were placed at the local pharmacy, GP surgeries, the needle exchange and the local shopping centre.

The participants were accessed through responding by texting "join" to the text number on the recruitment poster. The study also employed respondent driven sampling in the form of the snowball method. Snowball sampling is a non-probability sampling strategy where the first respondents recruited are asked to recommend the subsequent group of participants (Gray, 2009). The sample size was small and there were no difficulties securing ten respondents for the current research. On establishing contact the respondents were given a brief explanation about the research and its purpose. They were also given an information sheet for viewing and if agreeable a time was set for a future meeting after they had been given time to consider the information sheet (this was around five days). During the second contact any questions they had about the research were answered and if they decided to continue with their participation a further meeting was arranged where the interview was then conducted following the signing of the informed consent form (Cozby, 2007). The positionality of the researcher allowed for, proximity, openness and honesty which contributed to establishing a sense of trust with the respondents.

The only issue to occur during the recruitment process was when a respondent who had made contact through the recruitment poster thought that the research being conducted was a drug trial. They were informed of the nature of the current study and as they did not meet the criteria, they were thanked for their interest.

\section{Interviews}

In order to engage a hard to reach group who might be unable to travel for interviews or might be intimidated in formal settings, interviews were conducted at a negotiated location where interviewees felt comfortable, safe and able to talk freely (Griffiths et al., 1993). Before starting the interview process the information sheet was explained one final time and the purposes and potential uses of the research were discussed. Additionally, assurances of confidentiality and anonymity were reiterated and any final questions from the respondent were answered and the informed consent form was signed. The interviews were conducted in a face-to-face manner and were recorded on a small digital recorder. Conducting the interviews in a face-to-face manner allowed the interviewer to be aware of the interviewee's body language enabling the researcher to be more sensitive to the respondent's processing and feelings throughout the interview. The interviews were undertaken using a semi-structured method (Bryman, 2008). Wherever possible, questions 
were delivered in an open-ended style which allowed the people interviewed to draw from their own experiences and perceptions (Bryman, 2008). However, there was a set of prompts that could be utilised if the interviewee was struggling to answer or had in some way misunderstood the question asked. The prompts were standardised probes to maintain consistency throughout all interviews (Bryman, 2008). The ten interviews varied in length, the two shortest were approximately forty minutes long while the two longest were over two hours in duration. The remaining six interviews were approximately one hour in length.

\section{Thematic Analysis}

The qualitative method employed in the current research was thematic analysis. The six stages of thematic analysis as described by Braun and Clarke (2006) were followed. The data were drawn from the research interviews, transcribed verbatim in long hand and then transcribed into a word document. This provided a data corpus of 2,699 data extracts. The data extracts could be coded into multiple data sets due to the overlapping nature of the content and variation of the size of the data sets. The data sets were labelled Education/employment 313, Relationships 518, Trauma 214, Drugs/PDU 636, Exclusion 188, Stigma/Discrimination/Racism 705, Health 106, and Miscellaneous 19.

According to Braun and Clarke (2006:87) thematic analysis involves six steps: familiarizing yourself with your data; generating initial codes; searching for themes; reviewing themes; defining and naming themes; and finally producing the report. This process was conducted for this research project as follows:

(1) Becoming familiar with the data: In the current research the interview was recorded on a digital recorder. The entire interview was reviewed following the completion of the interview process. The full interview was reviewed again the following day and was reviewed again during the transcription process later that day. The data drawn from the research interviews was transcribed verbatim in longhand in the first instance. The following day the interview was reviewed once more and the long hand transcript was replaced by a word document that was also transcribed verbatim. This process was replicated for all ten interviews allowing the researcher to become thoroughly familiar with the research interviews/data.

(2) Generating initial codes: This was accomplished by exploring emerging features in a systematic fashion across the entire data set, then sifting the collated data to develop and refine the initial codes. Coding was accomplished by using different coloured pens to identify and code a data extract from within the data corpus. 
(3) Searching for themes: The use of coloured pens allowed data extracts to be coded and once coded and grouped potential themes were identified by a closer examination of the data, emerging themes were then placed within a theme-tree.

(4) Reviewing themes: Discussing the themes with the research supervisor and checking the qualitative extracts across the data set captured the key messages from the research and helped firm-up and check the validity of the initial understandings. Verbatim quotes from the respondents were colour coded according to the six main themes, extracted from the original word document and pasted into the relevant thematic file.

(5) Defining and naming themes: Data pertaining to each of the seven thematic areas were brought together. Each data extract within these broad thematic files was further interrogated and coded to explore, understand and highlight dominant shared experiences amongst this cohort. This additional thematic analysis utilised online computer software "Wordle" which can provide a "word cloud' allowing for the visual representation reflecting the prominence of dominant shared experiences amongst the sample interviewed. The creation of a "wordle" representation in this study required the key thematic sub-headings to be entered in strict accordance with the frequency of their occurrence. ${ }^{4}$

(6) Producing the report: The final opportunity for analysis was undertaken through the selection of rich and captivating extract examples to give voice to the people interviewed, and to gain an understanding of their experiences and perceptions of their lives. These extracts were used in the final analysis to relate back to the research question and to the international and national literature that informed the current study.

\section{Ethics}

The Victoria University's Human Ethics Committee granted approval for the study. During the research process the respondents were treated in a respectful manner at all times. Careful consideration was given to any potential risks or harms to the respondents. Interviewees were supplied with a form to provide informed consent and were advised that they could terminate their involvement in the current research at any point without prejudice. This informed consent form outlined the assurances of the researcher to protect the respondents' confidentiality and anonymity. The research draws from Low and Jose

\footnotetext{
${ }^{3}$ http://www.wordle.net/

${ }^{4}$ As I am severely dyslexic systematic coding and visual representations were extremely helpful in organising the research themes coherently.
} 
(2010) by setting out the processes for publication and dissemination of the research findings in the informed consent form. A leaflet of local drug agencies was also available to any respondent seeking help. On completion the respondents received a koha as a gesture of appreciation for their time and participation.

It was important that both the interviewee and interviewer felt comfortable and safe so appointments for interviews were arranged following a preliminary initial face-to-face discussion to explain the research, seek informed consent and build and establish rapport. It was only after this initial assessment was a decision to proceed with the interview taken. As a safety precaution the researcher texted a nearby friend immediately prior to and immediately following each interview. Most interviews took place at the respondents' home although some interviews took place in a public park. On the conclusion of the research process the people interviewed will receive a one-page feedback sheet that will explain the research and its findings. They will also be given the opportunity to discuss how they felt as they went through the interview process. Additionally a copy of the thesis will be provided for their reading and the researcher will answer any other questions that they may have.

\section{Reflections}

The key issues to arise from my reflections are related to the interview process. These issues include interviewer bias, maintaining a neutral disposition, body language and maintaining reflexivity. Interviewer bias is a term that describes all the biases that may arise when a one on one interaction between the interviewer who is a unique human being and the interviewee who is also a unique human being occurs (Cozby, 2007). Reflecting on this process made me become more aware of the potential for the interviewer to subtly bias a respondent's answers by unconsciously showing approval or disapproval of certain answers. A further form of interviewer bias described by Cozby (2007) is unintentional influence exerted by the interviewers' expectations. It was imperative for the author to be aware that some of the expectations I hold could influence and distort my ability to listen carefully to the answers provided by the interviewees. These actions could lead to the interviewee biasing their responses to meet the expectations of the researcher. Furthermore, the authors own perceptions and experiences may cause assumptions to be made that may leave an important issue unexplored. These issues highlight the need of the interviewer to maintain a neutral disposition so not to convey any approval or disapproval relating to any question. This enabled the researcher to be more sensitive to the respondents' feelings throughout the interview.

However, on further reflection the value of having a shared culture or sub-cultural experience must be acknowledged. The issues of interviewer bias and interview reciprocity 
discussed above could be viewed differently. As Keval (2009:52) posits the relationships established while conducting either outsider/insider research can be characterised as "processes of 'cultural validations', which allows multiple possibilities in the way in which aspects of ourselves as researchers- ethnicity, language, biographies and experiences- can connect and sometimes clash with those of the participants" On reflection the author feels that on some occasions an exchange may have being interpreted as interview reciprocity but was actually a process of cultural validation. Central to the entire research project particularly the gathering of qualitative data through interviewing respondents is the process of reflexivity. To spend time out reflecting on work completed that day and work done previously. Additionally, time was taken to critically reflect on my own perspectives and where I am actually placed in reference to the interviewees. It is important to reflect on any personal or emotional impact the interviewing process may have had on me. Also taking time to consider how the interview process may have impacted on the interviewee and to be pro-active in making any improvements. To keep my initial commitment to reflexivity and through this process stay aware of my responsibilities as a researcher throughout the study including the analysis, write up and debriefing of interviewees. In a final reflection, the term 'hard to reach communities' has appeared in the literature and has being used by the author in this study. However following contemplation the author now takes the perspective that there are no 'hard to reach communities' rather this is a terminology that describes an academic disconnection from these groups and highlights a lack of commitment to connecting with these communities. 


\section{Findings}

The following three tables illustrate the participant's background, their drug history and the themes that emerged from interviews. The Participants Background table contains demographic information volunteered by the participants. The Participants Drug History contains information that concerns the participants' drug using histories. The Emerging Themes table contains the key themes that emerged through the thematic analysis of the data corpus.

\section{The Participant's Background}

\begin{tabular}{|c|c|c|c|c|c|c|c|}
\hline Name & Gender & $\begin{array}{c}\text { Ethnicity } \\
\text { Self- } \\
\text { Identification }\end{array}$ & $\begin{array}{c}\text { Parents } \\
\text { separated in } \\
\text { their } \\
\text { childhood }\end{array}$ & Qualifications & $\begin{array}{c}\text { Excluded } \\
\text { from school }\end{array}$ & Employment & Prison \\
\hline Al & Female & White & No & No & Yes & Yes (Manual) & No \\
\hline Paul & Male & White NZ & No & No & Yes & No & Yes \\
\hline Doris & Male & Māori & Yes & No & Yes & No & Yes \\
\hline James & Male & White English & Yes & No & Yes & No & Yes \\
\hline Pete & Male & White & No & No & Yes & Yes (Manual) & Yes \\
\hline
\end{tabular}

Participant's Drug History

\begin{tabular}{|c|c|c|c|c|c|}
\hline & $\begin{array}{c}\text { Age started } \\
\text { using illicit drugs } \\
\text { (All cannabis) }\end{array}$ & $\begin{array}{c}\text { Main drug of } \\
\text { choice }\end{array}$ & $\begin{array}{c}\text { Main Method } \\
\text { of } \\
\text { Administration }\end{array}$ & $\begin{array}{c}\text { Length of PDU } \\
\text { (years) }\end{array}$ & $\begin{array}{c}\text { Currently Receiving } \\
\text { Methadone } \\
\text { (years) }\end{array}$ \\
\hline Al & $14 y r s$ & Heroin & Intravenous & $37 y r s$ & Yes (15yrs) \\
\hline Ben & $17 \mathrm{yrs}$ & Heroin & Intravenous & $36 y r s$ & Yes (10yrs) \\
\hline Doris & $17 \mathrm{yrs}$ & Opiates & Intravenous & $27 y r s$ & Yes (22yrs) \\
\hline James & $12 \mathrm{yrs}$ & Opiates & Intravenous & $27 y r s$ & Not currently \\
\hline Jasmine & $15 y r s$ & Opium & Intravenous & $26 y r s$ & Yes (17yrs) \\
\hline
\end{tabular}


Emerging Themes

\begin{tabular}{|c|c|}
\hline Thematic Coding & Number of extracts \\
\hline Stigma and discrimination & 705 \\
\hline Drug use & 636 \\
\hline Relationships & 518 \\
\hline Education and employment & 313 \\
\hline Trauma & 214 \\
\hline Exclusion & 188 \\
\hline Health issues & 106 \\
\hline Miscellaneous & 19 \\
\hline Total & 2,699 \\
\hline
\end{tabular}




\section{Stigma and Discrimination}

\section{Social Labellingschool \\ Self-perception Pharmacy \\ Alcohol Employment \\ Relationships

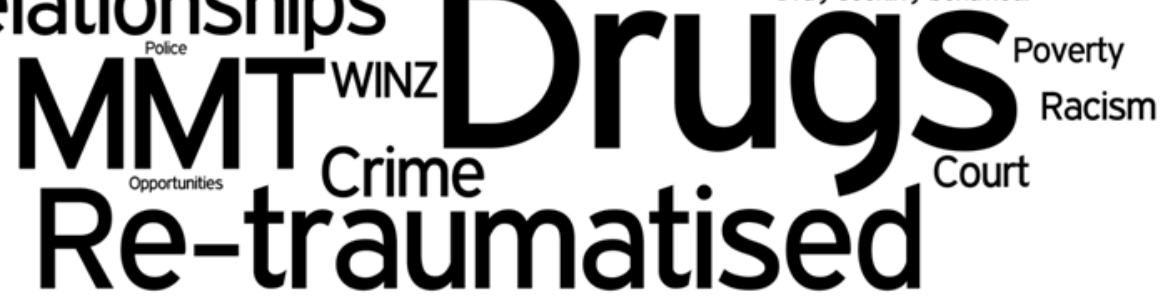 \\ Dirty-lying The-public-gaze \\ Slamming-Injecting}

Stigma was the most dominant theme with 705 data extracts from the interviews coded.

Stigma occurred prior and post the onset of problematic drug use and was experienced by all of the interviewees. Stigma was also experienced in a variety of social settings: the family; school; court; prison and interactions with government and social agencies. The most frequent experience of stigma related to drug use and personal interactions with medical and health professionals.

Three types of stigma were manifest amongst the interviewees: self-stigma - the internalisation of negative perceptions about one's social group (Ahern, et al, 2007); socialstigma - when a large social group endorses stereotypes about and acts against a stigmatised group or individual (Livingston, et al, 2011); and structural-stigma - the political and institutional procedures and policies that obstruct the rights and opportunities of a stigmatised group (Livingston, et al, 2011), particularly during interactions with health professionals. It was clear to the respondents that they had acquired the 'master status' (Goffman 1963) of 'drug addict', and that this had severe stigmatising consequences, sealing off opportunities for example. The onset of the stigma process was discussed and the impact of stigma was explored throughout the interviews.

Stigma occurred at an early age for some respondents. One respondent believed his family's name had stigmatised him. He saw his "Family representations [a] Black Mark." (Lenny). He felt poverty had led to their family being framed negatively and that he was not prepared to live his life in the same manner as his father: "Poverty [and] deprivation never any money. ...I'm not going to live my father's life." (Lenny) 
Pete also endured stigma arising from his family. He explained how his peers ridiculed his mother's serious mental health problem and how his reaction to this stigma and taunts was to lash out:

"I'd always have to go and visit her like on Sunday at **** which was you know way south of ****. Plus I copped a lot of stick at school you know from other kids you know saying [this] and that just riled me. Yeah and I [would] just attack people you know like anyone I guess like...yeah.” (Pete)

The stigma associated with being sexually active at a young age is described by Doris when she recalls her exclusion from school. She reflects that this was a little odd because she was a good student: "Fourteen years old [and] involved with a man sexually active. ...Left school at fourteen told to leave murky in [my] mind [I] was an academic student. (Doris)

The sexual abuse perpetrated on Alan was finally acknowledged when the police started an inquiry. However, he was apprehensive about disclosing the full extent of the sexual abuse perpetrated against him for fear of further stigma of being labelled a homosexual by his peers:

"We're back in the city and the police investigating this guy for sexually abusing children mainly his stepson and myself. So they come to the college they interview us ...I was still too much under the thumb and scared of being labelled a "homo" and all the rest of that sort of stuff as kids you know [a] teenager." (Alan)

Paul reports how being stigmatised as a child for being Māori left him feeling isolated from his peers and impacted on his ability to make friends and maintain relationships.
"Definitely had stigma and discrimination I was very aware of that sort of thing from an early age with racism and things like that ...I would negate it, ...always try to speak try and speak [well] be well spoken and polite that was my way of dealing with it ...Making new friendships and new relationships I found it quite difficult. I felt the need to elaborate or lie um I wasn't comfortable in myself and I held back... a lot." (Paul)

After leaving school securing a job and then losing it Alan was wrongly blamed for burglary of his employer. This left him feeling labelled and blamed. "I don't know what happened there, but I lost that job. But just after I lost it they were burgled and I was blamed. It wasn't me though' I was blamed" (Alan). The extent of stigma reported prior to 
the development of a long-term drug dependency has been significant and the remaining section will focus on stigma subsequent to drug dependency.

Lenny perceived himself negatively as 'an addict' because his life was centred on drug use and the commission of property crimes to pay for his drug use. "View myself as an addict [I] can't go out when 'hanging out'. Crime [to] 'score' and 'hoist'." (Lenny). He was incarcerated at the age of sixteen when he was sent to Corrective Training (CT). He believes he went to prison because he was seen as worthless and prison just hardened his attitude: "CT first time in court age 16yr [for] theft under $\$ 1,000$ and two driving charges. Poor white trash sent to jail. Beat down inside the life of a young inmate. [I] Hate authority." (Lenny)

Ben explains that when he became a problematic user he was very careful who he disclosed information about his dependency to, because society stigmatise IPDUs as being dishonest and untrustworthy. "Only my close friends knew I was using. Joe citizen thinks lock up your valuables and daughters....You're all the same, can't be trusted you're a drug addict." (Ben). He reflects on the recent prospect of securing employment, and recalls the stigmatising experience of applying for employment in a supermarket as a shelf-stacker when he was informed that there was a requirement to undergo a urine drug-screening test as part of the employment process. Ben explains he decided to be very open about him receiving MMT but the prospective employers' reaction to his honesty suggested he had little chance of the getting the job: "Drugs testing [for] packing shelves [it's] not being a brain surgeon. Attitude changes [negatively] when I'm honest [about being on MMT]. I did not lie because of the drug test. Slim chance of getting a job" (Ben). This negativity was also confirmed by Paul "Anywhere where you have to divulge certain details about yourself ... I'm on the MMT you can see their body language - the look on their faces." (Paul). He explains how being stigmatised in the circumstances outlined above has caused him to believe that he will always be framed negatively: "You expect them to say oh just to let you know there are no drugs kept on these premises, and you know all drugs are locked, there is no cash here or anything of value or any substance and things like that." (Paul)

In terms of stigma 'drug addict' appears to carry a master status that impacts negatively upon social interactions, particularly when interaction occurs as a 'mixed contact' between a stigmatised individual and a non-stigmatised individual (Goffman 1963). Doris recounts how she was told she was talking 'junky shit' by a health professional who she respected: "The therapist I talked to **** he was yeah he really put [me] in the picture with myself you know? Because sometimes you try and be brave you try and be strong and hey stop talking 'junky bullshit' that's all crap Doris." (Doris) 
Lenny explained he avoided contact with doctors unless absolutely necessary because of his status as a 'drug addict'. He states that as a PDU he is viewed with suspicion and is suspected of drug seeking by health professionals: "Drug seeking [trying to fake illness to obtain drugs] the State stigmatise [me]. Medical [I] won't go to doctors." (Lenny). Ben believes that he is looked down upon by the medical profession and has been framed as an untrustworthy: “Counsellors talk down to you 'junkie' they should understand. ...wanted takeaways for my band's tour I [needed] proof lying junkie" (Ben). Ben has transferred his MMT from the Methadone clinic to a local General Practitioner (GP) as he was seeking a more open and honest relationship, however, the only issue is the financial cost he faces when seeing his GP monthly for a repeat methadone script. "Private Dr much more understanding I can tell him the truth. The only issue is [the] cost to see a GP fifty dollars a month." (Ben)

When Paul was in extreme pain as a result of a broken back he would not visit the hospital for medical assistance because he was aware as soon as his PDU was disclosed he would be stigmatised and marginalised:

"I had a broken back. I wasn't eating properly. I was close to being a paraplegic and probably days away from death yet I was prepared to risk that rather than face the humiliation or stigmatization of coming to the hospital to seek help that's how real it is for me! ...I felt that the first reaction would be with painkillers they [the] hospital staff try to suppress what they think. Ok here we go he's trying it on [to] get something, trying to pull the wool over our eyes." (Paul)

Paul recalls his request for a short course of pain relief for the initial post-operative period during his stay in hospital: "I asked for an increase just until the pain - which was pretty incredible - was alleviated. ... She said no." (Paul). Being in the hospital and under-going surgery without access to adequate pain relief left Paul feeling untrustworthy and unworthy:

\footnotetext{
"It reinforced the stance I had taken about coming to hospital. I told you this would happen ...Like a second-class citizen someone they have to deal with they've got no choice. Someone they feel they can legitimately look down upon." (Paul)
}

Jasmine also reported the stigma of being framed as a drug seeker by the hospital while suffering extreme levels of pain caused by a hip problem: "They thought I was just a 
bleating junkie who was after more drugs and it was like my daily dose was covering the pain a smidge." (Jasmine). The worry of being subjected to stigma in the diagnostic setting is also voiced by Doris who was very uneasy about the prejudice and suspicion attributed to people on MMT: "Registered drug addicts under the Mental Health Act um no matter what happens they're going to know exactly where we are. Are we that bad?" (Doris). Johnny's experience of health professionals is similar and he will only seek medical help if it is absolutely necessary: "I'm not going there, especially just cause I want to get drugs. I don't go 'I want drugs so I'm going [to] make this shit up'. I never go to the doctor unless I have to" (Johnny).

When receiving MMT the consumption of methadone in the pharmacy is a requirement of the treatment, however, the number of occasions an individual is expected to consume on the premises (COP) varies significantly. The COP can range from once or twice a week for some individuals while others are forced to COP every day. Methadone consumed outside of the pharmacy is referred to as 'takeaways'.

A number of respondents mentioned consuming methadone in the pharmacy setting in the public gaze of other shoppers was a source of disdain and stigma and they generally felt unwelcome:

\footnotetext{
"Pharmacy [is] a hoop to jump through. Labelling as a PDU is [caused] through public consumption." (Lenny). "Well if people didn't know you were on the methadone the system that they use at where I go for example, that's ok because they will find out because of the way your given it right in front of everyone. ...Subtle things like going into the chemist and 'oh Mrs Jones would you like a calendar to 2014'. But you are not offered one because your different you fall under a different category." (Paul)
}

"Too many people there for the same things I think it's not looking good when other people come in and see a line of people waiting for their Methadone." (Brownie)

"You feel it yeah they look at you as if that they're trying to work out what you're doing they wonder if your schizophrenic or something like that because you have to you know consume in front. The whole thing of being eyeballed by the pharmacist. ...You know, thinking that you're going to divert or something like that." (Jasmine) 
Goffman (1963) interestingly refers to the "public gaze" and as part of MMT it is a requirement to consume methadone in front of the pharmacist. The interviewees discussed having to consume methadone in front of the pharmacist, as well as in front of other customers, and explained how they are subjected to the curious gaze of onlookers. The interviewees were asked by shoppers what they taking and why are they taking these drugs here? The central issue relating to COP was "now people in my community know I am on the MMT now they'll see me as a drug addict." (Alan) The stigma associated with this knowledge impacts upon relationships, employment and life opportunities.

The phenomenon of stigma occurring in the workplace during mixed contacts is apparent when Brownie explains how this process plays out when he is treated differently from the rest of the firm's employees. He explains his PDU has been used to frame him as 'other': "Cause he's a user or whatever, he's wasted ...not from all the workers, only some of the workers [and] one of the bosses. I wasn't aware before that cos I was young but [I am] now." (Brownie). Paul argued as soon as employers hear about MMT his prospects of employment are terminated: "Realistically speaking I believe it's unattainable, especially locally speaking. As soon as they find out what you're on 'bang' -it's the kiss of death, it's just the way it is." (Paul)

Work and Income New Zealand (WINZ), where most of the respondents receive state benefits, was a key source of humiliation and stigma. When Lenny approached Work and Income New Zealand he was informed that he was not entitled to other benefit because his difficulties with addiction were self-inflicted: "Benefit is unemployed as [I] choose my illness. Addiction so [I'm] not eligible for sickness benefit." (Lenny). Further, now in receipt of an unemployment benefit, he must fulfil strict obligations; non-compliance could result in a deduction or suspension of his benefit entitlement. "WINZ [obligations] - ten job interviews a month or benefit cut for noncompliance." (Lenny). The restricted benefit entitlement has affected his lifestyle: "I don't eat every day I just had to get used to it! No social life" (Lenny)

Ben explains his experience at WINZ community hub, where he was informed that he has 'issues' that stop him from getting work. This resulted in Ben's entitlement to the sickness benefit being withdrawn and his placement on 'unemployment with issues' benefit. "Unemployment with issues -you have issues. I thought I was on Sickness; no you have issues that stop you getting work" (Ben)

Jasmine explained that even though she has seen the same individual at WINZ for a long period she repeatedly has to prove her eligibility for entitlement and is made to feel inferior: "It's like going to the social welfare (WINZ). All the years dealing with them one 
person. I'm on [the] Invalids' Benefit. Once again they stigmatise you I feel like rubbish. I have to produce receipts' etc. etc. etc. to get what I'm entitled too." (Jasmine). When Johnny discusses WINZ his anger is palpable he explains how the relationship he has with WINZ is framed into a confrontation. "The welfare man talk about cunts [I] get out of hospital put my prescription in. ... I'm going well I've just got out of hospital for a fucking heart attack I don't need this shit eh I just want to go home." (Johnny). Future employment prospects are difficult economically but exacerbated by stigma of incarceration and widespread employer drug testing: "Opportunities sealed off my jail networks [only] make things worse. Town now [has] less opportunity [plus] drug testing for employment." (Lenny)

Pete thoughts reflect the work of Goffman (1963) when he mentions his intentions to live a quiet life and discusses his attempts to 'pass' as a normal non-stigmatised individual. However, he explains that if his spoilt identity of drug addict is discovered then he expects the stigma process will occur. "I try and keep it as low key as possible I've seen people looking at my old track [injecting] marks. Yeah there is a stigma about it you get treated as a second class citizen" (Pete).

Alan expects he will continue to be stigmatised as a 'drug addict' and explains this is due to his appearance:

\footnotetext{
"Look at me I've got the classic junkie face thin gaunt cheeks no teeth you know um. I find that... I don't know if they know I'm a drug user or is it the clothing I wear or whatever. [I] walk into a shop and you get followed around you know." (Alan)
}

\section{Summary}

Self-stigma, social-stigma and structural stigma occurred prior to and post development of problematic drug use by all of the people interviewed. Self-stigma was reported by Lenny when discussing his family. Brownie discussed the phenomenon of social stigma through his experience of being stigmatised in the work place. Structural stigma was reported by Jasmine, Lenny, Ben and Johnny when they discussed their interactions with WINZ.

Being stigmatised as a child was reported by Paul. He explained his experiences of racism and how he became aware that people are treated differently based on their backgrounds or their nationalities. Paul discussed being called a 'nigger' and how he was excluded from socialising with other children who also lived in the area. He explained that this was because of his dark colouring and how this exclusion made him want to show his mother 
off as she was white. Paul felt that this discrimination isolated him. Lenny also recalled the stigma he experienced as a child. He explained his family had a 'black mark' against them as they were poor and his brothers were known for their offending and had all been incarcerated. His experiences of poverty and feelings of deprivation propelled him into criminal offending.

Stigma in the work place was highlighted by Brownie. He explained he feels that he is always treated differently by one of his bosses. He revealed that he experienced discrimination on a daily basis at his place of employment. Brownie is drug tested as part of his employment contract which has resulted in the disclosure of his being in MMT. He explains that since his employers and co-workers have known about his drug dependence, his 'master status' (Goffman 1963), he has constantly experienced discrimination in the work place.

Doris recalled how she was told that she was talking 'junky shit' by a health professional that she respected. The phenomenon of stigmatisation in a health setting was a frequently reported experience in particular assuming any legitimate request for medical help was really a fraudulent attempt to obtain drugs (drug seeking). Being suspected of drug seeking behaviour was for a number of respondents a key reason for avoiding contact with health professionals, even when in serious medical need. All interviewees receiving MMT reported being stigmatised in a health setting.

The phenomenon of structural-stigma was reported by Lenny when he discussed experiencing stigma during a mixed contact encounter at the WINZ offices. He explained during a mixed contact interview he was informed that he was only entitled to the unemployment benefit because as a drug addict he had 'chosen' his illness. Ben also discussed experiencing stigma during a mixed contact at the WINZ community hub. $\mathrm{He}$ was informed that he had 'issues' that stop him from getting work. This resulted in Ben's entitlement to the sickness benefit being withdrawn and his placement onto the unemployment 'with issues' benefit which resulted in his entitlements being reduced.

The stigma associated with prison discussed at length hardly surprising given that eight of the ten respondents had been incarcerated. The findings from experiences of prison have been included in the exclusion findings section and for that reason will not be discussed in detail here.

Interviewees all reported experiences of stigma that have been categorised as self-stigma, social stigma and structural-stigma. The impacts and consequences of these types of stigma included the internalisation of negative perceptions about themselves; the experience of 
stigma imposed on them from social groups and having their rights and opportunities obstructed by political and institutional policies and procedures.

\section{Drug Use}

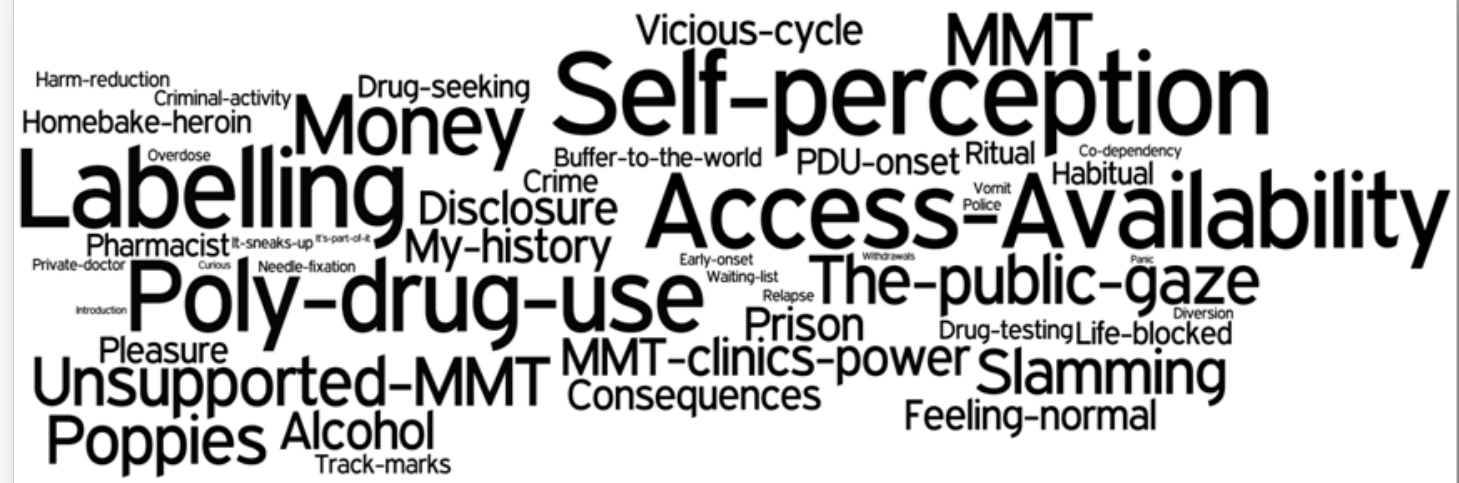

Drug Use appeared in 636 data extracts from the interviews. Drug use impacted upon a wide variety of life situations and these experiences are discussed in the chronological order of the interviewees' life course. The first introduction to illicit drug use and the recreational use of drugs for all respondents was cannabis. The main drug of choice was opiates $(n=9)$ with one respondent preferring methamphetamine. Of the ten people interviewed eight disclosed that they were currently receiving methadone maintenance treatment (MMT).

Stigmatisation, marginalisation and exclusion in connection with drug use were central to many of the life situations reported. These extracts will be included in the sections most appropriate to those findings. For this reason this section will focus on specific drug experiences including: exposure to drugs, first use (onset) of an illicit substance, the development of drug dependence, methadone maintenance treatment and future use.

\section{Introduction to drugs and the onset of drug use}

For all the respondents the first illicit drug used was cannabis. Jasmine explains how as a child she was aware that her father used drugs: "My dad used to grow a bit so I was always aware. It wasn't totally obvious but it was there you know what I mean, I knew it was there and that it was sort of an adult thing." (Jasmine). Similarly, Lenny became aware of drugs at a very early age as they were part of family life: "I was first exposed to drugs at the age of six drugs were normal in our family" (Lenny).

The onset of drug use was reported as occurring with peers by Jasmine who explained how her first use of cannabis (substance) was while she (set) was with her friends at a rock 
concert (setting): “The first time I got stoned I was ten years old at the Kiss concert. It just happened you know everybody around me was smoking pot and so I had a go you know what I mean." (Jasmine). The introduction to drugs and onset of use also occurred at a very young age for Brownie: "I tried cannabis when I was eight then I tried Ritalin and went on to P after that or speed I think you call it back then the P." (Brownie).

Paul discloses that his introduction to drugs occurred with his peers and during the school holidays. However, he states this initial use may not have affected him. "The first time I had any experience with drugs I was 16yrs it was during the 6week holiday from school. I had a few puffs and I don't know to this day if I was stoned or not." (Paul) However, Paul reports that his next experimentation with cannabis left a marked positive impression on him, giving him a confidence he'd lacked:

\begin{abstract}
"I was able to smoke some good stuff of head and it was just a real release ...It was like something money can't buy. If you struggle with confidence all your life and then all of a sudden someone gives you something and you feel like that it's an experience you'll never forget."(Paul)
\end{abstract}

The age of being exposed to illicit drugs ranged between six and seventeen years of age. The reported onset for the first time use ranged between eight and seventeen years of age and all began with cannabis. Two interviewees also reported being introduced to and using LSD at a young age. Johnny and James both recall being relatively young when onset occurred. "The first drug I ever had was pot. ...First pot ah um 13-12yrs old or something like that." (Johnny). "I would have been about 13-14 when I tried smoking some pot when I was young yeah."(James). The onset of drug use occurred at a slightly older age for Pete. "I suppose started smoking pot um the Buddha days was still around um early 80's um 15$1615 y$ rs yeah smoking pot." (Pete). Alan remembers his age of onset "[I was] about 17 for hard, pot first time I smoked about... 15." (Alan).

\title{
The development of drug dependence
}

Interviewees discussed their individual experiences and perceptions of using Class A drugs both recreationally and in a problematic manner. They shared their stories about using drugs and how they managed to navigate their way through daily life. Paul discloses his progression from using cannabis to his use of opiates.

"I got introduced to hard drugs (heroin) in the 1980s I was 21yrs. I met up with some of my old friends and they had been into it for a few years 
stealing doctors' bags this and that doing what they had to do. I'd seen them shooting up I just wanted to be a part of it."(Paul)

For James, the only respondent to predominantly use methamphetamine, problematic use of drugs began at a relatively later age he explains the consequences it had over his life:

"Yeah I had a habit for years yeah and I'd spent, lost everything I had on it. Um phew yeah that yeah probably [began] when I was like um in my 30 's probably middle 30's." Oh I just it was controlling my life I wasn't controlling it. It was like an everyday had to have it to feel happy, had to have it to feel energetic, had to have it to feel I could live to get through the day yeah. A crutch, an expensive crutch, felt I needed it to survive like I say I'd wake up in the morning and ya tired and you need some more to kick your energy going and to get motivated and that cause you're so tired and drained." (James)

The development of a problematic dependence on opiates is reported to have occurred in a very short period of time for Paul, Ben and Lenny

"With the harder drugs I would say definitely by the time I was $22-$ $23 y r s$ I was a regular user. Before I knew it I needed it every day. I got a physical habit."(Paul)

"The use of opiates became problematic after about 6 months of using I have to have it. It's a vicious cycle food goes out the window, drugs come first over everything." (Ben)

"First used hard when I was 18yrs. I experienced a lost weekend between the ages of 18-21yrs." (Lenny)

Discussing her introduction to hard drugs Doris reports how her initial use occurred in an overseas country and discloses that this initial introduction was associated with an infamous international drug syndicate: "I was 21yrs [and] I got introduced to ....Heroin yeah. About a year before I'd been travelling in the east around Asia and I had a few smokes of heroin and that it just made me sick right. ...I got questioned with the Mr Asia thing. I was a drug runner Ok yeah."(Doris). She recalls that on returning to New Zealand her use of hard drugs increased. "I came back to NZ and a friend of mine had some and you know I started smoking it so yeah I was sort of 20 going on 21 yrs and on my $21^{\text {st }}$ [birthday] a friend gave a gram of really good heroin for my 21st I always look at that as being poignant. (Doris)

Brownie explains his introduction to harder drugs happened at a comparatively older age, considering that he had been introduced to cannabis at the age of eight. He reflects on the 
influence of older people during the development of his drug dependence and recalls the methods used by him and his associates for meeting their drug related obligations:

\begin{abstract}
"We had people guinea pigging us and that is how I think now I look at it now. Ticking us up to our eyeballs you know what I mean to get them ahead and saying you owe us, so we'd go and do a crime to pay for it. Yeah this is over here. ...Crime, burgs anything to make [money] to square up, scrap. It took off yeah it used to pay for our habits." (Brownie)
\end{abstract}

Johnny described how his problematic drug use controlled his daily life: "You know I was doing it daily by then aye but then again. Seven days a week 365 days a year. If we weren't scoring morphine we were growing poppies it was always something. (Johnny). Alan describes how his initial introduction to hard drugs was totally unplanned. However, the high degree of pleasure he experienced the first time he used allowed him to gain a sense of release which helped him deal with the emotional turmoil that dominated his life.

Alan explains his introduction to locally grown opium poppies and had been shown the process to refine raw opium into a powder that is ready for use. "So about 17 I have my first taste I really like it I think where can I get more. You know so I start buying misty's [MST's] like most people then poppy season hits. ...I meet this guy who takes me out on poppy raids and shows me how to cook up nicely." (Alan)

Due to the geographically isolated nature of New Zealand and the relatively small population [market] drugs are less frequently imported compared to other countries and therefore harder to find in New Zealand. This has resulted in kiwi innovation, as reported by four of the ten people interviewed, that used locally grown opium poppies to produce opium. They explained the process: bleeding of opium poppies is achieved by making an incision in the pod to release the opium sap to extract raw opium. This is then processed into a form of black tar opium before applying acetic anhydride to produce an opium powder that can then be mixed with water, heated, filtered then cooled and injected. Other opiates that respondents mentioned processing included morphine sulphate tablets (MST) referred to as misty's and codeine tablets to produce home bake heroin.

Pete reports the pleasure and achievement associated with this ritual and discusses learning methods for manufacturing and the preparation of opiates.

“Well I soon learnt, it just follows. So we were getting home bake as well ... and that was probably the closest to heroin you know. It's amazing when it 
disappears in the spoon you know when you bring it back aye brown powder." (Pete)

The process of turning MST into diamorphine and the ritual associated with this procedure was discussed by Pete. Here he explains the satisfaction gained from completing this exercise on his own.

"I used to like, like coming home on Saturdays after work and scoring a grey I had a little pop up gas thing coz my flatmate the house was straight [I'd] open the French doors no smell of double. The greys I could get them like champagne pink I'd start them on the element and finish them in the oven like I had no one crowding around me like hurry up hurry up."(Pete)

The motivation behind locating and obtaining local poppies for manufacturing opium is summed up by Alan, who explains how he first begun to stockpile opium unconsciously. However, this soon developed into a fulltime project during the spring and summer months. The collection of opium poppies required vast amounts of travel around New Zealand.

"The following poppy season I'm going out every day and finding shit loads. More than I can use so I start putting it aside not really knowing. Gradually I started filling up film canisters. By the end of that poppy season I had about 10 canisters filled up with dry opium. I carried on like this for a few years. Hitch hiking around New Zealand on the poppy hunt. All good and then I kind of realised that I could not stop. ... I would have been 21-22 that's when I would have realised that I had a drug habit. ...It came down to bleeding poppies at the right time of the year and putting them away and then I didn't have to go out and fund a drug habit."(Alan)

\section{Methadone Maintenance Treatment}

Attempting to overcome problematic drug use was discussed by all of the people interviewed and nine of the respondent had received methadone maintenance treatment (MMT). Situations relating to MMT disclosed by the interviewees included difficulties approaching the methadone clinic when seeking support and help with their problematic drug use. The waiting list to receive methadone maintenance treatment was a frequent issue:

"After about three years I went on the MMT I had to wait about one year before I got on the programme. I had appointments all the time and I rang up first to get on 
the waiting list and then waited and ringing them up and hounding them. Finally eight months to a year later I got on it yeah." (Brownie).

Lenny discloses how he was trapped in a twenty-four hour cycle of hard drug use and committing crimes to finance his drug use. "[My] lifestyle [was] Crime - daily round score - hoist" He reports that even though he disclosed the amount and type of drugs he was using and the fact that he was committing a vast amount of crime to obtain revenue for the drugs, the methadone clinic informed him that he would be placed onto a lengthy waiting list: "no examination for two years" (Lenny). Being made to wait for treatment from the methadone clinic after disclosing repeated criminal offending and problematic drug use was also reported by Brownie. Johnny clarifies that when the resources to get drugs are depleted there will be consequences:

Although Johnny was prescribed methadone it was only available in oral form and he explained that he had a dependence upon drug injecting (banging it) drugs, so ending up injecting the oral methadone. Johnny underscores how issue of intravenous dependencies has not being addressed and the policy of MMT as an oral treatment may increase the health risks associated with PDU:

"If I got put on the done and they gave it to me um I would bang it, eh if I had the choice eh even having the choice you had a 1/2 dose that you could bang it or a double dose but you had to drink it I would probably take the 1/2 dose and bang it...When the money runs out you start doing things you shouldn't like thieving, wheeling and dealing, you know selling off your shit. I think it's not the drugs that do you the harm it's the hanging out you know that what's doing the harm." (Johnny)

Using intravenously while on MMT is prohibited and could result in the termination of treatment. Realising this Paul explains the importance of passing as compliant to the methadone clinic and the practice of this deception. Here Paul highlights the complexities that arise during 'mixed contacts' Goffman (1963) and the stress caused by 'passing':

"Sometimes with [injecting in] the arms it's been brought up with the things like the neck it's easier to hide with collars you know well in advance that you have an appointment at the MMT so you would dress and behave accordingly. You do not want to come across as problematic, moody or anything like that." (Paul)

A finding of significance reported by interviewees is the interactions between themselves and the counsellors they see as part of their MMT and how these 
interactions are perceived in a mostly negative manner. Feelings of being stigmatised and not heard are reported by Jasmine when she discusses a recent appointment at the methadone clinic:

"I felt as if I was being interrogated by the Gestapo. It was nothing to do with how I was doing. I mentioned an increase that was dismissed I wanted to um discuss that fact of maybe split dosing that was dismissed um I felt as though the guy was just trying to get into my head. I'm on anxiety pills and thank god I took some before I went because I was a basket case after I left." (Jasmine)

Pete discloses that he would keep things from his MMT counsellor. This was due to his belief that honesty would only result in some form of methadone related punishment. He spoke of the fear of returning a 'dirty' drug screening and the expected punitive treatment:

"No way, I wasn't going to tell them I'd been using my methadone intravenously no way that would be the end of it. I had to be creative and say I'd been using misty's again or speed. ... They penalise you with the urine analysis for taking some V's like a month earlier and there's a trace in your system to them that's like you used them yesterday. They'll just say liar you're a compulsive liar how can we believe [in] you." (Pete)

Doris recalls her early perception of MMT and how she now feels trapped on methadone maintenance. She feels her life has passed her by while she has remained stuck in the sticky web of MMT secured to the 'bullshit' by the 'liquid handcuffs' of her daily $120 \mathrm{mls}$ :

"For years I always said I'll never go on because I'd heard so much [negativity] about it. What possessed me to go on it I don't know but to me that was the turning point in my life. ...I need to get off methadone I'm on $120 \mathrm{mls}$ it's horrible it's like a sticky web. Mainly for me I don't want to see myself, time flies because I can't believe I'm heading for sixty but yeah I'm over this methadone it's the whole bullshit about it. (Doris)

When discussing their experiences of MMT the interviewees voiced concerns relating to their recovery. They felt they had little input to the process they were undertaking and felt excluded from their recovery plan discussions. The problem of feeling excluded from the processes of recovery and the need for client participation was summarised by Lenny: "MMT clients need power over their recovery processes versus state control." (Lenny). Ben identifies the high turnover of clinical staff as an issue. "Staff stepping stone to something else three months later a new person - should write my history down so here you 
go here is my history, I can just give it to them, feel like waste of time and effort." (Ben). Paul discusses his experience of being on MMT for two decades:

"It's supposed to be a maintenance programme, but you're treated as worst case scenario. We've had problems with people in the past so you mind if we treat you like absolute shit then?" (Paul)

Alan reports that MMT was not really about his overcoming PDU. Instead he states a belief that MMT is used as a method of social control.

"The way I look at it is they were happy for me to be on a truck load to keep me zombified. I wasn't out there in the community ripping people off or doing anything and that was the problem I was doing nothing; nothing to help myself nothing to better myself in life. ...Even today I find my emotions quite flat. Even with the lower doses that I'm on I still feel quite flat I don't very often feel very happy with life." (Alan)

\section{Summary}

All respondents reported their first exposure to drugs as occurring before the age of eighteen although the settings varied including family home, older adults and their peer group. The onset of using drugs occurred between the ages of eight and seventeen. All interviewees disclosed cannabis as being the first illicit substance they had used.

The onset of Class A drugs (opiates, heroin, cocaine and methamphetamine) ranged between fifteen and thirty five years of age. In all situations the first use occurred with their peer groups. The drift into problematic drug use progressed without realisation, Ben explained that it took about six months for him to become an IPDU and he realised: "a vicious circle, food goes out the window, drugs become before everything". Paul reflects on the advance of his PDU when he recalls that "before I knew it, I needed it every day".

The geographical isolation of NZ, small population and effective border controls has caused the supply of heroin to NZ to be erratic (Wilkins, Sweetsur and Griffiths, 2011). This has resulted in the use of other opiates and opioids by IPDUs. The types of drugs most used were reported to include pharmaceutical morphine, MST, homebake heroin that is manufactured in clandestine laboratories from codeine precursors, opium extracted from locally grown opium poppies and methadone that has been diverted from the medical system. The cost of supporting PDU was mentioned by respondents. The prices for morphine sulphate tablets (MST) was claimed to be around two dollars per milligram thus a 100 milligram misty would cost $\$ 200$. As a consequence, Alan explained how he realised it 
was more financially prudent to go on what he referred to as poppy hunts. Alan explained how during the spring and summer months he would traverse NZ searching for locally grown opium poppies. Once he had located the poppies he would return later and bleed the raw opium from the seedpods. Over the season he would obtain enough raw opium to last him until the next poppy season. Having some left over to sell also subsidised his living costs throughout the year. Additionally Alan stated that doing the poppy hunts allowed him to keep to himself and avoid interactions with other IPDUs or with drug dealers. Furthermore, the industry, purpose and focus of Allan's venture gave him a sense of achievement.

Of the people interviewed nearly all had reported contact with the methadone clinic. The eight interviewees currently receiving MMT discussed the reality of being in MMT and how this has negatively impacted on their lives. The phenomenon of stigma was reported as occurring in both the community and diagnostic settings. The experience of the public gaze when consuming methadone publicly in the pharmacy setting was discussed. The drug and health related experiences are summarised in the findings of the stigma and health sections. 


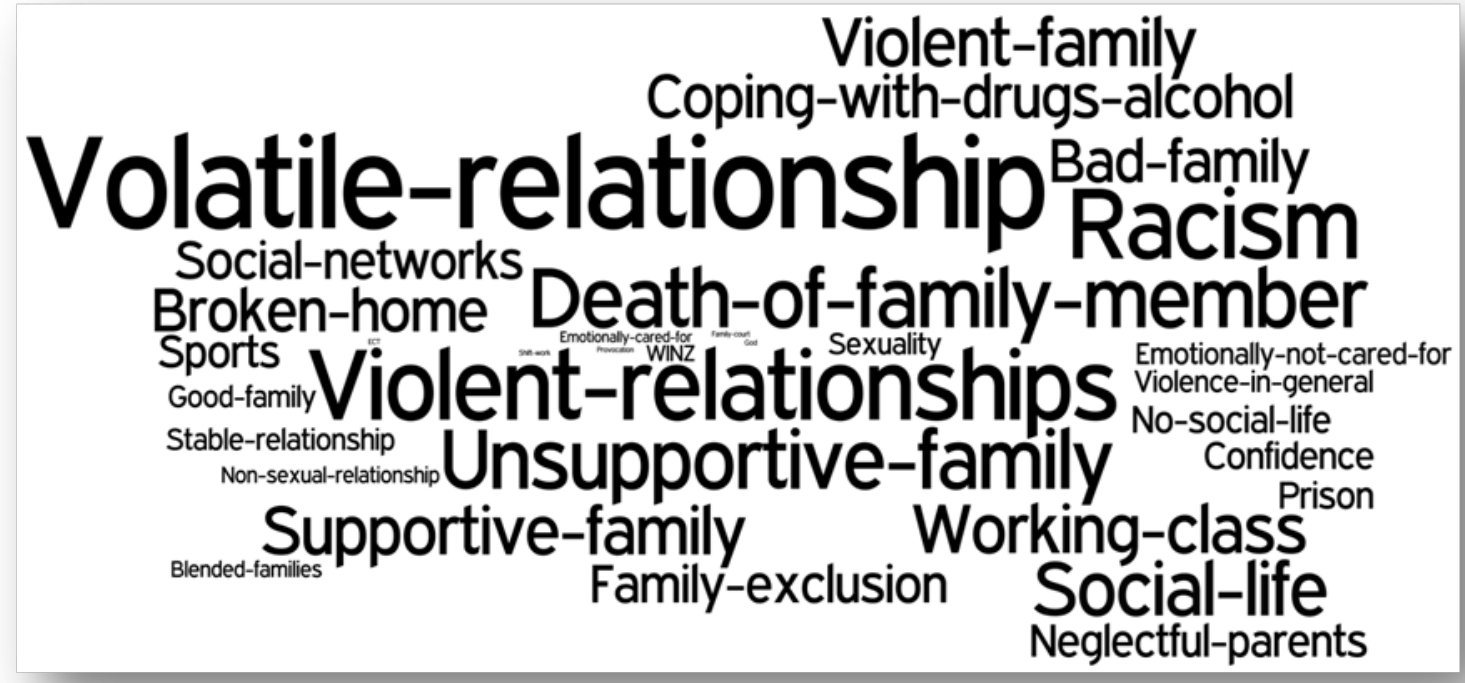

Relationships was a dominant theme in 518 data extracts from the interviews, covering intimate relationships of marriage/partners, familial relationships with children, siblings and extended family. The lives of the interviewees as children are considered here first as seven of the ten respondents highlight growing up in fractured family environments caused through volatile relationships, conflict and the ultimate separation of parents. Eight respondents spoke about the nature of their own long-term relationship with a partner. Growing up in fractured family environments was recalled with considerable pain and unhappiness by most respondents:

"I was very aware of it all. I felt it coming, the shift of patterns at home. I never thought it was anything to do with us kids or anything. Mum and dad weren't getting on that's what I put it down to. There was a bit of shit I remember when I was about five the police coming because of fisticuffs and that. That scared me I can still actually visualise it this policewoman coming in and taking me out and taking me away you know to my Nanas.

...It was a bummer that my parents split up I spent half my time with dad and half my time with mum. The thing that pissed me off the most about growing up was step-fathers and step-mothers and shit like that." (Jasmine) 
Like Jasmine here James recalls the tension, conflict and violence along with excessive use of alcohol:

"Mum and dad ... used to fight and argue a lot, there was a lot of aggro there. Drinking yeah dad used to drink and stuff and there was a lot of fighting through all through the relationship when we were kids really. ... Yeah there was always aggro and violence in the place yeah." (James)

Alan recalls his father's violence toward him and the fear he had as a child. That painful experience appears to have scarred his memories and damaged his relationship with his father:

"I was I, I, I, was very fearful of my father. I was extremely fearful of him ah ... I never remember a time when he wasn't beating me you know and um I don't have a childhood memory of him that's good, let's put it that way. I just don't and yeah I haven't spoken to my father in about 8 years now at all." (Alan)

Alan stated that as a child he wished that the Social Services would get involved and remove him from his family: "As a kid I wanted to be uplifted and taken out of the situation I was in." The experience of living in fear as a child was also reported by Johnny who felt violence and intimidation was used by his father to control their family:

"He was quite violent like he would punch her and break things he never hurt us really except when we were naughty kids. There was not undue violence towards us but it was always there. ...You know when you're a little kid you're just scared all the time. ... it was more like the olden days ... you know don't you fucking dare say anything or look at me sideways I will knock you, you know that kind of bully."(Johnny) 
Pete discloses that his mother was diagnosed with mental health problems during his childhood and recalls how the deterioration of his mother's mental health and violence impacted on their family:

\begin{abstract}
"Growing up I saw because of my mothers' illness I saw like you know um and because of the medication um she'd sleep all day because of the medication you know and like that was part of the reason my old man you know just couldn't cop it. Um they'd have the odd fight but remembering that my mother would pick up a knife you know and but my old man would just disarm her you know he would never like tonk her you know so...mmm (Pete).
\end{abstract}

Doris recalled her mother's struggle to cope with the demands of raising the family: "Just mum was at home and she'd lost control of us, I guess we could do what we wanted which I find really sad now. ... I knew I could get away with a lot." She recalls how as a teenager the lack of parental control at home was in part to blame for her becoming pregnant as a young woman:

\footnotetext{
"Dress up, make up and I met this guy ...I was like 13yrs old [he] was llyrs older than me. I was sexually active with him. ... Both my parents are dead now but looking back I couldn't ask for help. I knew my dad just didn't want to know and mum was sort of fragile in a way. ... So yeah, all on my own, I dropped that child out and it was pretty hard right." (Doris)
}

For Johnny the divorce of his parents and the violence that surrounded his early life influenced his ability to manage and maintain future interpersonal relationships. This was similar to childhood experiences reported on by a number of interviewees including Paul and James. However James blames his problematic use of drugs for the collapse of his relationship, although he and his partner colluded in taking drugs: 


\begin{abstract}
"The second week living in [DNZT] we go to this party. ... My partner says such and such has got some morphine do you want to go halves? And I'm going, I've given up my job, fucking house, my fucking friends and give up all the drugs, and I fucking get up here in two weeks and now you're offering, you're asking me if I want to have fucking drugs. ... I just went ballistic I remember going ballistic, but going by the way, 'yes I fucking do' [laughs] 'give it to me'." (Johnny)
\end{abstract}

When struggling with the conflict of trying to make relationships work alcohol and other

"We'd be going out on different nights - growing apart. ... I was dabbling more after the marriage broke up using drugs and alcohol to 'cloak it'." (Ben)

"Yeah things do come to a head... it is really hurtful ...I choose for whatever reason to block it out with drugs or not to face up to it." (Paul)

drug use featured as a form of escape or relief:

While many witnessed violence and abuse as children some continued to encounter it in adulthood: "I've had good relationships I think but, but, also um.... Especially son's dad was very abusive which was really sad. He beat the shit out of me mate, nearly killed me." (Doris) Furthermore, Doris believes her own problematic drug use has negatively impacted on the lives of her children.

\title{
Summary
}

This section highlighted the important influences of family life. Numerous family conflicts and incidents occurred during childhood that had a significant influence over the participants' own future relationships. The phenomenon of family violence was frequently reported. This included: shouting at and threating family members; hitting and punching; fighting with family members; sexual abuse and a serious assault of family members that resulted in incarceration. The experience of living in fear as a child was inevitably a feature of their early lives for these respondents and the experience was explicitly discussed by Alan and Johnny. 
The disruption and upheaval from family breakup was a common problem faced by the respondents. The build-up of tension and conflict prior to parental separation was something a number of the interviewees had painful memories of. The subsequent struggles of adjusting to step-parents and blended families proved difficult for some of the respondents.

Growing up in a family where there was financial hardship was commonly reported, although one of the respondents recalled a good childhood with loving, successful and supportive parents. This isolated experience contrasted Lenny's where going to prison was considered normal. He described experiencing social exclusion and the sealing off of opportunities because his family had a bad name in the community.

The two female respondents both reported becoming sexually active at a young age and one mentioned that she becoming pregnant under age. Eight of the respondents reported being married or in a long-term relationship with a partner at some point in their life. Perhaps not surprisingly most of these relationships have been volatile and placed under further pressure by drug dependency. The difficulty of being able to be honest with one's partner about PDU was an issue, as was concern about the impact it had upon the wider family. Two of the respondents (Paul and Doris) were particularly stigmatised and blamed their drug use for having a detrimental impact on their family.

A number of respondents confined or declined relationships believing that a drug centred lifestyle was incompatible with a good relationship. Lenny reported being so heavily into drugs he did not want to entertain a relationship, as he believed a drug using woman partner would inevitably become involved in prostitution. Ben explained how drugs come before everything. Others spoke about platonic long-term relationships based on friendship and support. Alan discussed how sexual abuse as a child has affected his intimate adult relationships and led to a decision to abstain from sexual relationships because they did not work.

The 'covering' and 'passing' (Goffman, 1963) of his PDU in mixed contacts and interpersonal relationships were reflected on by Brownie, who spoke of how he would try to cover his drug use and how he would shut down when confronted by his father and block things out, further isolating himself from his family. The alienation experienced by Brownie is argued by Ahern, et al (2007) to be associated with poorer mental health. Ben discussed being excluded from his family after his drug dependency became known. Ben saw this exclusion as being a form of parental 'tough love'. The stigma experienced and internalised by Ben, that was produced by his family is reflective of research conducted by 
Ahern, et al (2007:191) which found "the most common type of discrimination experienced by drug users is attributed to family ( $72 \%)$ ". 


\section{Opportunities-sealed-off No-uualications $_{\text {- }}$ Discrimination Trouble-ate-at-school Heavy-industry Exclusion Squess Squeezed-out-of-school Job-satisfaction Employment-networks Drug-use-at-work}

Education and employment was the dominant theme in 313 data extracts from the interviews. These extracts articulate the experiences and perceptions reported by the respondents when discussing their schooling and work histories. The most frequently reported experiences include blocked opportunities to employment. For most of the respondents, any initial enjoyment and participation in early education was replaced over time by isolation and ultimately exclusion. The impact of unhappiness and dislocation within the schooling system is reflected by the many incidences of misbehaviour and ultimately most respondents found themselves excluded or 'squeezed out' of school altogether. Respondents coped and reacted differently with some withdrawing from active participation:

"If a teacher sort of picked me out for any sort of um you know put me in the spotlight for any sort of reason I would rebel against it. It didn't matter if it was a good reason or a bad reason I just didn't want to be noticed anymore I just wanted to be the kid in the back of the class who doesn't get noticed I just wanted to be left alone." (Alan)

Bullying featured strongly at school. As James says, there were "a lot of guys who were trying to bully you' and this process continued into his next school: 'but you still had your bullies and scumbags trying to you know'. James also recalls racism: 'between people that had grown up together. A lot of whites against a lot of racial stuff yah the Mãori against the whites back in the days." 
Two respondents thought their progress and experience in education had been adversely impacted by dyslexia: "if I'd had a good education things could've been a lot different for me. ... I don't know how to spell, don't know how to read and write as such, I'm dyslexic or something like that." (Brownie). Jasmine benefitted from additional support but this didn't continue throughout her schooling. "Been a dyslexic and shit, but luckily I had a really good teacher at primary school. They picked up on it and I did remedial reading and sort of guided me to help, but it was great until I got to college." When support at school was withdrawn for Jasmine she disengaged from the learning process and began truanting (wagging). Truancy was an issue for three of the respondents; Brownie spent most of his schooldays "wagging and stealing". Johnny who was the third respondent who mentioned truancy explained: "I got expelled from that college and went to another city college. We wagged school one of the guys with us got alcohol poisoning, we got told 'you've got a week off for fucks sake go get a job'."

The use of exclusion and expulsion to 'squeeze out' the respondents from the education system occurred in nine of the ten accounts. They described unofficial agreement where the individual was placed on long-term study leave, where if successful in their undirected and unsupported study they may be included back into the education system. However, none of the respondents squeezed out returned to complete their education. As Pete explained: "they gave me extended study leave meaning I wasn't expelled or suspended but yeah if you pass well, we'll talk to you at the start of next year you know but um but I mean half way through my 5th form year when I was 15yrs 3/4 the way through they had an agreement with my old man like well just tell him to piss off and go and tell him to work you know which you could in those days". Others described a similar process:

"Na they just let me go to work experience every day for the rest of my time I was there so I just didn't go there anymore." (Brownie)

"I was strongly encouraged to not to come back. ... Teacher would say if you're offered an apprenticeship take it - don't bother with school." (Paul)

"Leave on your accord or we will expel you." (Ben)

None of the respondents managed to gain qualifications at school but one subsequently reported gaining qualifications by attending night school. Respondents felt the limitations of formal education negatively impacted on their life journey particularly in seeking employment, with opportunities blocked due to a lack of formal qualifications. For some respondents the lack of qualifications and employments placed them in an awkward position at home as Brownie explains: "My old man yeah kicked me out of home coz I wasn't going to school so yeah. ... Coz I got kicked out of home as well it didn't help coz I 
got kicked out of school. ... My dad gave me a week to find a job or get out... you're not living here when you can't pay your own way that's it."

The squeezing out process from education and employment appears to have had a long lasting consequence occurring at a time when deindustrialisation was just beginning to have an impact on DNZT diminishing opportunities and increasing competition for the few jobs that remained. In this changing environment the possibility of finding employment for those without formal qualifications were now rapidly reducing in the wider industrial area. Most of the jobs obtained by the respondents appeared to be achieved via contact through family and friends:

"My cousin hooked me up to do you know the floristry and stuff." (Jasmine)

"Dad goes in has a chat with him and I go in and he gives me a job". (Al)

"First job... my Uncle's factory manufacturing paper." (Paul)

"Dad's networks got me into NZ Railways as Porter/Store man" (Ben)

"No pretty much straight away I got a job at the hospital through the old man yeah." (Pete)

James recalls how he got the opportunity to secure employment through his social networks and remembers how things were and the advantages that were associated with having this job:

\footnotetext{
"Bob started working at Fords and they were looking for workers there and it was better money and close over in the city, I started working at Fords yeah. ... It was a good job, good money back then you got overtime yeah and you got meals, put meals on for you and everything at lunch time you'd get cheap meals you know roast dinners and whatever. They looked after ya there [they] were good. They looked after you good back then good money yeah. ... But nothing like that now the work's very far and few between, you know, and it's very competitive. I mean in those days you could go in for a job and they'd have 10 positions or 50 positions available. Now days it's 50 people for one job - it's the other way round."
}

Paul explains how scarce jobs have become "I would be lucky to have worked 18 months out of the past 20 yrs. People scrutinise a lot more ...It's been 10 years or longer since my last job." The lack of work opportunities reported by the interviewees places these individuals into vulnerable situations. Furthermore, the punitive attitude of Work and Income New Zealand (WINZ) was frequently reported as a key issue in the participants' 
management of their day-to-day lives. Lenny explained stringent conditions attached to receiving benefit: "WINZ- ten job interviews a month or my benefit is cut for noncompliance."

The introduction of drug testing in the workplace has now resulted in pre-interview drug testing of job seekers. In the case of people who inject drugs or who are IPDUs this ultimately disqualifies them from obtaining employment. As Johnny says: "What job could I get? I'm going to fail a drug test. ... No jobs here”. Paul supports this view "Realistically speaking I believe it's unattainable especially locally speaking. As soon as they find out what you're on - bang -it's the kiss of death, it's just the way it is." Alternative ways of sourcing funds are found as Alan explains: “As a pot grower I was growing about \$20,000 every eight weeks." And from this (albeit diverse) horticulture experience Alan has managed to start his own gardening and mowing business. However, being in receipt of MMT and being forced by the medical clinicians to consume on premises (COP) makes operating his business difficult:

"Chemist ....I don't like where I go now... too open and I have a problem with that because I'm trying to start a business ok and every person that's in there when I drink my Done know exactly what I'm doing. So I really don't like it. Also his constantly opening up late I'm trying to run a fucking business."

Ben, a long-term Registered Drug User who suffers from related health complaints, had been receiving the sickness benefit until new rules recently reclassified him 'unemployed with issues'. Ben explains "I have Hep C, attitude changes when I'm honest - 'You can't have a job'. ... I did not lie because of drug tests. [I've] slim chance of getting a job."

\section{Summary}

Respondents spoke unanimously about early childhood struggles with education and employment that was further hampered by limiting opportunities and increased competition as a result of deindustrialisation. The process of securing work and being dependent upon WINZ appeared marred by stigmatisation and marginalisation possibly indicative of a Moral Underclass Discourse (Levitas, 1998). Rashbrooke's (2013) notions of sealed off life opportunities, social exclusion and childhood poverty seem to be relevant to this cohort of respondents - a situation that appeared to intensify through failure to engage in the educational process and the subsequent struggle to secure on-going employment.

The negative experience of not fitting into the education system included coping with learning disabilities, truancy, bullying, violence, racism and being squeezed out of school. 
The phenomenon of being squeezed out of school was a key experience reported by nine of the ten people interviewed. The respondents commonly reported experience of truancy, which led to school exclusion for some and one person being told to leave home.

All the respondents expressed difficulties in securing employment while stigma and social exclusion appeared to regularly feature as blockages. Disclosure of being dependent on drugs was the main issue for employers and WINZ who demanded drug tests, and further health related issues such as the Hepatitis C virus (HCV) was another barrier to employment.

Finally the lack of work opportunities in DNZT and resulting problems faced when trying to secure employment was discussed by all of the people interviewed. They all talked about their need to rely on social and familial networks to initially secure employment opportunities when they left school, but once unemployment became a significant issue in the town, employment opportunities became scarce. Most respondents described their work history as sporadic at best, with only short periods of time in work and usually semi-skilled or unskilled labouring jobs. When asked about their hopes and expectations of securing work in the future the response was generally pessimistic. There was a commonly reported perception that there was virtually no chance in securing legitimate long-term employment. 


\section{Trauma}

\section{Fighting-violence}

Trauma appeared in 214 data extracts from the interviews. These instances of trauma reported by the interviewees cover a range of personal experiences including witnessing family violence as a child and experiencing extreme levels of fear, as a result of on-going family violence. The disclosure of physical and sexual abuse and the associated trauma experienced was reported. The deaths of close friends and loved ones and the resulting experiences of trauma were disclosed. Interviewees also discussed their experiences of having to re-live trauma during encounters with counsellors. This is reported as occurring during methadone maintenance therapy (MMT) when personal details from the clients' past and present were brought up in an attempt to gain insight into their problematic drug use. The experiences and perceptions of trauma reported will be presented in a chronological order.

The experience of trauma as a child was reported by Paul who discusses how as an infant he was taken into care and placed with different members of his extended family:

"I've been placed in care quite a bit right from my earliest memories ah I was looked after by an old lady in Gisborne and quite often my mum would go out and would drop me off at different peoples' places ah and then I would be dropped off with dad's family, sometimes it could [be] a day a week and sometimes it could be 8 months or a year a bit of a lucky dip." (Paul)

Paul highlights the trauma of being removed from the family unit for long periods of time when he explains how as a seven year old he found out he had two siblings that he had not been aware of: "I did not know I had a brother and sister until I was about 7yrs. I was told about them the day before we picked them up." (Paul). Living in a home where family 
violence was the norm was another traumatising experience for Paul. He explains how his stepfather's behaviour impacted on the family unit:

"Growing up with mum and Bruce the violence was really bad; my mum would come to school with black eyes. ...The police would come and Bruce would tell them to fuck off. Bruce was an intimidating man he was big and really quick to anger." (Paul)

Johnny also disclosed that his father was violent: "I grew up in a very ... violent family home I think you could say. The father was you know... wasn't as if he was a drinker he was just an angry man." (Johnny). He recalled how the violence came to a head when his father broke in to the family home and attempted to kill his mother and her new partner, this incident resulted in his father's incarceration:

"So he breaks in, she jumps out of a second story window, [he] stabs him, yeah, the [step dad], you know we come down stairs, and there's like blood everywhere, [we] look in the bedrooms everyone's gone [I] go and hide up in the attic. ... [The Cops] took us to Grandmas, you know the step-dads all stabbed up, the dad ends up in jail for 4 yrs. (Johnny)

Experiencing trauma at a young age is also reported by Pete who discusses, the memory of his mentally ill mother having to leave the family home and then the disturbing experience of going to visit her in psychiatric institutions and seeing physical damage from ECT:

"Yeah well mum had to move out. Mum was in and out of hospital when they were still together and I mean I remember in the 70's ...but I just remember ah you know like um clearly burn marks on her head on her temples from the ECT, you know and like oh you know it just it seemed like cruelty to me. (Pete)

Alan discloses that as a child he was sexually abused by a friend of his father. This trauma clearly continues to have an immense influence on his life. He reflects upon using drugs as a way of escaping painful realities:

When I was about 6yrs old um my father's best friend started to abuse me. ...I actually quite vividly remember the very first time that he raped me. I, I, I, can remember it. You know ah there's a lot of shit that I've blacked out over the years. I use drugs as a mask you know um and even now there's stuff I don't remember." (Alan) 
The trauma of being placed into boys' homes followed by incarceration into youth prison and finally sentencing to a prison term is a journey discussed by a number of respondents. Johnny explains the custodial pathway. "All my fucking youth I've been in foster homes boys homes ah youth prison um fucking aye all my youth until I turned 20yrs." (Johnny). The importance of managing one's image and ensuring physical survival, while in prison and by not becoming perceived as a victim, as this would lead to repeated victimisation was emphasised by Johnny and Alan:

"You just get sort of used to it, you know, institutionalised to it, aye hey from boys home to the foster homes, to fuck what are they gonna do, some cunt might beat me, aye you know, well go on do it, coz when you turn around I'm gonna pick up an ashtray or a chair or something, I'd just, I'd just goof off, aye just fucking and they'd go fuck this little cunt man, they'd pick on ya till Ya lose it in the boy's home, aye I'd just lose it, and attack these cunts, and they'd go 'oh that cunts a nutter just stay away from him' you know, and that was good." (Johnny).

"II had] chisels put to my throat, threats [made] to the missis and child. ...Long story short I went into seg's [segregation] not for myself, but more for them you know. So I did that, I now wish I hadn't. I wish I just turned around and stabbed him." (Alan).

\section{Bereavement and Loss}

Experiencing trauma associated with the passing of loved ones and close friends were mentioned by nine of the ten interviewees. The deaths discussed were diverse as was the amount of sadness and loss disclosed. Furthermore, the trauma associated with the loss also varied. Paul explains how he felt when his mother told him about his father's death:

\footnotetext{
"I was eleven when my father died she said your father's dead and I said which one hoping it was Bruce and she said your real one. I cried but to me I was crying just to conform it took a while to sink in and realise what I'd lost." (Paul)
}

The death of his brother was a very traumatic experience for Paul who discloses that the trauma associated with the loss of his brother caused him to suffer severe depression:

"Looking back the first sort of real trauma or upset in my life was losing my brother and the circumstances when it happened. ...Oh fuck what happened, she said he jumped off the Sydney harbour bridge, I said shit is there anything left to bury she said yeah. I just went into a pretty deep 
depression for a while two or three years I closed the curtains all the time. I wouldn't answer the door or phone. I remained pretty stationary for a while; I thought I wouldn't pull out of it." (Paul).

Doris mentioned the trauma of having a child at a young age and losing that child to adoption. Furthermore, the loss of a second child later in life and the overwhelming feelings of sadness that accompanied this tragic event are disclosed by Doris:

"We lost a child. We had him home for three weeks and um yeah then I woke up one morning and he was dead next to me... Beautiful little boy ...Nobody can know how it feels, like it sounds a bit silly but..." (Doris)

Doris's loss was amplified when after becoming aware of her problematic drug use the hospital staff tested her for drugs. Doris explains how the hospital believed that she had smothered her son; leaving her feeling guilty, confused and stigmatised: "I felt guilty, I guess they took the monster away to test, [she is talking about herself as the monster] I might have smothered him? No because I was a drug user." (Doris)

Experiencing situations that were traumatic as an adult was mentioned by nine of the ten people interviewed. The witnessing of a violent death and having to help clean up the aftermath is discussed by Jasmine

"Me and my girlfriend actually had to clean the walls so and like when you walked in like a bar we cleaning up the bar and finding bits of flesh and shit you know and there all the [holes] in the wall so you know that was a bit of a ... I can talk about it casually now but that was a bit of a mind fuck." (Jasmine)

Trauma was experienced by all interviewees and included family violence, the loss of loved ones, being attacked and beaten in prison, witnessing murder, cleaning up after a violent death and sexual abuse. These experiences above only represent some of the incidents of severe trauma reported. Due to word limit restrictions the full scope of the occurrences could not be included. However, having to disclose traumatic experiences as part of health care or therapy was reported by four of the interviewees. Discussing traumatic experiences in therapy with counsellors has opened old wounds for Jasmine:

"You become very anxious, um just having to repeat yourself and dig up old wounds that you've buried. Why should I have to dig up this crap? [it's] retraumatizing yeah." (Jasmine) 
Additionally Jasmine identifies the problem of staff retention at MMT clinic and how this is linked to the issue of privacy. She states that the disclosure of previous personal experiences to new counsellors has left her feeling re-traumatised. "He was goading me to break down and yeah once again I [have] this counsellor I had never met before listening on all this." (Jasmine).

\section{Summary}

The data extracts above show that the people interviewed have all experienced unusually high levels of trauma throughout their lives. The traumatic episodes discussed were wide ranging and included, but were not limited to, the witnessing of family violence, the breakup of parental relationships, being thrown out of home at a young age, being placed on the custodial pathway, sexual abuse and the deaths of close friends and loved ones. The traumatic experiences disclosed as occurring during early childhood included living in fear, being sexually abused, the breakdown of parental relationships and being removed from the family unit.

Pete's mother developed serious mental health problems and he explains that seeing his mother in a psychiatric institution with burn marks on her temples from under-going ECT had left a marked impression on him. Additionally Pete states that he was stigmatised by his peers at school because of his mother's illness. He explains how he reacted to the taunts and cruelty from his peers by attacking them violently.

The breakup of parental relationships was a commonly reported experience. Of the respondents only Lenny, Ben and Brownie reported that their parents had remained married or in long-term relationships. Therefore the experience of parental breakup and its associated trauma had a high incidence within the people interviewed. Paul explained how he was often left in the care of relations or friends of his mother for varying lengths of time and had no knowledge that he had siblings until aged seven.

Both Johnny and Alan discussed living in fear as a child and the trauma stemming from this situation. Johnny describes how he felt as a child when he says "You know when you're a little kid you're just scared all the time." Alan reports his father would beat him at any opportunity and he was anxious not to draw attention to himself as he was extremely fearful of his father. Alan disclosed he was traumatised at the age of six when he was sexually abused by his father's best friend, sexual abuse that occurred over a ten year period. Alan mentioned that he did not disclose the sexual abuse for a considerable time because he was scared, ashamed and confused. When Alan disclosed his abuse to his mother, she told his father who did not believe his son had been abused. Alan's father still continues to believe nothing happened, even after the perpetrator was arrested and incarcerated for sexually 
abusing other children. The impacts from these experiences are still evident in Alan's life, he explained that he has used drugs in an attempt to mask his feelings and block out the experience of being sexually abused.

James explained that his parents had a volatile relationship and that drinking alcohol was a common thing in their family. James recalled how his father repeatedly used violence on his mother and constantly criticised everyone in the family. James' resentment of his father increased until he was fifteen when he ending up having a serious fight with his father - it started in their house and ended up on their front lawn in view of the neighbours. James was told by his father that he had to leave home, an experience also shared by Brownie and Alan.

Trauma during adolescence as a result of being placed into boy's homes followed by incarceration into youth prison and finally sentencing to a prison term is a 'custodial pathway' that was experienced by a number of respondents. Johnny explained the stress of maintaining one's image inside and the importance of not being perceived as weak. Being weak was explained as inviting victimisation and the associated trauma of repeated victimisation. Alan explained that when he was in prison this perception led to threats being made against his partner and their child. Brownie discussed how not being supported while in prison was traumatic and had associated consequences, including having no money to purchase canteen and having no visitors which increased his isolation.

Interviewees reported a continuation of life situations that resulted in them experiencing trauma as they moved from adolescence into adulthood. The trauma associated with the passing of loved ones and close friends was a frequently reported experience appearing in nine of the ten interviewees.

Doris disclosed the trauma of a cot death and the experience of feeling that the health professionals were blaming her or intimating she somehow caused the death of her child. The repeated nature of traumatic events experienced by respondents is underscored when Doris later disclosed the trauma of waking up to find her partner dead in bed.

The death of his brother was reported as being an extremely traumatic experience by Paul. When his father died some years earlier Paul said he did not really know how to feel at the time and recalls crying to fit in. However, Paul disclosed when his brother committed suicide it left him deeply depressed for two years. Ben recalls being traumatised as sixteen year old when he discovered his closest friend had developed an undiagnosed schizophrenia problem and, in a psychotic state, beheaded his own father. Ben knew and was fond of, the boy's father, so the loss was upsetting, disturbing and acute. It also resulted in Ben's closest friend being compulsorily admitted to a secure psychiatric hospital for many years. 
Finally, some of the interviewees disclosed feeling re-traumatised after having discussed their life in health care or drug therapy settings that appeared to lack empathy. The discussing of traumatic experiences has opened old wounds for some of the people interviewed. Respondents disclosed experiencing trauma throughout their lives. Trauma was discussed occurring in childhood, adolescence and adulthood. The impacts of these traumatic experiences are reported to still be reverberating through the lives of the interviewees. The use of drugs was reported as being a way to block out traumatic life events and to help make their lives normal. 


\section{Exclusion}

\section{Drugs \\ courtSchool Health Self-perception Blocked-opportunities Prisuros Prison rosthoshame Boys-home

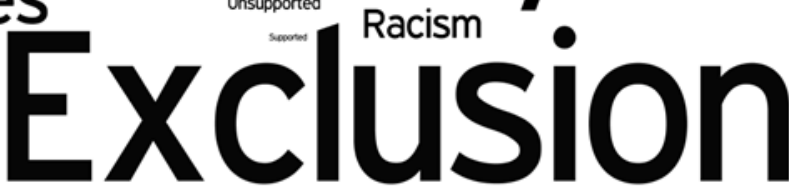

Exclusion was the dominant theme in 188 data extracts from the interviews. Experiences included exclusion from schooling and the family with respondents being sent to foster care, boy's homes, borstal and youth and adult prisons. All eight males were incarcerated and followed the 'custodial pathway'. Alternatively the two female respondents had never being incarcerated. The interviewees' experiences of exclusion from life opportunities were also a common theme.

Experiencing exclusion from within the family unit will be summarised first. Lenny recalls his childhood experience of deprivation as a significant factor during his development. “Hunger and poverty propelled [me] into crime." (Lenny). Paul recalls how as a child racism directly excluded him from spending time with his peers, whereas his younger brother who had a pale complexion and who could 'pass' as European and was allowed to play at other children's homes. He recalls a typical response to his presence from a school friend's father:

"Yes when I was younger I was excluded a lot [from] playing and going out [for] just being Māori, that's what the kids would say. My brother could go and play with them but I couldn't, that used to be annoying. [And when at a friend's house the father said:] ... 'What have I told you about bringing niggers home?' [Paul explains:] ...From about when I was 7 or 8 I noticed it; I noticed that there were differences in the way you were treated depending on [your] nationality and things like that. ...I remember thinking real feelings. I always wanted to show my mother off to say look she's white. " (Paul) 
Being excluded from school led to Brownie's father kicking him out of home and ultimately to the exclusion from his family. The process of being squeezed out (excluded) from school had an on-going impact and he feels it led to his offending: "I was like mischief you know what I mean doing burglaries and things like that at the time just to make money to survive." (Brownie). Some respondents like Johnny felt disconnected from their family and instigated their exclusion from the family home: "How can I put this I can't give a fuck to be honest I'm not very family orientated. ...I think it's because of my upbringing being shunted around boy's homes and fucking ah foster parents you know I'm a bit like that anyway." (Johnny)

Alan who was a victim of sexual abuse between the ages of six to sixteen years of age believed this caused him to withdraw from social interaction with his peers and from school. "When I was 8 or 9 I'd already reached that point where I didn't want to socialise anymore you know" (Alan). He feels the abuse he suffered still reverberates through his life particularly affecting relationships: "I don't get on with others anymore I don't flat very well with people. As far as relationships go I'm not very good at them they don't work I've given up." (Alan) Further isolation has occurred due to his health and drug problem: "Community work - I found I couldn't do it in certain places because of hepatitis, um, or they didn't want a drug addict around - plain and simple." (Alan)

In addition to family and childhood difficulties the shared experience of incarceration by all the males interviewed further marginalised the respondents although in some families prison was a normal adolescent transition to adulthood: "Jail - no big deal It's just something you go through" (Lenny). Although he was shocked to be incarcerated (Corrective Training) for his first offence: "C.T. first time in court age 16 years [for] theft under \$1,000 and two driving charges. ...Poor white trash sent to jail." (Lenny). This experience of C.T. did not act as a deterrent to Lenny's offending and was the first of numerous sentences: "Jail? A cake walk after C.T. ...Time served actual ...9.5 years." (Lenny)

Paul also remembers being shocked at being sent to prison for his first offence. Brownie recalls being sent to prison at a young age and later transferred to an open mainstream prison even though he was far from being a man. "I went to jail for my 16th birthday a jail term yup. It was 3 months jail main stream." (Brownie). He then reflects on how many times he has been incarcerated:

"Maybe C.T. or something could've been a bit different yeah I'm not sure if that was the right thing to do. ...I have been back to jail since then for right up till I was 21years 22years and then from there I just worked yeah full 
time haven't been in trouble since. Ten [lags] all up little bits here and there." (Brownie)

Johnny describes his part in a serious offence and how committing this crime led to a lengthy period of imprisonment:

"C.T. aye short sharp shock, nah that was Rangipo, and then we moved to Christchurch. I think we were only there two weeks and I got the three years in Invercargill. Yeah fucking phew we were staying in one of those night shelters and beat the fuck out of him and went a bit over the top and other people jumped in and somebody took his fucking watch yeah aggravated robbery ah you know." (Johnny)

James discussed the experience of being incarcerated and not receiving any outside emotional or financial support. This is a significant issue because, without money, prisoners are unable to purchase toiletries needed for maintaining personal hygiene, fruit to supplement the limited prison food, or letters and envelopes for writing etcetera. Most importantly money is necessary to purchase a phone card - this allows the inmate to call home and receive much needed emotional support from family and friends. A lack of financial support while in prison is likely to increase levels of social exclusion. James explains his prison experience:

"Was pretty like by myself, so pretty um, ah not supported. Not supported at all. Pretty much I mean, a couple wrote letters and cards, but no one, no visits, um no money, nothing yeah, just, I was basically by myself. ...No visits, no money - I was basically on my own." (James)

During his incarceration James put himself through 'cold turkey' and abstained from further illicit drug use. James explains that he alone made the decision to undertake this process and has successfully maintained this resolve since his release: "Yeah I was straight in jail the whole time, and then I got out and I kept straight ever since, because that's what I wanted to do with my life." (James). However, he had problems with re-integration due to the limited amount of money he received upon his release, which was meant to secure him accommodation, feed him and equip him to apply for employment and meet the conditions of his release until he became eligible for benefit payments: "Yeah got $\$ 300$ steps to freedom and I had to do men for non-violence and um drug and alcohol thing and then I had probation for 12 months yeah." (James) 


\section{Summary}

Exclusion was a recurring theme amongst the respondents. A number of interviewees were taken into care in childhood, and in the education system a number were excluded from school. All the male respondents moved from childhood to adulthood via the custodial pathway. For some, this process began suddenly and abruptly upon their first court appearance. Once in prison, outside support from family or loved ones was often missing. Resettlement following imprisonment was a common challenge that interviewees found particularly difficult.

Paul described becoming aware of racism at an early age and how this became more apparent to him because of his brother who had a much lighter skin colouring. Paul noticed that his brother's lighter skin tone allowed him to move in the worlds of both Māori and European New Zealanders, while he was often exposed to racism, being called 'nigger'. This isolation and exclusion had a significant negative impact upon Paul.

The two female interviewees both discussed their experiencing social exclusion. As females they face double jeopardy if they are framed as deviant, the deviancy of "the act and as an act against gender norms and expectations regarding 'feminine' behaviour" (Bradley \& Walters, 2005:100) this was evidenced by the manner Doris reported being treated when she lost a child to sudden infant death syndrome. Doris recalled how instead of feeling cared for and sympathy she felt guilty and stigmatised for her drug use. Exclusion from quality healthcare was also discussed by Jasmine who says she feels traumatised after attending meetings with her MMT counsellors because of a lack of privacy in a situation she finds highly stressful.

Brownie, Alan and Ben recalled being excluded from the family unit. Brownie discussed his two year isolation from his family and explained that this was imposed on him because he had been squeezed out from school and then incarcerated. Ben, in contrast to other respondents, describes his family as successful and respected but his lifestyle of rock music and drug use was a significant factor in his exclusion from the family unit, although he perceives his familial isolation as being a form of 'tough love'. Interestingly, Ben was the only interviewee to believe his exclusion was solely attributable to the life choices he had made.

In contrast Alan, who suffered physical abuse from his father and systematic sexual abuse from a friend of his father, ultimately was involved in a major fight with his father and was thrown out of home. It is clear these life events have damaged and traumatised some respondents. Alan feels he lacks the ability to conduct and maintain intimate adult relationships, remains isolated from his family, and uses opiate painkillers to suppress 
memories and mask the feelings associated with the sexual abuse and the breach of trust he suffered.

Finally the experience of being excluded by organisations, government departments and social networks was discussed, this included education, employment, housing and social security entitlements. The exclusion from having a participatory role in the management of their MMT and ultimately their recovery was a commonality among those receiving MMT. Negative experiences with WINZ were reported and feelings of stigmatisation and exclusion dominated the interviewees' perceptions of their treatment when inter-acting with this department. For some interviewees a pattern of social exclusion had become imbedded throughout their life course. Beginning with exclusion from general childhood participation because of poverty, followed by exclusion from the educational process, exclusion from the work place then the ultimate form of exclusion from society, incarceration. Finally, all of these in conjunction with various other phenomena including structural inequality and the discourses that emanate from the 'war on drugs' consolidate to construct what Buchannan (2004) describes as "a wall of exclusion" that prevents inclusion. 


\title{
7. Health
}

\section{Mental-health
Alcohol-drugs \\ Unsupportive-medical-professionals}

Physical and mental health was the dominant theme in 106 data extracts from the interviews. Responses were dominated by revelations of problematic drug use and the associated complications arising from drug dependency particularly methadone maintenance treatment MMT. In the drugs findings section Lenny described himself as an 'addict' and identified long term problematic drug use as his main health concern. However, malnourishment is also an issue for him due to his limited income "I don't eat every day I just had to get used to it!' When his mental health is poor he uses drugs to cope with life. He explains: "Drugs - a buffer to the world".

Ben used opiates problematically before moving on to MMT over ten years ago. He now has a serious 'drink' (alcohol) problem and his health is further damaged by the Hepatitis $\mathrm{C}$ virus: "On MMT ten years. ... [I have] Hep C you can't have a job”. His difficulty securing employment due to his PDU, MMT, alcohol problem and the associated health issues result in a limited diet "Vicious cycle. Food goes out the window; drugs [are] first over everything. ... [I] compensate with alcohol." Paul who has being receiving MMT for over twenty-two years reflects that his PDU has impacted negatively upon his physical and mental health: "there is also the spiritual cost [and] physical cost. You don't look after yourself."

Doris is concerned about her PDU and has contracted HCV. She consumes too much alcohol and now has cirrhosis of the liver:

\begin{abstract}
"I worry all the time ... no I do, cause the same thing with me I got really bad track marks and even going for blood test, is oh God. I had Hep C I go to the hospital I've got to [I] have um I got cirrhosis of the liver right.
\end{abstract} I drink too much."

Johnny another long-term IPDU who drinks heavily, suffered a heart attack three months ago and needed a stent placed into an artery within his heart. He seemed more concerned by 
the discrimination from the social care and health professionals than the ordeal of the operation:

"Three months ago I had a heart attack. They put one of those stent things in there I was only in there three days. ... Oh heart attack, phew, I was in there for three days it was like normal in like getting your car, your tyre changed. It's no big deal about it. I didn't make a big deal about it, so it doesn't seem to be a big deal about it eh. Apart from the shit you get from the welfare and the doctors." (Johnny)

While in hospital he disclosed his history of PDU to the medical professionals. When asked if he takes drugs Johnny detailed all the drugs he takes and how he uses them: "I told them everything, you know 'Do you take drugs?' I told them all the fucking drugs I took, I told them, how you know." He was informed that there might be care related consequences if he still continued his PDU:

"If you're [going to] keep up that behaviour and you have another heart attack they probably won't give you another stent. ... We could give that stent to a twelve year old child who has not done anything." (Johnny)

Pete has been receiving MMT for fourteen years and is prescribed medication for high blood pressure. He has been accused of 'drug seeking' behaviour and of 'abusing' his script: "Charge nurse goes I hope you're not been going out and doubling up." Otherwise Pete regards that his GP's management of MMT has been a positive arrangement for him apart from the added financial cost.

Alan contracted HCV and suffers from depression, the combination of which results in him feeling frequently fatigued. Further, as a result of an accident Alan had to undergo surgery where steel plates were inserted into his legs: "I've got Hep C um and I've got steel plates in my legs other than that yeah. I suffer from depression quite badly at times so because of my depression and fatigue I get really tired because of the Hepatitis."

Alan reflects on his seventeen years 'parked' on MMT, he is disappointed the health professionals have never suggested any strategies or plans for coming off methadone. "That's the problem I see with methadone is that there doesn't seem to be any desire to get people off it from the clinic and I think that's wrong." He believes that MMT has also impacted upon his emotional state often leaving him feeling emotionally flat. 
In contrast, James whose main drug of choice has been methamphetamine described his general health as very good. He exercises regularly and does not smoke or drink alcohol.

\section{Summary}

Eight of the ten interviewees had been on MMT for considerable time and problems were identified as stemming from the way this treatment was managed and dispensed. The ongoing issue of stigma arising from being a PDU in a medical setting was widely reported as a process that can impact negatively on the mental health of an individual (Anderson \& Ripullo, 1996; Radcliffe \& Stevens, 2008). Financial hardship and as a consequence poor diet was frequently reported, although choosing alcohol or drugs over food was also an issue. There are a myriad of long-term health consequences including anaemia that are caused by malnutrition (Mila, 2013).

The Hepatitis C virus (HCV), which is spread by sharing drug injection instruments, was mentioned as a concern by three of the ten people interviewed. The long-term prognosis for HCV is poor due to damage the virus causes to the liver (Fraser, 2013) although only Doris mentioned a liver complaint.

The interviewees were aware of their stigma and how they had to carefully present themselves to 'pass' and 'cover' (Goffman, 1963) as acceptable when accessing health care. Earnshaw et al., (2012) demonstrated that individuals receiving MMT experience prejudice, stereotyping, and discrimination from healthcare workers and pharmacy workers. Link and Phelan (2001) suggest stigmatisation occurs when the elements of labelling, stereotyping and status loss co-occur in a power dynamic. The high number of people who drop out from MMT demonstrates the current treatment approach to be problematic (Harris $\&$ McElrath, 2012). The impacts of the stigmatisation and discrimination that occurs in the health care setting include poor mental health which may exacerbate PDU rather than reducing it through social deterrence (Caulkins, et al., 2005).

Mental health was an issue for a number of interviewees and problems were exacerbated by social exclusion, stigma and trauma. Isolation from social interactions can impact on an individual's ability to access socio-economic services or other protective factors such as relationships with pro-social individuals (Commission on Narcotic Drugs, 2012). 


\section{Analysis}

This section will analyse the findings in their totality and seek to explore the messages from this research within the wider context of the existing literature and theoretical debates. Thematic analysis (Braun \& Clarke, 2006) will be used to analyse and contextualise the narratives provided by this small scale qualitative study of long-term dependent drug users in this deindustrialised geographically isolated town.

The lives of the ten people interviewed have been affected by seven main areas: Damaged Childhoods; Blocked Transitions; Extreme Trauma; Drug Dependence; Crime and Incarceration; Social Exclusion, Stigma \& Discrimination; and Hopelessness.

\section{Damaged Childhoods}

The analysis will begin by exploring the childhoods discussed by the respondents. Key themes from their childhoods identified during the coding process as re-occurring throughout the data corpus will be discussed. Key events and key relationships were also identified by the interviewees as being a central experience during childhood will also be explored. However, the seven main areas that are to be investigated are not of equal weight and for this reason there will be variance in the length of the discussions. Respondents reported a number of common experiences during childhood and discussed how these damaging life situations have impacted on their lives.

Broken homes were discussed by most of the participants and only Ben, Lenny and Brownie, said their parents were still together or had remained married until the death of one of the parents. Of the people interviewed, five experienced the break-up of their parents' relationship as a child. The remaining two parental break ups occurred after the interviewees had left the family home. The influence of parents in the lives of their children has been a highly researched area in the academic fields of psychology (Ainsworth \& Bell, 1970) and sociology (McLennan, Ryan \& Spoonley, 2004). In criminology, the parental influence during childhood development has being studied with the focus on early offending, in particular longitudinal studies (Fergusson \& Horwood, 1998; Farrington \& West 1990). Experiencing the breakup of the family unit through divorce or parental separation before the age of ten was shown to be associated with future offending by West (as cited in Arthur, 2007). Of the seven respondents from broken homes, six disclosed 
witnessing or being subjected to violence in the family home. Experiencing or witnessing abuse over a prolonged period impacts on the developmental processes and increases the likelihood of an individual emerging as a severely damaged adult (Arthur, 2007).

A key life event identified as occurring during Jasmine's childhood was the experience of joining a blended family. Jasmine recalled having to join a new family following the divorce of her parents and spoke about how this event changed her life. The current research shows those interviewees who reported the experience of being a child under ten years of age in a broken home, disclosed the onset of drug use at an early age. They also disclosed that they engaged in juvenile offending from an early age.

The longitudinal studies above identify the impact of life events and categorise life events as either being a risk factor or a protective factor in the development of an individual. Risk factors for an individual can result in their developing drug dependence which can be conceptualised across three distinct paradigms: biological, psychological and environmental (Coomber et al., 2013:13).

Biological explanations have been drawn on to argue that drug use is related to a biological or inherited, genetic predisposition. This is expanded on by (Muscat, Korf, Neigerros $\&$ Vuillame, as cited by Coomber, et al, 2013) who argue the presence of a genetic predisposition is the result of a combination of genes rather than a specific gene. However, Coomber et al (2013:14) posit that drug use, particularly PDU "may be the result of a complex interaction between biological factors, familial transmission or hereditary factors, and social and economic circumstances". This perspective is in keeping with some of the aspects of the Psychological explanations for drug use.

Psychological explanations suggest people who use drugs can be seen as being distinct from 'normal' people (abstainers). Coomber, et al (2013:14) claim that "at certain points in their lives individuals may psychologically be in 'need' of drugs". Additionally, Coomber, et al, (2013) state that severe mental illness has a strong correlation with PDU. People with drug dependencies who are also diagnosed with a mental illness may self-medicate using illicit substances as a means of fulfilling their psychological needs. The term comorbidity is used to signify a dual diagnosis such as post-traumatic stress disorder and PDU. Coomber, et al, (2013:14) argue "comorbidity of severe mental illness and alcohol and drug misuse is connected to suicidal behaviour, increased risk of psychiatric admission and poor treatment outcomes". Seven of the ten respondents disclosed having multiple medical issues including alcoholism, PDU, depression, HCV, Cardiovascular problems, High/low blood pressure, artificial body parts, arthritis and PTSD. 
Psychological explanations for why people use drugs are centred on the belief that certain personality characteristics, which include being more or less neurotic, extroverted, introverted, impulsive and risk taking, coalesce into an addictive personality that can result in risky behaviours which include drug use (Coomber, et al 2013). However, Buchanan (2004:124) argues that "psychological approaches run the risk of decontextualizing dependent drug users, by suggesting that dependence can largely be controlled by internal adjustments in thinking, motivation or the development of cognitive behavioural techniques". Psychological explanations also include individuals with psychological problems who use drugs as a form of self-harm and a method of self-destruction. Additionally the use of drugs by young people may be influenced by reasons related to their life-course including more leisure time, fewer responsibilities and as a method to generate 'time out' from the grind of daily life (Coomber, et al, 2013). Furthermore, Buchanan (2006) agrees that while physiological and psychological understandings make significant contributions they fail to deliver a complete understanding of the nature of problematic drug use. However, Buchanan warns of the dangers of not understanding and addressing the underlying social inequalities and deep rooted local cultures when attempting to tackle the problematic use of drugs and its associated individual and social problems. The structural inequalities experienced during the childhoods of the respondents included poverty, deprivation, social exclusion and racism.

Environmental explanations are hypothesised to include having a family break-up, a chaotic home life, child neglect, physical and sexual abuse, placement in institutional care, educational underachievement and the consequences this entails, truancy, being squeezed out of school, unemployment and the lower socio-economic position this brings and having parents who are drug users or who are or have been incarcerated (Arthur, 2007). The above are identified as being risk factors for drug use. However, risk factors should not be put forward as being a causal explanation for why people use drugs. Coomber et al (2013) state that "locating the 'cause' of drug use solely on one or several of these factors can result in the stigmatising of individuals and social groups. In the New Zealand context, problematic use of methamphetamine is argued by Coomber et al (2013) to be experienced at a higher prevalence rate by those who experience material deprivation and by those who are members of the indigenous culture. A majority of respondents explained that as children they lived in a dysfunctional family. Being subjected to harsh parental discipline was a commonly reported experience. The introduction to drugs at an early age was also discussed and the belief that drug use was normal was explained by Lenny.

\section{"I was first exposed to drugs at the age of six. Drugs were normal in our} family" 
Arthur states: "parental alcohol and drug abuse affects parenting skills" (2007:10). The problematic use of drugs and alcohol by parents diminishes their ability to run their lives and care for their families. This inability to organise the day-to-day necessities required to keep a family functioning in a positive fashion impacts on the lives of their children. The effects of problem drug and alcohol use are argued by Arthur (2007) to cause parents to become unpredictable, inconsistent and ineffective when caring for their children. In addition parents may become neglectful of their child's and their own physical needs and act in an insensitive and unresponsive manner. Finally, problem drug and alcohol use may result in the parent becoming angry and critical towards their children (Arthur, 2007).

In the current study, the experience of living with a parent who suffered from mental health problems was discussed. Pete recalled the memory of his mother picking up knives and threatening his father. Pete stated that his father was able to control his temper and he would disarm his wife without striking her. Having a mentally ill parent may impact on the developmental processes of children. The importance of the development of a mother child bond and the traditional role of the father as provider and protector are central to a stable and happy family life (McLennan, et al, 2004). The Christchurch child development study (1977) found that "adult children's memories of maltreatment and memories of their parents' domestic violence are both significant correlates of their own conduct disorder and criminal offending" (Moffitt \& Caspi 2001:116). The key messages from Pete regarding his mother were how, as a family, they would go and visit his mother who was at that time committed to an Auckland mental health institution. He recalled the memory of his ill mother and seeing burn marks that were clearly obvious on her head and temples from under-going ECT. Pete spoke about this memory and how he believed his mother was treated in a cruel manner: "You know it just seemed like cruelty to me."

The damaging effects experienced by the interviewees during their childhoods included being exposed to stigmatisation during their development. Stigma was a commonly reported experience by the participants and the perception of being stigmatised was reported as first occurring during childhood or adolescence. Pete discussed how stigma was imposed on him because his mother was mentally ill. He recalled receiving 'stick' from the children in his community. Pete states how as a counter to this he would attack without hesitation anyone who gave him stick about his mother. The effects of Pete's mother's illness on him included: the break-up of the family unit, the stress of seeing his mother subjected to what he considered to be a cruel treatment and the stigma imposed on him from his peers. Pete reported adult offending and the development of his problematic drug use. This experience is in keeping with the longitudinal development of a criminal or drug centred lifestyle or the adult syndrome of antisocial personality disorder (Coid, 2003). 
Conversely, as Buchanan argues, "PDU may be seen as self-inflicted and stemming from poor choices. However, it must be understood that these poor choices may have been influenced by a range of powerful negative pressures and aggravating factors that limit the alternatives and opportunities available to some sections of society" (2004:390).

Being subjected to sexual abuse was disclosed by Alan who reported that he was repeatedly victimised between the ages of six and sixteen. The impacts from the sexual abuse still reverberated throughout his life. He stated that feelings of anger and sadness are still with him every day and the social isolation of his childhood is still a constant in his life. Arthur argues "there is little doubt that suffering this type of childhood abuse constitutes unresolved trauma which is likely to manifest itself at a later date" (2007:14).

Living in fear was a key life event during the childhoods of some interviewees. The experience of being subjected to violence from a parent or the witnessing of violent acts between parents was discussed by a majority of respondents. Earlier research by Hawkins, Catalano and Miller (1992) has identified a number a poor parenting practices. These include a lack of supervision, inconsistent or overly punitive disciplinary practices and high levels of family conflict. Hawkins, Catalano and Miller posit that these parenting variables increase the risk of a young person engaging in criminal offending (1992:10). Additionally, Ritchie describes the frequent use of physical punishment on children as being 'the dark stain' that permeates New Zealand child rearing practices (2007:51). This statement is evidenced by the annual number of deaths per 100,000 children in rich nations over a five year period during the 1990s. New Zealand is placed third behind Mexico and the USA which heads the twenty seven nations surveyed (Ritchie, 2007).

The violence experienced by Alan, James and Johnny is situated at the extreme end of the violence continuum. The violence perpetrated by their fathers was highlighted as being severe in nature and repeated often. The occurrence of this violence in the lives of these people has resulted in behavioural consequences later in their lives. These include finding it difficult to maintain intimate relationships and friendships, isolation and withdrawing from extended family. All three men disclosed that they have been charged with committing violent offences later in their lives and these offences resulted in their being incarcerated. Yoshikawa (1994) argues that neglect should be understood as being a significant risk factor in developmental outcomes such as juvenile offending. Having neglectful parents and experiencing poor maternal and domestic care before the age of five alongside with not experiencing a good parental relationship with either a mother or father have been shown to intensify behavioural problems and increase the risk of future offending. 


\section{Adolescence/Transition}

The period of adolescence was discussed by the interviewees. This is a particularly important phase in the life course of individuals as this is when transition into adulthood and independence begins (MacGregor \& Thickett, 2011). Respondents reflected on their experiences of school. Attending school was first described as being an exciting and pleasant experience. However, for a majority of the participants, by the time they were attending high school their perceptions of this experience had changed to one of unhappiness and exclusion. For those interviewees who were living in blended families or living in poverty, adolescence was reported as being a period when they experienced deprivation and familial exclusion. The experience of high school was described as being an unhappy time in their lives. Of the ten people interviewed, nine reported being squeezed out of school (excluded).

Being squeezed out from school had extreme consequences for these people which included the failure to obtain a formal education, stigmatisation, separation and isolation from one's peers and for several, expulsion from the family unit. The geographical location of DNZT alongside educational failure, poor education and limited opportunities are in keeping with the phenomena studied by MacGregor and Thickett (2011) who argue these factors are key in the relationship between deprivation and drug use. As these problem phenomena can become concentrated in certain groups in certain areas and can result in social and spatial segregation becoming established. The records of achievement from earlier periods at the local high schools were not available as DNZT high schools underwent restructuring in 2002. However, the levels of recent academic achievement in the location researched reveal some disturbing findings. The achievement rates obtained for the year 2012 show the main local high school in the town had the lowest achievement in the region when compared to more than forty other schools in the region ${ }^{5}$. These results are in keeping with the past experiences of schooling in the DNZT and indicate how the transition into adulthood from adolescence through education and employment is particularly challenging for those growing up in the area.

Adolescence was mentioned by the women interviewees as being the point when they became sexually active and began to experiment with drugs. Additionally similar to other research studies, the male interviewees explained that it was during their adolescence when the onset of their offending and drug use occurred: "many research studies have found

\footnotetext{
${ }^{5}$ Reference omitted to protect anonymity
} 
evidence of a strong association between juvenile substance abuse and anti-social behaviour in young people" (Arthur, 2007:31).

The process of being squeezed out of school was confusing for some of the interviewees. Doris recalled that she thought the process was all rather murky as she stated that she believed that she was a good student and could not quite understand what was occurring.

Lenny was squeezed out of school and this had significant consequences for him. He explained that he felt his goals and opportunities had been sealed off. He was fifteen years old when this occurred and he disclosed that within a year's time he was before the courts for theft under one thousand dollars and two driving chargers. The ultimate outcome for Lenny was being sentenced to corrective training (C.T) and getting sent to borstal. The work of Farrington (1996) using an antisocial behavioural construct found a significant interaction between early school leaving and an unskilled manual job. The report produced by the Foreign Policy Centre and authored by Young (2002:43) posits that "lack of identification with the mainstream" helps to explain how some people become drawn into drug misuse. Furthermore, Young argues individuals who perceive themselves to be excluded or cut off from mainstream society and culture seek out alternative ways for selfexpression and recognition (2002). The entrepreneurship described by Allan when he discussed his poppy hunts is in keeping with ideas expressed above by Young (2002).

Lenny's experience of school being closely followed by incarceration was similar to those experiences discussed by Johnny and Brownie who were also squeezed out of the schooling system and placed into the justice system custodial pathway before their seventeenth birthdays. Johnny was sent to C.T while Brownie was sentenced to a mainstream prison while he was still aged sixteen. The links between crime, unemployment and drug use in the current study are comparable to the findings from much earlier research conducted in America by Preble and Casey (1969) whose study of a New York Ghetto identified crime, unemployment and heroin as being serious social problems. They found that $43 \%$ of their respondents had been incarcerated at some time in their life.

\section{Extreme Trauma}

Extreme trauma was an experience commonly reported by respondents. Several interviewees discussed witnessing or being the victim of extreme levels of family violence during their early childhoods. The violence reported included fist fighting with their father, witnessing their father beat their mother, their father attempting to their kill their mother, 
their mother attacking their father with a knife and being physically or sexually abused. The interviewees also reported experiencing extreme trauma during their life course. The extreme trauma disclosed included, but was not limited to, losing friends because of their being murdered, coming home to a murder scene and later having to clean up the home following this event, having a child at fourteen years of age without familial support, losing a child to sudden infant death syndrome (SIDS) and then losing a partner to a preventable death. Experiencing trauma in an institutional setting (prison) such as being beaten by the prison offices and violent conflicts with other inmates was also disclosed.

In previous research; Dube, et al., (2003) investigated the influence of adverse childhood experiences (ACEs). Dube et al (2003) conducted a study where a retrospective cohort of 8,613 adults made up of four successive birth cohorts that dated back to 1900 completed a survey about childhood abuse, neglect and household dysfunction, illicit drug use and other health related issues. The results from Dube et al (2003) show that ACEs increased the likelihood of the early onset of illicit drug use 2-4 fold. Additionally, they found that people who reported greater than 5 ACEs were 7-10-fold more likely to report illicit drug use problems and that forms of childhood abuse, neglect and household dysfunction tend to cooccur. Dube et al (2003:564) argue: "the effects of these developmentally disruptive childhood experiences have been shown to be strong and cumulative". The current research is in keeping with the study completed by Dube et al (2003) in that the respondents disclosed early onset illicit drug use and increased drug use in adolescence that resulted in problematic drug use in adulthood.

The males in the current research all disclosed that they had been incarcerated at some time in their lives. Experiencing extreme trauma during their childhoods was disclosed by five of the men interviewed and the other three had experienced trauma during their childhoods. Sindicich et al (2013) conducted research into comorbid substance use disorder(s) and posttraumatic stress disorder and found that exposure to traumatic events is nearly universal among inmates. The rates for experiencing trauma were reported as being up to $90 \%$ exposure for both sexes in this Australian study. Additionally Sindicich et al., (2013:45) report that "most have experienced multiple traumas". They also state that two thirds of Australian inmates meet the DSM-IV criteria for substance use disorder (SUD). The international literature, for example, Mills (2006), Najavits, (2007) and Najavits and Hien (2013), on individuals who are diagnosed with comorbidity of SUD-PTSD and are within the community shows an association with poorer outcomes in terms of substance use, mental health and psychological functioning which includes criminal involvement and offending. 
In the current research, nine of ten interviewees had been in MMT and eight of ten were currently in MMT. This is also in line with the research undertaken by Sindicich et al (2013) who found "a greater proportion of male prisoners were likely to have sought community aftercare for drug issues and re-offend post release" (Sindicich et al 2013:47). The interviewees in the current research are similar in that they have reported extensive drug histories and have extensive histories of trauma. Furthermore, while incarcerated, the interviewees state that they did not receive any drug treatment or counselling that could have improved their chances of re-integration following their release from prison.

The association between childhood physical abuse and the onset and extent of drug use among regular injecting drug users was the focus of research compiled by Darke and Torok (2013). They found childhood physical abuse (CPA) was highly prevalent among injecting drug users (IDU) with "half or more reporting such abuse" (2013:1). Their recent research found that almost three-quarters of their IDU sample reported having an abuse history and $40 \%$ of that sample stated that the abuse they had experienced was severe. Darke and Torok also state that estimates of CPA prevalence in the general population are found to range from 5 to $20 \%$ (2013:1). They term experiencing CPA as a "shattered childhood" that can produce long lasting clinical ramifications which include increased risk of attempted suicide and is associated with drug dependency (Darke \& Torok 2013:1) The findings from the current study are in keeping with the work of Darke and Torok (2013) in that the severity of the trauma experienced was associated with the onset and extent of drug use among the people interviewed. The findings from the current research are of clinical importance as they reported early onset of illicit drug and substance use which is linked to increased levels of drug dependency, the onset of which is rapid and is more problematically developed. The early onset of illicit drug use and its reported association with childhood trauma (Sindicich et al, 2013) demonstrates that there is a need for strategies to reduce rates of childhood trauma. Childhood trauma is identified as being a driver of polydrug use and PDU, which are in turn linked to poorer individual and social outcomes (Darke \& Torok 2013).

\section{Drug Dependence}

The previous section discussed the associations between trauma and drug dependency. In the current research all of the interviewees disclosed that they have had or still have drug dependency. Of the ten people interviewed nine reported opiates as the drug of choice. In the case of not being able to access heroin, pharmaceutical opioids were most favoured in 
particular morphine sulphate or methadone. However, the associated cost of procuring these was problematic. The sourcing of locally grown opium poppies was discussed and these were reported as being a popular source of drugs in the spring and summer as during this time they are available and accessible throughout NZ. Additionally the fact that there was little associated cost with locally sourced raw opium was put forward as a reason for their popularity among the interviewees. As reported above, eight of the people interviewed are currently in MMT and one of the two not receiving it had been in MMT in the past. The only individual never to have being in receipt of MMT was James who disclosed that methamphetamine was his drug of choice. James also reported that he has managed to maintain abstinence from all drugs since his last period of incarceration.

In the current study introduction occurs when an individual becomes aware of drugs and drug use. Introduction had a range of six to sixteen years of age in the current research. Onset of drug use is when the individual first reported use of drugs occurring. All the interviewees reported cannabis as being the first illicit drug they used. Onset of first drug use ranged between eight and seventeen years of age, and onset of hard drug use ranged between fifteen and thirty five years of age. The age of onset for hard drug use was as follows, Lenny 18 years, Ben 19 years, Paul 22 years, Doris 21 years, Brownie 18 years, Jasmine 24 years, Johnny 23 years, Pete 30 years, Alan 21 years, and James 30 years. The age of the onset of intravenous drug use in the current study ranged between 18 and 30 years of age and onset occurred on average at 22.6 years of age. This is reflective of the Ministry of Health Report (MOH) into Intravenous opioid dependence in NZ (Deering et al., 2008) that stated onset of drug use for its sample ranged between 13 and 40 years of age and an average onset age being 19.4 years. The current small scale qualitative study had a slightly higher average age of onset but the sample showed a higher rate of interviewees in MMT than the sample used in the Ministry of Health report (2008). The drugs of choice that were nominated in the current research are also in keeping with the findings from the MOH report (2008) where heroin, morphine, homebake and methadone were the primary drugs of choice.

The development of drug dependency may emerge for differing reasons. It may develop through medical illness or elective surgery resulting in opiate use for the management of chronic non-cancer pain (CNCP) (Huxtable, Roberts, Somogyi and Macintyre (2011). The exposure to risk factors for an individual during the life course has been identified as an influence in developing drug dependence (Coomber et al., 2013). In the current study the people interviewed reported numerous life experiences that would be categorised as risk factors for the development of drug dependency. These included the early introduction to 
drugs, coming from a broken home and the experience of being exposed to a traumatic event or experiencing multiple traumatic events (Darke \& Torok 2013).

The international and national research broadly shows that economic deprivation and social exclusion are correlated to drug use particularly PDU. However, proving a direct causal relationship with drug use has been problematic. Recently the explanatory gap for PDU has been filled with the concept of risk factors. Other environmental explanations for drug use include Durkheim's (1961) concept of 'anomie' which is a situation when social norms have ceased to have a hold over individuals. The taking up of alternative drug centred lifestyles can offer a marginalised or socially excluded individual routine, income and status (Buchanan, 2006). However, this can lead to the individual or sub-cultural group being labelled as deviant due to their drug use which can in turn increase their social exclusion in a process of 'deviancy amplification' (Coomber, et al, 2013). The sociological explanations discussed here highlight how people's drug use cannot be explained without referencing the historical, social and cultural context in which the drug use occurs.

\section{Banging up}

All of the nine people interviewed who reported heroin or opiates as their drug of choice spoke of their needle fixation and the ritual and pleasure associated with the administering of drugs through the intravenous method. The pleasure gained through drug use has, until recently, been overlooked as a motivational factor for drug use (Coomber et al, 2013). The dominant discourse frames all illicit drugs as being dangerous and fundamentally problematic and this has obscured pleasure seeking as a main motivational factor for drug taking (Coomber et al 2013). Paul explains the ritual, pleasure and sense of control that he associates with his drug use.

"It's more than just a matter of having drugs. It was the whole culture surrounding it, the trip to the pharmacy, the excitement and euphoria you felt the going home the preparation of the paraphernalia the knowing of how you're gonna feel shortly and knowing you're gonna have the confidence and ability to do what you want to do throughout the day and you don't have to worry about any of this sort of stuff till tomorrow."

Those on MMT acknowledged their preference for administering their methadone in this fashion. The interviewees stated how the ritual of preparing drugs was associated with the pleasure they anticipated prior to and received following intravenous drug use. It was put 
forward by Johnny that if he was offered a dose of methadone but had to drink it or he could have half the dose if he choose to use it intravenously, Johnny said he would take the half anytime. These statements are in line with the findings of the MOH Report (2008) that found $30.5 \%$ of their sample disclosed methadone as the drug most recently injected.

\section{Treatment}

As reported above, eight of the ten people interviewed are currently in MMT. Respondents who are in receipt of MMT had a number of thoughts on their treatment. These included waiting times, drug testing, relapse, needle fixation, drug seeking, pharmacies, ritual, health, mental health, lack of control over their dependency, private doctors, reliving trauma, banging up, social exclusion, marginalisation and stigma.

The issue of the 'elephant in the room' (giving people with intravenous dependencies oral treatments) was discussed. Paul spoke of the methadone clinic's lack of concern over his physical health. Paul has extremely scarred and collapsed veins and for this reason he has banged up in his neck for the last three years. The track mark on his neck running along his jugular is highly visible. However, he states he has never been asked about this or advised on the dangers of this behaviour. Paul stated his perception of his clinical assessments.

I honestly think you know you do what you want to do as long as it's not blatantly obvious and you know we'll just keep up the facade.

Alan spoke how MMT was harder to get off than it is to get on it.

That's the problem I see with methadone is that there doesn't seem to be any desire to get people off it from the clinic and I think that's wrong.

These statements are in keeping with those that appear in Harris and McElrath (2012), whose research focused on theoretical concepts of social control and stigma and examining experiences of MMT from the perspective of the clients. They found structural factors can influence the retention of individuals in treatment and the success of individual treatments. Harris and McElrath (2012) found clients voiced concerns about daily collection of methadone, supervised consumption for stable clients, lack of privacy in pharmacy settings and the control of methadone over daily life styles. Some of the respondents in the Harris and McElrath (2012:816) study stated: "they feared long term use of treatment more than heroin itself". In their study Harris and McElrath found that, overall, treatment was determined largely if not solely by Addiction Services staff. Additionally MMT clients 
were found to be passive recipients of treatment and this regime reinforced power imbalances between service providers and clients (2012:816).

\section{Stigma}

A key issue raised by respondents was their experiences of stigma and in particular drug related stigma. All of the people interviewed reported having experienced drug related stigma. Lloyd (2010) states that the precise form of stigma is culturally determined. Thus for all stigmatised groups there is hope of change. This culturally determined change has been evidenced in NZ by the homosexual law reform Act (1986) and recently the right for same sex marriages with the Marriage Amendment Act (2013). However, those people interviewed and other people who are IPDUs in NZ and other western countries, are currently stigmatised more than any other group within society (Lloyd 2010). The levels of stigma that IPDUs are exposed to are attributable to the Anglo American tradition of drug policy also known as 'the war on drugs' (Young, 2002). The war on drugs frames illicit drugs as intrinsically evil and suggests that there is almost no price too high to pay in money or civil liberties for the trafficking of drugs to be stopped or for the immoral dealers to be punished for supplying the weak and misguided users (Young, 2002:5).

The experiences of stigmatisation disclosed by respondents occurred across a range of places and situations. However, experiencing stigma in health settings in both the diagnostic and community levels was a commonly discussed experience. The reporting of these experiences by the interviewees is in keeping with the findings of Luoma et al (2007) who reported that the current treatment system may actually stigmatise people in recovery in that those people with more episodes of methadone maintenance treatment reported a

“Counsellors talk down to you 'junky' they should understand. ...wanted takeaways for my bands tour I [needed] proof lying junkie"

higher level of stigma related rejection. In an example of the stigma process Ben describes the feelings of stigma he experienced when at an appointment with his MMT worker. He had gone to the clinic to ask for take aways so he could embark on a tour with his rock band but he was required to provide proof as his word was not enough, in the following he describes this encounter. 
Johnny spoke of a similar encounter where he was exposed to stigma when visiting the Doctor for a pre-existing health condition. Johnny stated that he was accused of being a 'drug seeker'. In the following he describes his perception of this occurrence:

A further example of stigma occurring in a health setting is discussed by Paul when he explains what it is like to be subjected to the public gaze during mixed contacts in the pharmacy setting while consuming his methadone publicly:

"Well if people didn't know you were on the methadone the system that they use at where I go for example that's ok because they will find out because of the way you're given it right in front of everyone."

In their work on stigma, Link and Phelan (2001: 367) state that stigmatisation is entirely contingent on access to social, economic, and political power that allows the identification of differentness, the construction of stereotypes, the separation of labelled persons into distinct categories, and the full execution of disapproval, rejection, exclusion, and discrimination.

There are key issues outlined by Lloyd (2010) that can help explain the stigma process in relation to drugs and IPDUs. First, there is the criminalisation of drug use because of their illicit nature. If PDU was viewed as a health issue rather than a crime this would likely decrease the stigma of PDU. The illicit standing of drugs plays an important role in the stigmatisation of IPDUs encouraged by the language used in the "war on drugs". The second point is that language does matter and the media is fundamental in influencing the general public. The use of pejorative terms such as 'junkie' in broad sheets and mainstream media cements negative stereotypes which impact on the public's general understanding of IPDUs (Lloyd, 2010). Language can also influence medical professionals during their interactions with IPDUs (Kelly \& Westerhoff, 2010). The use of blame is central to the stigma process associated with PDU as it places blame on IPDUs for engaging with drug use in the first place; blame also creates the perception that IPDUs have a choice in their current or future use of drugs (Lloyd, 2010). Additionally, the argument that some stigma is good because the stigma attached to IPDUs prevents the use of drugs by others and shames IPDUs into treatment. Lloyd (2010) disputes these claims and draws on White and Kelly (2011) who argue that terms such as abuse are highly inaccurate as their origins can be traced to associations with sinful acts and have modern associations with sexual and physical violence. Thus the use of this term contributes to the stigma fixed to problematic drug use. The work of Lloyd (2010) and White and Kelly (2011) raises the issue that there is a great need for the construction of a new terminology for those engaged with the dependencies field. 
The experience of being the focus of the 'public gaze' was frequently raised by respondents. The lack of privacy when consuming their methadone was described as being highly stigmatising and also contributing to their marginalisation from the wider community. The impact of these mixed contacts (Goffman, 1963) can be diverse and can range from a bystander's interest in what the interviewees are consuming to being exposed to stigmatisation and marginalisation. Jasmine reflects on mixed contacts within the pharmacy setting in the following.

"You feel it yeah they look at you as if that they're trying to work out what you're doing they wonder if you're schizophrenic or something like that because you have to you know consume in front."

Additionally mixed contacts with bureaucrats such as those at WINZ were also reported as being situations where the stigma process occurred. The stigmatising nature of these mixed contacts was reflected on by Ben. He explained how he was told during a meeting about his entitlement for his sickness benefit that he was now on "unemployment with issues". The language used fixes a master status such as PDU as being an issue that prevents their participation in the work force. Framing drug dependency and health problems as being a choice in Ben's life rather than something he was not in control of: "Unemployment with issues you have issues. ... I thought I was on the Sickness benefit? No you have issues that stop you getting work." Lenny also spoke of a very similar occurrence that he experienced during an appointment with WINZ where during a mixed contact his master status of 'drug addict' was framed as being a lifestyle choice that prevented his participation in the work force: "Benefit is unemployed as [I] choose my illness, addiction so [I'm] not eligible for sickness benefit."

The stigmatisation that occurs during mixed contacts has negative impacts on those exposed to the process. Ahern, Stuber and Galea (2006) state that stigmatisation may adversely affect the health of those who use illicit drugs. The negative health consequences associated with stigmatisation include a "direct detrimental influence on mental and physical health which stems from exposure to chronic stress" (Ahern, Stuber, \& Galea 2006:189) The experience of rejection by others and expectations of rejection may cause chronic stress which may in turn lead to the development of coping approaches that use withdraw and isolation, and the increased level of isolation may cause further harm to an individual's wellbeing (Ahern et al 2006). Other coping strategies may include passing (trying to pass as a normal individual) or covering (to try and cover the attribute that causes the individual to be stigmatised). These strategies are utilized by people who have a stigmatising master status fixed to their identity (Goffman, 1963). Passing and covering 
was discussed in the research conducted by Luoma et al (2007) who found intravenous drug (IV) uses reported that they experience more stigma than non IV users and that they use secrecy as a coping strategy. Furthermore, the impact of stigma on the mental and physical health of individuals was investigated by Hatzenbuehler et al who argue "stigma is in fact a central driver of morbidity and mortality at a population level" (2013:813). The effects of stigma are described by Hatzenbuehler et al (2013) as being an added encumbrance that impacts on the stigmatised individual above and beyond any deficiencies or failings they may have already have.

\section{Hopelessness}

The Respondents discussed their hope for the future and the aspirations that they hold. Experiencing a life where stigmatisation, marginalisation and exclusion are routine has left an impact on most respondents. These experiences have also affected their ability to believe that the future is somehow going to be a better place for them. Brownie was incarcerated following his interview for the current study. He has recently been released and he is currently trying to find employment. The following were his thoughts on his ability to secure a new job if he had lost his last position which unfortunately is what occurred as a result of his latest incarceration.

"Getting a job would be harder if I didn't work for who I work for now it would be real hard to get a job definitely."

The reality of his situation is summed up here by Johnny who reflects on his position and how this affects his chances of securing a job.

"What job could I get? I'm going to fail a drug test. No jobs here!"

Paul's assessment of his future and his ability to gain employment are similar to those voiced by Brownie and Johnny in that he does not see it as a realistic possibility.

\footnotetext{
"Realistically speaking I believe it's unattainable especially locally speaking as soon as they find out what you're on Bang it's the kiss of death, it's just the way it is."
}

However, there were a minority of the interviewees who did have jobs and who did perceive the future with some hope. Doris spoke of her ability to maintain employment. 
"I have always had work I've always yeah.... I do their gardens you know... I never let them down I'm responsible."

Alan also spoke of how he created his own opportunities and how support came from a section of the community that he least expected it to emerge from. Additionally, Allan reflected on how the support he has received has caused him to re-assess how he viewed the Indian section of society.

"My flatmate put me onto this woman and that was really good job for me it was a \$500-\$600 job it was a full week. So um and that is good from her word of mouth. Now she was an Indian lady. Now $80 \%$ of my work is in the Indian community. Um and I must admit my opinion of Indians have changed a lot."

In summary, the cohort in this sample has endured damaged lives before drugs, experiencing significant trauma and exclusion, and most had difficult family environments. Their experiences of not fitting in began early (in the home or at school). They are a group that have experienced blocked or difficult transitions into adulthood. All of the males in this study have been incarcerated and all of the interviewees have experienced trauma during their life courses. Navigating their way through life was always going to present challenges that would be difficult to overcome for this group of people. In terms of drugs and other substances, they were exposed to drugs at an early age although PDU became established later in their lives. Once dependent on drugs, life became centred around and dominated by drugs. As their drug dependencies increased, so did the difficulties and the levels of stigma they experienced. For this group, opportunities for change and desistance from reincarceration appear to be limited, and in collusion with treatment providers they appeared to have resigned themselves to an identity of 'addict' on methadone. While change and desistence opportunities may have been possible at different stages such transformations have always been and will be a significant challenge for people that have limited experience in any alternative lifestyle, lack personal resources and generally struggle to access social and cultural capital. Rarely have this cohort been integrated or included in society since they experienced social exclusion during childhood. To what extent the respondents 'hopeless addict' status has become internalised and to what degree it may be reinforced by the state as 'troublesome self-inflicted addict' is worthy of future research. 


\section{Concluding Discussion}

Stigma, marginalisation and social exclusion consistently featured in the lives of those interviewed. They reported life courses often encompassing negative and traumatic experiences that thwarted their opportunities of a positive future. These respondents seemed discarded by society. They are a group whose labour (for a variety of reasons) is largely surplus to current capitalist requirements. Murray (1994) might regard them as the underclass, while Marx might refer to them as a "lumpen-proletariat", a discarded working class. Grover (2008) argues a section of unskilled workers, like the respondent group, need to be unemployed to keep wage costs down and maintain a flexible unskilled workforce. However, the downward trajectory of this respondent group began before they encountered long term unemployment and before they experienced the onset of their drug use, initiated at an early age by experiences of serious trauma, exclusion and damaged home environments. The trauma reported by the respondents was major and occurred during their childhood, adolescence and, for some, has continued throughout their life course. For this cohort it appears drug use became a coping mechanism to distract from the reverberating impacts of stigma, exclusion and marginalisation. Furthermore, a lifestyle preoccupied by problematic drug use (PDU) offers a twenty-four hour daily cycle that provides routine, focus and purpose (Buchanan, 2008).

The respondents seem to see themselves as people without worth, lacking agency and selfdetermination and eventually this appears to have culminated in an accepted identity as 'junkie' and 'addict'. This identity does not totally prevent their resistance to the stigmatisation and marginalisation this produces. However it does impact on the cohort's ability to resist by diminishing their sense of self-worth and impinging on their ability to secure support by framing them as 'dirty' or 'dishonest'. The fixing of the master status of 'addict' acts to firm up the internalisation of this identity (Lloyd, 2010). The stigma that the bearer of the 'addict' master status is exposed to is argued by Ahern et al (2006) to cause chronic stress that has a direct detrimental influence on both the mental and physical health of the individual. Additionally the expectations of rejection and stigmatisation that were voiced by respondents are claimed by Ahern et al (2006:188) to "cause chronic stress and may lead to coping approaches that involve withdrawal and isolation further harming mental wellbeing".

The master status of 'addict' that the people interviewed seem to have fixed as their identity was applied a long time ago and the issue of their ability to change must be raised. The 
social construction of the addict identity is argued by Earnshaw et al (2012) to be accomplished through the association of illicit drug use with criminality and the negative language used in the socio-cultural stigmatisation of drug users as part of 'the war on drugs'. The understanding of drugs and IPDUs that people hold is usually gained from remote sources such as the media. Lloyd (2010:49) states that gaining knowledge about drugs and PDU remotely "provides fertile ground for the growth of myths and stereotypes". The respondents' capacity to change their lives is associated with their ability to overcome their identities master status of 'junkie'. However, as Lloyd (2010) points out, there is the convenience of the 'junkie' identity for the person, the community and the state to use in a number of ways. The use of this identity involves a downward social comparison, othering, excluding and blaming. Respondents have the master status of IPDUs and as such they are cast in Cohen's (1972) role of 'folk devil'. Similarly, Buchanan (2004) argues that othering of illicit drug users frames IPDUs as 'the enemy within' further stigmatising and marginalising those in our communities who have drug dependencies. The respondents stated that being identified as an IPDU in a deindustrialised New Zealand town (DNZT) may have impacted on their ability to obtain the social capital required to gain employment and secure acceptance. The entrenched negativity sustained through the deep seated and dominant anti-drug discourse appears to have legitimised the stigmatisation of this group. The experiences of the respondents highlight the need for a new language/terminology that goes beyond addict/junkie this could be drawn from a human rights perspective. But more than that, the language is simply reflecting the values and beliefs towards this 'blamed' group.

The results from this small sample study are in keeping with the findings of MacGregor and Thickett's UK study that concluded: "post-industrial towns and cities are characterised by growing spatial and social segregation and a concentration of problems in certain groups and localities" (2011:489). The central problem to emerge from the current research is what can be done to help uplift the people interviewed from their PDU, exclusion, isolation and poverty. The multilayer complexity of health, financial, and social problems in the lives of the respondents makes any attempt to address the underlying causes of poverty, exclusion, PDU and stigmatisation challenging. However, the experiences of respondents showed that identifying needs and opportunities earlier rather than later would support people with complex needs with their moving forward from lives that are dominated by drugs, crime, poverty and trauma. The multifaceted needs of this group of people include co-morbidity in physical and mental health. The alienation and poverty experienced by the interviewees and the development of drug dependencies has resulted in the majority of these people being placed into methadone maintenance therapy (MMT) where they have experienced further 
stigmatisation. This has produced a lack of trust, as a consequence of trying to 'pass' or 'cover' and having to re-tell traumatic events in front of more than one counsellor. MMT has offered little opportunity for change, growth or integration. Respondents who are currently in MMT all report being in long term treatment and occupy a position of being 'parked up' on methadone. The implication is that society has given up on them and through limited personal resources, blocked opportunities and internalised self-blame these people have also given up on themselves.

The medical model presents 'addicts' as suffering with a lifelong disease for which immediate abstinence achieved through the 12-step model and maintained through lifelong 'recovery' is the preferred strategy to manage their status as addicts (Nowinski \& Baker 1992). Stigma also arises where drug problems are seen as self-inflicted and the user is held responsible for the creating his or her own problem (Lloyd, 2010). Some treatment for PDU suggests that dependence can be overcome by cognitive behavioural therapy with appropriate support networks in place in which individuals are motivated to change (Ward $\&$ Brown, 2004). However, this also needs to incorporate and address structural inequalities that have blocked and/or denied opportunities for change.

The current research findings show that all of the participants have experienced some type of negative phenomena during their childhoods. These included childhood poverty, broken family unit, and exposure to violence or the experience of an extremely traumatic event. Based on these findings, the author argues, that it is imperative to look beyond the present problem of addiction. There is a need for MMT to be part of a holistic capabilities building programme that is client driven. This programme should bring a focus to education, employment and personal development. This would be in line with the recommendations made by the UK Home Office (as cited in European Monitoring Centre for Drugs and Drug Addiction, 2010:24) that stated "the solutions need to be holistic and centred around each individual, with the expectation that full recovery is possible and desirable". Implementation of the suggested strategy would enable individuals such as the respondents to receive not a second chance but the first chance they have yet to receive. If there were opportunities created through full employment and a shortage of unskilled labour to meet the capitalist demand (as there was in DNZT during the 1950s -1970s) would this group of people be stuck where they are today? Tackling the underlying poverty and inequality in this community will require long-term multi-agency responses to build capabilities and maintain these processes in partnership with the community.

Employment Creation is a complex challenge; nevertheless there are some approaches that could be used in the NZ context. Grover (2008) puts forward the strategy of ecological 
employment. This would be a perfect fit within the NZ context where large scale dairy farming is impacting on the environment and there is a need to enhance NZ's status as clean and green. Tourism creates many opportunities for ecological employment which may lead to increased prospects for the people living in disadvantaged communities. Additionally capability building could be used to connect the community with the local education providers. Retired or unemployed people with defined skill sets could be utilised by local high schools to introduce various skills from their fields of expertise. The reconnection to the community that would occur may help build positive community relationships and be a valuable method for providing pro-social role models while also creating employment.

The findings from this small-scale study recognise that there is a need for further research in this area to inquire if these phenomena are replicated nationally. If so the findings from research on a national scale could act as a starting point to guide preventative work for establishing avenues of desistance for the following generation. 


\section{References}

Adamson, S. J., Deering, D. E. A., Sellman, J. D., Sheridan, J., Henderson, C., Robertson, R., Pooley, S., Campbell, S. D. (2008) Report for the Ministry of Health: Intravenous Opioid Dependence in New Zealand. The National Addiction Centre New Zealand.

Adamson, S. J., Deering, D. E. A., Sellman, J. D., Sheridan, J., Henderson, C., Robertson, R., Pooley, S., Campbell, S. D., \& Frampton, C. M. A. (2012) An estimation of the prevalence of opioid dependence in New Zealand. International Journal of Drug Policy. Vol. 23. Pp. 87-89.

Ahern, J., Stuber, J., \& Galea, S. (2007) Stigma, discrimination and the Health of illicit drug Users. Drug and Alcohol Dependence, Vol. 88 pp. 188-196

Ainsworth, M. D. S., \& Bell, S. M. (1970). Attachment, exploration, and separation: Illustrated by the behaviour of one-year-olds in a strange situation. Child development, 49-67. Vol.41.

Alexander, V. (2000). Tales from the Swamp, Wainuiomata, Wainuiomata New Zealand.

Anderson, T. L., \& Ripullo, F. (1996) Social Setting, Stigma Management, and Recovering Drug Addicts. Humanity and Society. Vol. 20. Number 3. Pp.2643

Arthur, R. (2007). Family life and youth offending: Home is where the hurt is. Routledge. London.

Barry, M. (1998) Social Exclusion and Social Work: An Introduction. Social Exclusion and Social Work. Issues of Theory, Policy and Practice (Eds.) Barry, M. \& Hallet, C. Russell House Publishing Ltd. Dorset.

Berger, P. L., \& Luckmann, T. (1966). The social construction of reality. Garden City, NY: Anchor.

Boeckmann, R. J., \& Tyler, T. R. (1997). Commonsense justice and inclusion within the moral community: When do people receive procedural protections from others? Psychology, Public Policy, and Law, 3(2-3), 362380 .

Boland, P. (2008) British drugs policy: Problematizing the distinction between legal and Illegal drugs and the definition of the 'drugs problem' Probation Journal. Vol.55 (2) pp. 171-187. SAGE Publications UK.

Braun, V., \& Clarke, V. (2006). Using thematic analysis in psychology. Qualitative research in psychology, 3(2), 77-101.

Bryman, A. (2008) Social Research Methods $3^{\text {rd }}$ Edition. Oxford University Press. Oxford.

Buchanan, J. (2004) Missing Links? Problem drug use and social exclusion. Probation Journal Vol. 51(4). Pp. 387-397. UK. 
Buchanan, J. (2004) Tackling Problem Drug Use: A New Conceptual Framework. Social Work in Mental Health. Vol. 2, No 2/3, pp.117-138.

Buchanan, J. (2006) Understanding problematic drug use: A medical matter or a social issue? (Glyndwr University Research Online: http://epubs.glyndwr.ac.uk/siru/18).

Buchanan, J. (2008) Understanding and engaging with problematic substance use, Addressing Offending Behaviour-Context, Practice, Values, Chapter 14, pp.246-264 in Green, S Lancaster, E., and Feasey, S. (Eds.) Routledge

Buchanan, J. (2009) Understanding and Misunderstanding Problem Drug Use: Effective Practice in Health, Social care and Criminal Justice. (Eds.) R. Carnwell \& J. Buchanan $2^{\text {nd }}$ Ed. Open University Press.

Byrne, D. (1999) Social Exclusion. Issues in Society. Seriesr Editor: May, T. Open University Press. Buckingham Philadelphia.

Carter, S. M., \& Little, M. (2007). Justifying knowledge, justifying method, taking action: Epistemologies, methodologies, and methods in qualitative research. Qualitative Health Research, 17(10), 1316-1328.

Caulkins, J. P., Reuter, P., Iguchi, M. Y., \& Chiesa, J. (2005) Rand Report: How Goes the War on Drugs. An Assessment of U.S. Drug Problems and Policy. Rand Drug Policy Research Centre. Pittsburgh, PA.

Cohen, S. (1972). Folk devils and moral panics: The creation of the mods and rockers. Psychology Press. UK.

Coid, J. W. (2003). Formulating strategies for the primary prevention of adult antisocial behaviour: 'high risk' or 'population' strategies. Early prevention of adult antisocial behaviour, 32-78.

Coomber, R., McElrath, K., Measham, F., \& Moore, K. (2013). Key concepts in drugs and society. Sage.

Cozby, P. (2007) Methods in Behavioural Research Ninth Ed. California State University, Fullerton North central University. Published by McGraw Hill.

Cram, F., \& Kennedy, V. (2010). Researching with whānau collectives. MAI Review, 3. New Zealand.

Creswell, J. W., Hanson, W. E., Plano, V. L. C., \& Morales, A. (2007). Qualitative research designs selection and implementation. The Counselling Psychologist, 35(2), 236-264.

Crocker, J., Major, B., \& Steel, C. (1998). Social Stigma in New York. The Handbook of Social Psychology. ed, 2, 4th.

Darke, S., \& Torok, M. (2013). Childhood physical abuse, non-suicidal self-harm and attempted suicide amongst regular injecting drug users. Drug and alcohol dependence, 133(2), 420-426.

Davidson, Y. A. (1974) A brief history of Wainuiomata. Wainuiomata New Zealand.

Davies, P. (2005). Insider research: From a position of privilege. In TASA Conference University of Tasmania, 6-8, December. 
Deering, D., Sellman, D., Adamson, S., Campbell, S., Sheridan, J., Pooley, S., \& Henderson, C. (2008). Intravenous opioid dependence in New Zealand. A report prepared for the Ministry of Health. Christchurch, New Zealand: National Addiction Centre.

Dube, S. R., Felitti, V. J., Dong, M., Chapman, D. P., Giles, W. H., \& Anda, R. F. (2003). Childhood abuse, neglect, and household dysfunction and the risk of illicit drug use: the adverse childhood experiences study. Pediatrics, 111(3), 564-572.

Durkheim, E. (1961). Moral Education: A Study in the Theory and Application of T. Free Press of Glencoe.

Durrant, R., \& Thakker, J. (2003). Substance use and abuse: Cultural and historical perspectives. Sage Publications.

Earnshaw, V. A., Smith, L. R., Chaudoir, S. R., Lee, I. C., \& Copenhaver, M. M. (2012). Stereotypes about people living with HIV: implications for perceptions of HIV risk and testing frequency among at-risk populations. AIDS education and prevention: official publication of the International Society for AIDS Education, 24(6), 574.

Farrington, D. P. (1996). Psychosocial influences on the development of antisocial personality. Psychology, law and criminal justice: International development in research and practice, 424-444.

Farrington, D. P., \& West, D. J. (1990). The Cambridge study in delinquent development: A long-term follow-up of 411 London males. In Kriminalität (pp. 115-138). Springer Berlin Heidelberg.

Fergusson, D. M., \& Horwood, L. J. (1998). Early conduct problems and later life opportunities. Journal of Child Psychology and Psychiatry, 39(08), 10971108.

Fraser, S. (2013). The missing mass of morality: A new fitpack design for hepatitis C prevention in sexual partnerships. International Journal of Drug Policy, 24(3), 212-219.

Glaser, B.G. \& Strauss, A.L. (1967). The Discovery of Grounded Theory: Strategies for Qualitative Research. Chicago: Aldine.

Global Commission on Drug Policy. (2011) Report of the Global Commission on Drug Policy: War on Drugs.

Goffman, E. (1963) Stigma, Notes on the Management of Spoiled Identity. Spectrum Books Prentice-Hall, Inc. Englewood Cliffs, N.J.

Gossop, M. (2013). Living with drugs. Ashgate Publishing, Ltd.

Gray, D. E. (2009) Doing Research in the Real World. SAGE Publications London

Greenberg, S. W., \& Adler, F. (1974). Crime and addiction: An empirical analysis of the literature, 1920-1973. Contemp. Drug Problems. 3, 221.

Griffiths, P., Gossop, M., Powis, B., \& Strang, J. (1993) Reaching hidden populations of drug users by privileged access interviews: Methodological and practical issues. Drugs Transitions Study, National Addiction Centre. Addiction Vol. 88. Pp.1617-1626 London UK. 
Grover, C. (2008) Crime and Inequality Willan Publishing Devon. UK.

Haden, M. (2006). The evolution of the four pillars: Acknowledging the harms of drug prohibition. International Journal of Drug Policy. Vol. 17. Pp. 124126. Vancouver Canada.

Harris, J., \& McElrath, K. (2012). Methadone as Social Control Institutionalized Stigma and the Prospect of Recovery. Qualitative health research, 22(6), 810-824.

Hatzenbuehler, M. L., Phelan, J. C., \& Link, B. G. (2013) Stigma as a Fundamental Cause of Population Health Inequalities. The American Journal of Public Health. Vol. 103, No. 5.

Hawkins, J. D., Catalano, R. F., \& Miller, J. Y. (1992). Risk and protective factors for alcohol and other drug problems in adolescence and early adulthood: implications for substance abuse prevention. Psychological bulletin, 112(1), 64.

Hellawell, D. (2006). Inside-out: analysis of the insider-outsider concept as a heuristic device to develop reflexivity in students doing qualitative research. Teaching in Higher Education, 11(4), 483-494.

Hobsbawm, E. J. (1994). The age of extremes: a history of the world, 1914-1991 (p. 2). New York: Pantheon Books.

Holman, D., Wall, T. D., Clegg, C. W., Sparrow, P., \& Howard, A. A Guide to the Human Impact of Modern Working Practices.

Howden -Chapman, P., Bierre, S., \& Cunningham, C. (2013) Building Inequality in M. Rashbrooke (ed.) Inequality and New Zealand. (Pp. 39-52) M. Bridget Williams Books. Wellington New Zealand.

Humpage, L. (2006). An 'Inclusive' society: a 'leap forward' for Māori in New Zealand? Critical Social Policy. Vol. 26(1): pp. 220-242

Huxtable, C. A., Roberts, L. J., Somogyi, A. A., \& Macintyre, P. E. (2011). Acute pain management in opioid-tolerant patients: a growing challenge. Anaesthesia and Intensive Care. Vol. 39. No. 5. Pp. 804-823.

Irving, B. A. (2009) Locating Social Justice in Career Education: What can a Small-Scale Study from New Zealand Tell Us? Australian Journal of Career Development. Vol. 18. No. 2. Published by Sage on behalf of the Australian Council for Education Research.

Jones, E. E., Farina, A, Hastorf, A., Markus, H., Miller, D. \& Scott, R. (1984). Social Stigma: The Psychology of Marked Relationships. New York.

Kaye, K. (2012) Rehabilitating the 'drugs lifestyle': Criminal justice, social control, and the Cultivation of agency. Ethnography 0(00) pp.1-26. SUNY Collage at Old Westbury, USA.

Kelly, J. F., \& Westerhoff, C. M. (2010). Does it matter how we refer to individuals with substance-related conditions? A randomized study of two commonly used terms. International Journal of Drug Policy, 21(3), 202-207.

Keval, H. C. (2009). Negotiating Constructions of 'Insider'/‘Outsider' Status and Exploring the Significance of Dis/Connections. Enquire, 4, 51-72. 
Koller, V. \& Davidson, P. (2008) Social exclusion as conceptual and grammatical metaphor: A cross-genre study of British policy-making. Discourse and Society Vol. 19 (3) pp. 307-331. Sage Publications London.

Kreek, M.J., Nielson. D.A., Butelman. E.R. and Laforge. K.S. (2005) Genetic influences on impulsivity, risk-taking stress responsivity, and vulnerability to drug abuse and addiction. Nature Neuroscience, Vol. 8, pp. 1450-7.

Law Commission. (2008). the history of development in drug regulation. In Law Commission's, Controlling and Regulating Drugs: A Review of the Misuse of Drugs Act 1975. Wellington: Law Commission.

Levitas, Ruth. (2005). the inclusive society? Social exclusion and New Labour. Basingstoke: Palgrave Macmillan.

Lindesmith, A, R. (1938). "Dope fiend" mythology. Journal of Criminal Law and Criminology, 31(2), 199-208.

Link, B.G. \& Phelan, J.C. (2001) Conceptualizing stigma. Annual Review of Sociology, Vol. 27, pp. 363-85

Link, B.G., Yang, L.H., Phelan, J.C. \& Collins, P.Y (2004) Measuring Mental Illness Stigma. Schizophrenia Bulletin, 30 (3). Pp. 511-541.

Livingston, J. D., Milne, T., Fang, M. L., \& Amari, E. (2012). The effectiveness of interventions for reducing stigma related to substance use disorders: a systematic review. Addiction, 107(1), 39-50.

Lloyd. C. (2010) Sinning and Sinned Against: The Stigmatisation of Problem Drug Users. University of York. Published by U.K. Drug Policy Commission, London.

Low. J. \& Jose. P. (2010) Life Span Development New Zealand Perspectives second edition, Published by Pearson New Zealand Ltd.

Luoma, J. B., Twohig, M.P., Waltz, T., Hayes, S. C., Roget, N., Padilla, M., \& Fisher, G. (2007) An investigation of stigma in individuals receiving treatment for substance abuse. Science Direct Addictive Behaviours issue 32. Pp. 1331-1346 Elsevier Ltd.

MacGregor. S. \& Thickett. A. (2011) Partnerships and communities in English drug policy: The challenge of deprivation. International Journal of Drug Policy Vol.22, pp. 478-490.

Mantzoukas, S. (2004). Issues of representation within qualitative inquiry. Qualitative Health Research, 14(7), 994-1007.

McClure, M. (2013). A civilised community: a history of Social Security in New Zealand 1898-1998. Auckland University Press.

McLennan, G., Ryan, A., \& Spoonley, P. (2004). Exploring society: Sociology for New Zealand students. Hird, M., \& Pavlich, G. (2003). Sociology for the asking. NEW ZEALAND SOCIOLOGY, 19(2), 339-342.

Mercer, J. (2007). The challenges of insider research in educational institutions: Wielding a double-edged sword and resolving delicate dilemmas. Oxford Review of Education, 33(1), 1-17. 
Merton, R. K. (1972). Insiders and outsiders: A chapter in the sociology of knowledge. American Journal of Sociology, 9-47.

Mila, K. (2013). Only One Deck in M. Rashbrooke (ed.) Inequality and New Zealand. (Pp.148-158) M. Bridget Williams Books. Wellington New Zealand.

Miliband, D. (2006). Social exclusion: The next steps forward. London: ODPM.

Miller, R. L., \& Brewer, J. D. (Eds.). (2003). The AZ of social research: a dictionary of key social science research concepts. Sage.

Mills, K. (2006). Dr. Mills Replies. American Journal of Psychiatry, 163(10), 18401840 .

Ministry of Health (2010).Drug Use in New Zealand: Key results of the 2007/08 New Zealand Alcohol and Drug Use Survey. Wellington: Ministry of Health.

Moffitt T. E., \& Caspi, A. (2001). Childhood predictors differentiate life-course persistent and adolescence-limited antisocial pathways among males and females. Development and psychopathology, 13(02), 355-375.

Murji, K. (1998). The agony and the ecstasy: drugs, media and morality. The Control of Drugs and Drug Users: reason or reaction, 69-85.

Murray, C., \& Alcock, P. (1994). Underclass: The crisis deepens. London: IEA Health and Welfare Unit.

Najavits, L. M. (2007). Seeking Safety: An evidence-based model for substance abuse and trauma/PTSD. Therapist's guide to evidence-based relapse prevention, 141-167.

Najavits, L. M., \& Hien, D. (2013). Helping vulnerable populations: a comprehensive review of the treatment outcome literature on substance use disorder and PTSD. Journal of clinical psychology, 69(5), 433-479.

Nowinski, J., \& Baker, S. (1992). The twelve-step facilitation handbook: A systematic approach to early recovery from alcoholism and addiction. Jossey-Bass.

Nutt, D., King, L. A., Saulsbury, W., \& Blakemore, C. (2007) Development of a rational Scale to assess the harm of drugs of potential misuse. The Lancet. Vol. 369. Pp. 1047-1053.

Pearson, G. (1987). The New Heroin Users Basil Blackwell Ltd Oxford UK.

Poata-Smith, E. S. (2013). 'Inequality and Māori' in M. Rashbrooke (ed.) Inequality and New Zealand. (Pp.148-158) M. Bridget Williams Books. Wellington New Zealand.

Pratt, J. (2008) When Penal Populism Stops: Legitimacy Scandal and the Power to Punish in New Zealand. The Australian and New Zealand Journal of Criminology, 41 (3) pp. 364-383.

Preble, E., \& Casey, J. J. (1969). Taking care of business-the heroin user's life on the street. Substance Use \& Misuse, 4(1), 1-24. 
Radcliffe, P., \& Stevens, A. (2008). Are drug treatment services only for 'thieving junkie scumbags'? Drug users and the management of stigmatised identities. Social Science \& Medicine, 67(7), 1065-1073.

Radcliffe, M. (2013) Inequality and New Zealand. In Inequality A New Zealand Crisis. (Eds) Rashbrooke, M. Bridget Williams Books. Wellington New Zealand.

Rashbrooke, M. (Ed.). (2013). Inequality: A New Zealand Crisis. Bridget Williams Books. Wellington New Zealand.

Reinarman, C. (1979) Moral Entrepreneurs and Political Economy: Historical and Ethnographic Notes on the Construction of the Cocaine Menace. Drugs, Crime and Criminal Justice, 3(3), 225-254.

Richardson, L., Wood, E., Montaner, J., \& Kerr, T. (2011). Addiction treatmentRelated employment barriers: The impact of methadone maintenance. Journal of Substance Abuse Treatment, 43 Pp. 276-284 Vancouver.

Ritchie, J. (2007). New Zealand families: Child-rearing practices and attitudes. In: Weatherall, A. and Wilson, M. and Harper, D. and McDowell, J., eds. Psychology in Aotearoa/New Zealand. Pearson Education, Auckland, NZ.

SANE Australia (2013). A life without stigma: A SANE, Report, SANE Australia.

Shiner, M. (2009) Drug Use and Social Change: The Distortion of History. London School of Economics and Political Science. Published by Palgrave Macmillan London.

Sindicich, N., Mills, K. L., Barrett, E. L., Indig, D., Sunjic, S., Sannibale, C., \& Najavits, L. M. (2014). Offenders as victims: post-traumatic stress disorder and substance use disorder among male prisoners. The Journal of Forensic Psychiatry \& Psychology, 25(1), 44-60.

Soldera, P. (1999). Spatial hysteresis and the clustering of urban unemployment (Doctoral dissertation, Master's thesis, Department of Geography, Victoria University, Wellington).

Stafford, M. C., \& Scott, R. R. (1986). Stigma, deviance, and social control. In The dilemma of difference (pp. 77-91). Springer US.

Stainton Rogers, W., \& Stainton Rogers, R. (2001). The psychology of gender and sexuality: An Introduction. McGraw Hill Publishing.

Stevens, A. (2007). When two dark figures collide: Evidence and discourse on drug-related crime. Critical Social Policy, 27(1), 77-99.

Social Exclusion Unit (2002). Reducing re-offending by ex-prisoners. London: Social Exclusion Unit, 9.

United Nations Office on Drugs \& Crime (2013) Chronology: 100 years of drug control. Down loaded from www. UNODC. Org. At Victoria University on $14 / 10 / 2013$.

Wade, R. (2013). Inequality and the West in M. Rashbrooke (ed.) Inequality and New Zealand. (Pp. 39-52) M. Bridget Williams Books. Wellington New Zealand. 
Walters, R. \& Bradley, T. (2005). Introduction to Criminological Thought. Published By Pearson Education New Zealand.

Ward, T., \& Brown, M. (2004). The good lives model and conceptual issues in offender rehabilitation. Psychology, Crime \& Law, 10(3), 243-257.

Watters, J. K., \& Biernacki, P. (1989). Targeted sampling: options for the study of hidden populations. Social problems, 416-430.

White, W. L., \& Kelly, J. F. (2011). Alcohol/drug/substance "abuse”: The history and (hopeful) demise of a pernicious label. Alcoholism Treatment Quarterly, 29(3), 317-321.

Wilkins, C. \& Sweetsur, P. (2008) Trends in population drug use in New Zealand: findings from national household surveying of drug use in 1998, 2001, 2003 and 2006. The New Zealand Medical Journal. Vol. 121. No 1274. Pp. 61-71.

Wilkins, C. Sweetsur, P. \& Griffiths, R. (2011) Recent trends in pharmaceutical drug use among frequent injecting drug users, frequent methamphetamine users and frequent ecstasy users in New Zealand, 2006-2009. Drug and Alcohol Review Vol. 30. Pp. 255-263.

Workman, K., \& McIntosh, T. (2013). Crime, imprisonment and poverty in M. Rashbrooke (ed.) Inequality and New Zealand. (Pp.120-131) M. Bridget Williams Books. Wellington New Zealand.

Wylie, C. (2013) Schools and inequality in M. Rashbrooke (ed.) Inequality and New Zealand. (Pp. 134-147) M. Bridget Williams Books. Wellington New Zealand.

Yoshikawa, H. (1994). Prevention as cumulative protection: effects of early family support and education on chronic delinquency and its risks. Psychological bulletin, 115(1), 28.

Young, J. (1999). The Exclusive Society. Social Exclusion, Crime and Difference In late Modernity. SAGE Publications Ltd. London.

Young, R. (2002). From war to work: Drug treatment, social inclusion and enterprise. Foreign Policy Centre. London. 


\section{Appendix 1: Semi Structured Interview Schedule}

\section{BACKGROUND REMINDER OF THE AIMS}

1. Explore respondent's life experiences and perceptions of poverty and social disadvantage through the life journey.

2. Explore the onset and development of PDU and the resulting life journey.

3. Explore respondent's experience of stigma and marginalisation prior to the development of drug dependence.

4. Explore respondent's experience of stigma and marginalisation following the development of drug dependence.

\section{Background info data:}

Age

Gender

Disability/Difficulties

Education / Qualifications

Employment: first / last / longest

At what age do you think drug use became a problem to you?

\section{Questions}

1. Tell me about what it was like for you growing up?

2. Tell me about your experience of education.

3. Tell me about your experience of work.

4. Tell me about your experience of relationships.

5. Have you ever been excluded, removed or placed in care/prison?

6. Have you ever experienced stigma or discrimination?

7. Tell me about your experience of drugs? 


\section{Appendix 2: Manufacturing Decline in the DNZT 1986-1996}

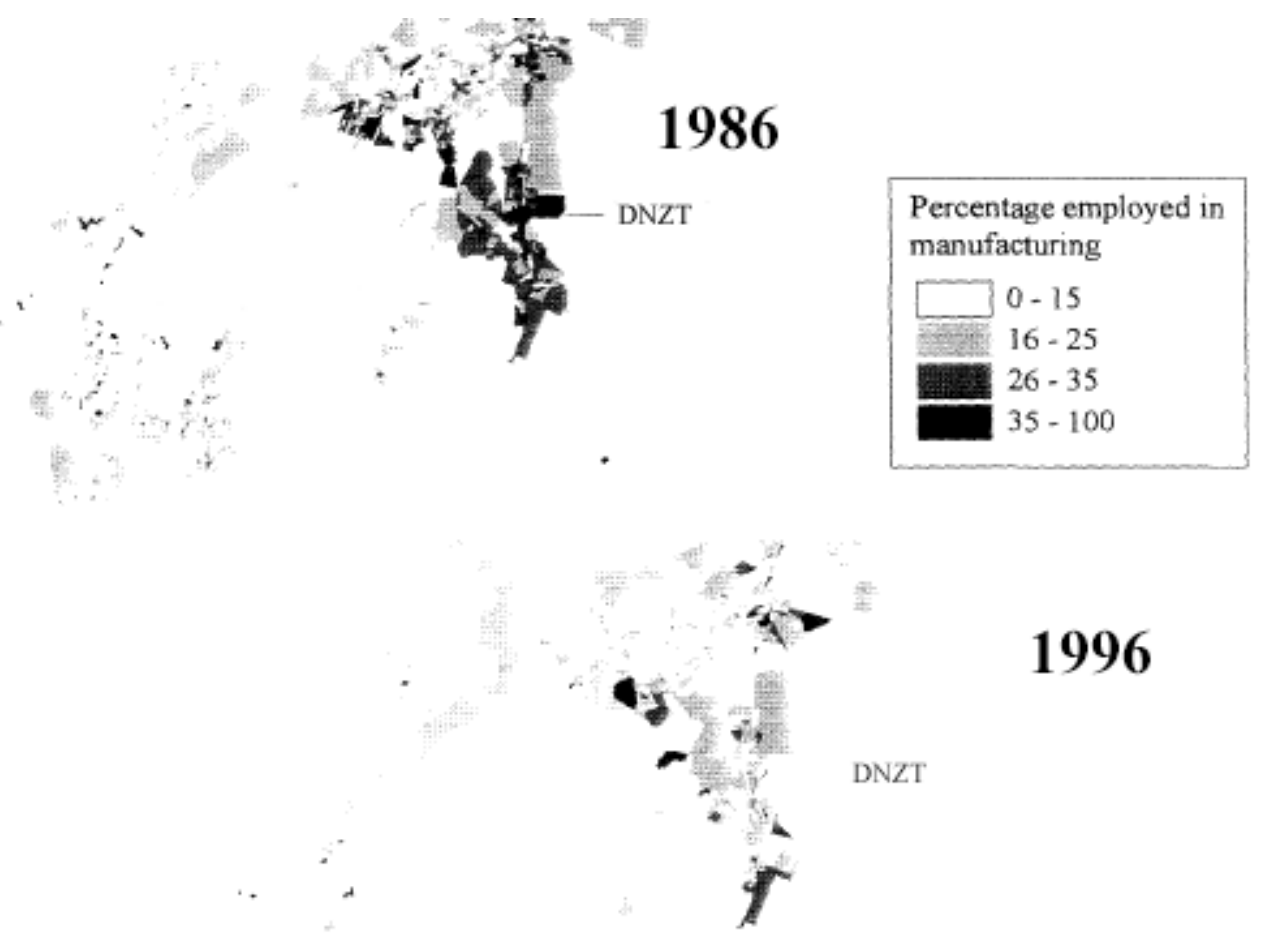

Map demonstrates the Deindustrialisation of DNZT [adapted from Soldera (1999: 16)]. 